Geoffrey B. Severin ${ }^{1 \# @, ~ B r i a n ~ Y . ~ H s u e h " \#, ~ C l i n t o n ~ A . ~ E l g ~}{ }^{3}$, John A. Dover ${ }^{1}$, Christopher R.

Rhoades $^{2}$, Alex J. Wessel ${ }^{2}$, Benjamin J. Ridenhour ${ }^{4}$, Eva M. Top ${ }^{3}$, Janani Ravi ${ }^{5}$, Kristin N.

1Department of Biochemistry and Molecular Biology, Michigan State University, East Lansing,

${ }^{2}$ Department of Microbiology and Molecular Genetics, Michigan State University, East Lansing,

${ }^{3}$ Department of Biological Sciences, Institute for Bioinformatics and Evolutionary Studies,

${ }^{4}$ Department of Mathematics and Statistical Sciences, University of Idaho, Moscow, Idaho, USA,

\#These authors contributed equally to this work.

$21 @$ @urrent address: Department of Microbiology and Immunology, University of Michigan, Ann

22 Arbor, MI, 48109

\title{
$23{ }^{*}$ Corresponding Author:
}

245180 Biomedical and Physical Sciences

25567 Wilson Road

26 East Lansing, MI 48824 
E-mail: watersc3@msu.edu

Keywords: cytidine deaminase, phage, genomic island, toxin-antitoxin, thymineless death,

\section{SUMMARY}

The El Tor biotype of Vibrio cholerae is responsible for perpetuating the longest cholera pandemic in recorded history (1961-current). The genomic islands VSP-1 and -2 are two understudied genetic features that distinguish EI Tor from previous pandemics. To understand their utility, we calculated the co-occurrence of VSP genes across bacterial genomes. This analysis predicted the previously uncharacterized vc0175, herein renamed deoxycytidylate deaminase Vibrio ( $d c d V$ ), is in a gene network with $d n c V$, a cyclic GMP-AMP synthase involved in phage defense. DcdV consists of two domains, a P-loop kinase and a deoxycytidylate deaminase, that are required for the deamination of $\mathrm{dCTP}$ and $\mathrm{dCMP}$, inhibiting phage predation by corrupting cellular nucleotide concentrations. Additionally, DcdV is posttranslationally inhibited by a unique noncoding RNA encoded 5' of the $d c d V$ locus. DcdV homologs are conserved in bacteria and eukaryotes and our results identify $V$. cholerae DcdV as the founding member of a previously undescribed bacterial phage defense system.

\section{INTRODUCTION}

Vibrio cholerae, the etiological agent responsible for the diarrheal disease cholera, is a monotrichous, Gram-negative bacterium found ubiquitously in marine environments [1]. There have been seven recorded pandemics of cholera, beginning in 1817 , and the fifth and sixth pandemics were caused by strains of the classical biotype. The seventh pandemic, which began

51 in 1961 and continues today, was initiated and perpetuated by circulating strains of the El Tor

52 biotype. Numerous phenotypic and genetic characteristics are used to distinguish the classical 
and El Tor biotypes [2]. It is hypothesized that El Tor's acquisition of two unique genomic

54 islands of unknown origins, named the Vibrio Seventh Pandemic Islands 1 and 2 (VSP-1 and 2) [3], played a pivotal role in El Tor's evolution to pandemicity and the displacement of the classic biotype in modern cholera disease [4].

Combined, VSP-1 and VSP-2 encode $\sim 36$ putative open reading frames (ORFs) within $\sim 39 \mathrm{~kb}$ (Figs. 1A and S1B) [3, 5-7]. While the majority of the genes in these two islands remain to be studied, it is hypothesized that the biological functions they encode may contribute to environmental persistence [8] and/or the pathogenicity [9] of the El Tor biotype. In support of this idea, VSP-1 encodes a phage defense system encompassing the genes $d n c V$, capV, vc0180 and vc0181 called the cyclic-oligonucleotide-based antiphage signaling system (CBASS) [10] (Fig. 1A). CBASS limits phage invasion of bacterial populations via a process termed abortive replication whereby upon phage infection cyclic GMP-AMP (cGAMP) synthesis by DncV activates cell lysis by stimulating the phospholipase activity of CapV [10,11]. During our search for VSP-1 and 2 gene networks, we determined that the gene vc0175, renamed herein as deoxycytidylate deaminase in Vibrio ( $d c d V)$, cooccurs in bacterial genomes with $d n c V$, suggesting a common function.

We show that $d c d V$, exhibits deoxycytidylate deaminase (DCD) activity, catalyzing the deamination of free deoxycytidine monophosphate (dCMP) substrates to form deoxyuridine monophosphate (dUMP) and is part of the broader $\mathrm{Zn}$-dependent cytosine deaminase (CDA) family of enzymes [12-14]. The activity of DCD enzymes play a vital role in the de novo synthesis of deoxythymidine triphosphate (dTTP) by supplying the dUMP required by thymidylate synthase (TS) to form deoxythymidine monophosphate (dTMP) [12]. CDA enzymes belonging to the APOBEC (Apolipoprotein B mRNA editing enzyme catalytic polypeptide-like) family also play an important role in viral immunity in higher organisms where their catalytic activity is utilized for the deamination of nucleic acids rather than free nucleotide substrates to restrict several types of viruses, such as retroviruses, and retroelements [15-19]. 
A primary challenge faced by lytic phage is to rapidly replicate many copies of its genome, which requires sufficient nucleotide substrates [20]. During DNA phage infection, total DNA within a bacterium can increase 5-10 fold, illustrating the vast amount of DNA replication that must occur in a short window of time $[21,22]$. To accomplish this feat, invading DNA phage often corrupt the delicate balance of enzymatic activity across a host's deoxynucleotide biosynthetic pathways by deploying their own DCD, dUTPase, TS, and ribonucleotide reductase to ensure the appropriate ratio and abundance of deoxyribonucleotides [23-27].

Here we show that DcdV is a dual domain protein consisting of a putative N-terminal Ploop kinase (PLK) and C-terminal DCD domain, and this novel domain architecture is present across the tree of life. Overexpression of DcdV promotes cell filamentation, which has hallmarks of nucleotide starvation resembling thymine-less death (TLD) toxicity [28-31]. Our results demonstrate that ectopic expression of DcdV indeed corrupts the intracellular concentrations of deoxynucleotides and this activity protects bacteria from phage infection. Moreover, we demonstrate that DcdV activity is negatively regulated by a non-coding RNA encoded 5' of the $d c d V$ locus [renamed herein as DcdV insensitivity factor in Vibrio (difV)]. Furthermore, dcdVdifV systems are widely encoded in bacteria and we show that a subset of them function similarly, establishing cytidine deaminase enzymes as antiphage defense systems in bacteria.

\section{RESULTS}

\section{$d n c V$ and $d c d V$ co-occur in bacterial genomes}

To help identify functional interactions within the largely unclassified VSP-1 \& 2 genes, VSP island genes were classified into putative "gene networks" or sets of genes that form a

101 functional pathway to accomplish a biological task. Since gene networks often share deep

102 evolutionary history among diverse taxa, we hypothesized that the set of genes in a gene

103 network would co-occur together in the genomes of diverse taxa at a higher frequency than 
chance alone would predict. Our software package was named 'Correlogy’ inspired by [32] and is described in detail in the materials and methods.

We calculated a Pearson correlation followed by a partial correlation correction between each of the VSP island genes from the same island across the sequenced bacterial domain. This resulting partial correlation correction " $w_{i j}$ " has an output normalized to a range of -1 to 1 , opposed to a value of 1 in which homologues of genes $i$ and $j$ always co-occur in the same species. Previous research using well-classified Escherichia coli gene networks showed that

112 partial correlation values $w_{i j}>0.045$ were highly correlated with shared biological functions [32].

113 Using the above-mentioned approach, we calculated a partial correlation value $w_{i j}$ for all genes

$114 i$ to $j$ in VSP-1 (Supplemental File 1) and VSP-2 (Supplemental File 2). We generated a

115 visualization of the Maximum Relatedness Subnetworks (MRS) showing the single highest $w_{i j}$ 116 value for each VSP gene (Figs. 1B, S1A, 1B).

121 that co-occurrence of $d n c V$ with $d c d V$ may indicate a shared or common biological function, we 122 sought to understand the biological activity of $d c d V$.

\section{Ectopic expression of $d c d V$ induces cell filamentation in the absence of VSP-1}

To assess the function of DcdV, we generated growth curves in both wild type (WT) $\mathrm{V}$.

126 cholerae and a double VSP island deletion strain ( $\triangle \mathrm{VSP}-1 / 2)$ over-expressing $d c d V(\mathrm{pDcdV})$ or 127 vector control (pVector). DcdV overexpression did not impact WT growth but did reduce growth 
yield in the $\Delta$ VSP-1/2 background (Fig. 1C). We evaluated the cellular morphology of WT and $\Delta \mathrm{VSP}-1 / 2$ strains after overexpression of $\mathrm{DcdV}$ and observed expression from $\mathrm{pDcdV}$ in the $\Delta \mathrm{VSP}-1 / 2$ background yielded filamentous cell morphologies, suggesting these cells have a defect in cell division that manifests in a reduced growth yield (Fig. 1D). We performed the same image analysis in single island mutants ( $\triangle \mathrm{VSP}-1$ and $\Delta \mathrm{VSP}-2)$ and found that the mean cell length increased significantly upon DcdV overexpression only in cells lacking VSP-1 (Fig. 1E). Likewise, overexpression of $\mathrm{pDcdV}$ in a laboratory strain of $E$. coli also induced cell filamentation that was inhibited by provision of a single copy cosmid containing VSP-1 (pCCD7) but not the vector cosmid control (pLAFR) (Figs. S2A and S2B). The spiral nature of $V$. cholerae filaments (Fig. 1D) is due to the natural curvature of $V$. cholerae mediated by $\operatorname{crvA}[33,34]$. Taken together, these results indicated that DcdV overexpression severely impacts cell physiology in the absence of VSP-1.

\section{DifV is encoded immediately $5^{\prime}$ of the $d c d V$ locus in VSP-1}

To identify the negative regulator of DcdV activity encoded in VSP-1, we generated partial VSP-1 island deletions and quantified cell filamentation following DcdV expression. Three sections of VSP-1; $d c d V$-vc0176, vspR-vc0181, and vc0182-vc0185, were individually deleted. Of the three partial VSP-1 deletion strains, expression of pDcdV only induced filamentation in the $\Delta d c d V$-vc0176 mutant (Fig. 2A). Individual gene deletion mutants of $d c d V$ and $v c 0176$ maintained WT cell morphology following expression of DcdV (Fig. 2B), suggesting the $504 \mathrm{nt}$ intergenic region between $d c d V$ and $v c 0176$ is the source of DcdV inhibition. We identified a 222 nucleotide (nt) open reading frame we named $i g^{222}$ encoded in the same orientation immediately 5' of $d c d V$ as a possible candidate for the DcdV regulation (Fig. 1A).

Overexpression of DcdV in the $\Delta i g^{222}$ mutant led to cell filamentation (Fig. 2B). Furthermore, complementation of $i g^{222}$ co-expressed from a second plasmid in the $\Delta i g^{222}$ strain prevented DcdV induced filamentation (Fig. 2B). We conclude that $i g^{222}$ contains the necessary genetic 
components for inhibiting DcdV activity and refer to this negative regulator as DifV for DcdV insensitivity factor in Vibrios.

As $d c d V$ and $d n c V$ cooccur in a gene network (Fig. 1B), we hypothesized that the role of DncV was to inactivate DifV, leading to the liberation of DcdV activity. However, co-expression of both DncV and DcdV did not liberate DcdV activity as these cells were not filamentous (Fig. S3). The $\Delta i g^{222}$ mutant is not filamentous in the absence of $\mathrm{pDcdV}$ expression which is likely due to a polar effect originating from the deletion of $i g^{222}$. Indeed, $d c d V$ expression was reduced at all growth phases in the $\Delta i g^{222}$ mutant (Fig. S4).

\section{DifV is an sRNA that post-translationally regulates the activity of DcdV}

The fact that DifV inhibits DcdV expressed from a plasmid with exogenous transcription and translation start sites suggests DifV regulates DcdV at a post-translational level. To test this hypothesis, we expressed a $d c d V$ C-terminal 6x histidine tagged construct (DcdV $\left.{ }^{6 \times H I S}\right)$ in WT and $\Delta i g^{222} V$. cholerae and probed for the cellular abundance of DcdV ${ }^{6 \times H I S}$ using Western blot (Fig. 2C). When this tagged DcdV is expressed, $\Delta i g^{222}$ manifest a filamentation phenotype while the WT strain does not, indicating the $6 \mathrm{x}$ histidine tag does not change the activity of DcdV nor does it inhibit the ability of DifV to regulate DcdV (Fig. S5). Despite the lack of filamentation in the WT strain, the cellular abundance of DcdV ${ }^{6 \times H I S}$ was slightly greater than $\Delta i g^{222}$ with an average signal intensity ratio WT: $\Delta i g^{222}$ ) of $1.5 \pm 0.3$ across three biological replicates, although this difference was not statistically significant. This result connotes that DifV limits DcdV activity after it has been translated and not by reducing the abundance of DcdV.

Given that DifV regulates the activity of DcdV at the post-translational level, we wondered if DifV was a small peptide or an untranslated small regulatory RNA (sRNA). Mutation of the ${i g^{22}}^{22}$ rare CTG start codon to a TAG stop codon (222 $\left.\mathrm{nt}^{\text {STOP }}\right)$ did not abrogate the ability of this construct to inhibit DcdV activity in trans when co-expressed in the $\Delta i g^{222}$ strain (Fig. 2D). We then examined a 174 nt ORF completely encoded within $i^{222}$ (174 nt) and found it was also 
sufficient to prevent DcdV induced filamentation (Fig. 2D). Additionally, expression of this $174 \mathrm{nt}$

ORF from constructs either lacking a ribosome binding site $\left(174 \mathrm{nt}^{-\mathrm{RBS}}\right)$ or where the native ATG start codon was mutated to a TAA stop codon (174 $\mathrm{nt}^{\mathrm{STOP}}$ ) each retained the ability to inhibit DcdV activity (Fig. 2D). We also identified an ATG start codon on the interior of the 174 nt ORF corresponding to an alternative reading frame and mutation of this interior start codon to a TAA stop codon (174 $\mathrm{nt}^{\text {InteriorSTOP}}$ ) also failed to abrogate DifV inhibition of DcdV activity (Fig. 2D). Together, these results suggest that translation of a gene product originating from within $\mathrm{ig}^{222}$ is not necessary for DifV activity.

To identify the minimum functional size of difV we further truncated this $174 \mathrm{nt}$ segment from both the 5' and 3' ends and found that removal of either $18 \mathrm{bp}$ from the 5 ' end or $4 \mathrm{bp}$ from the 3' end was sufficient to abolish DifV activity (Fig. 2D). Additionally, expression in trans of

npcR_3991 [35], a 104 nt non-coding RNA of unknown function contained within $i g^{222}$, was also unable to inhibit DcdV filamentation (Fig. 2D). Collectively, these results suggest that DifV is a regulatory RNA that is between 152 to 174 nt long encoded 5' of the dcdV locus, and we will therefore refer to the $174 \mathrm{nt}$ locus as difV for the remainder of these experiments.

\section{DifV and DcdV constitute a two gene operon that resembles a Toxin-Antitoxin System}

The genomic orientation and proximity of difV to $d c d V$ suggest they may constitute an operon and two previous genome-wide transcriptional start site (TSS) analyses previously identified a common putative TSS 5' of $\operatorname{difV}[36,37]$. To test if $\operatorname{dif} V$ and $d c d V$ are indeed expressed as an operon, we performed diagnostic PCR with primers located within difV and

$201 d c d V$ on cDNA generated from both WT and $\Delta i g^{222}$ RNA (Fig. 3A). As expected, dcdV was detected in the cDNA generated from each strain while difV was only amplified using the WT cDNA template (Fig. 3B). The presence of an $839 \mathrm{nt}$ PCR product amplified using primers spanning difV to $d c d V$ from the WT cDNA template, that was not present with $\Delta i g^{222}$ cDNA, 
quantified the relative abundance of $\operatorname{difV}$ and $d c d V$ RNA using qRT-PCR and found the difV locus was approximately 40-, 20-, and 60-fold more abundant than $d c d V$ at early exponential, late exponential, and stationary phases, respectively (Fig. 3C). While having several unique features, the co-transcription of $d i f V$ and $d c d V$ and the post-translational regulation of DcdV activity by the abundant sRNA DifV resembles Type III Toxin-Antitoxin systems [38].

DcdV induced filamentation requires conserved features of both the PLK and the CDA

\section{domains}

DcdV is a 532 amino acid polypeptide composed of two putative domains: an unannotated $\mathrm{N}$-terminal domain and a DCD-like C-terminus (Figs. 4A, 4B). Analysis of the Nterminal domain using Pfam did not reveal any conserved domains. However, Phyre2 [39] and

217 PSI-BLAST searches combined with InterProScan $[40,41]$ analyses revealed that the $\mathrm{N}$ residue\} that is partly involved in coordinating $\mathrm{Mg}^{2+}[42,43]$. Interrogation of the Phyre2 DcdV model (Fig. 4A), InterProScan predictions, and PSI-BLAST primary sequence alignments (Fig.

227 S6) revealed these three features are likely present in the $\mathrm{N}$-terminal domain, suggesting the $\mathrm{N}$ -

228 terminus of DcdV is a PLK domain involved in binding nucleotide substrates and performing a

229 phosphotransfer reaction. The C-terminal DCD domain contains a highly conserved zinc-

230 dependent CDA active site motif ([HAE]X ${ }_{28}[\mathrm{PCXXC}]$ ) (Figs. 4A,B and S6). The constellation of residues that make up the $\mathrm{Zn}^{2+}$ binding pocket is composed of three critical amino acids in 
$232 \mathrm{DcdV} ; \mathrm{H} 382, \mathrm{C} 411$, and $\mathrm{C} 414 . \mathrm{Zn}^{2+}$ is required for the catalytic deprotonation of water by a 233 conserved glutamate residue (E384 in DcdV) for the hydrolytic deamination of a cytosine base 234 to uridine.

Hypothesizing that one of the two domains present in DcdV is responsible for cell

236 filamentation in the absence of difV, we made site-specific mutations in the conserved residues

237 predicted to be essential for activity in both the PLK and DCD domains. Two variant constructs

238 were generated in the PLK domain targeting the Walker A motif (DcdV ${ }^{\mathrm{S} 52 \mathrm{~K}}$ ) and the Walker B

239 motif $\left(D c d V^{D 162 A}+\right.$ Q163A $)($ Fig. 4B). Two variants were constructed in the DCD active site; a

240 double substitution of both $\mathrm{C} 411 \mathrm{~A}$ and $\mathrm{C} 414 \mathrm{~A}\left(\mathrm{DcdV} \mathrm{V}^{\mathrm{C} 411 \mathrm{~A}}+\mathrm{C414A}\right)$ to abrogate $\mathrm{Zn}^{2+}$ binding and

241 an E384A substitution $\left(\mathrm{DcdV}^{\mathrm{E} 384 \mathrm{~A}}\right)$ to inhibit the deprotonation of water required for the hydrolytic

242 deamination of cytosine (Fig. 4B). Unlike WT DcdV (DcdVWT), all four of the variants failed to

243 induce filamentation when ectopically expressed in E. coli (Fig. 4C). The cellular abundance of

244 these variants is comparable to WT DcdV (Fig. S7). This result shows both DcdV domains are

245 necessary for induction of filamentation.

We performed a genetic screen to identify DcdV variants whose activity was no longer

247 inhibited by DifV by expressing a random library of $d c d V$ mutants in a $\Delta d c d V$ mutant strain

248 where difV remains intact. Ectopic expression of WT $d c d V$ in a $\Delta d c d V$ mutant does not induce

249 filamentation (Fig. 4D) or produce small, wrinkled colonies on solid agar due to the genomic

250 copy of difV. However, $d c d V$ mutants that are insensitive to difV exhibit a small colony

251 phenotype. Screening 15,000 potential mutants, we identified five unique dcdV mutations that

252 encoded single amino acid substitutions (E123K, A126T, K201R, K511E, and Q514R) located in

253 both the PLD and DCD domains that rendered DcdV insensitive to DifV inhibition (Figs. 4B, 4D).

254 Based on the Phyre2 DcdV structural model, all five residues are located on the exterior of the

255 protein (Fig. 4A) suggesting they may be involved in mediating molecular interactions between

256 DifV and DcdV. The only mutation found within a conserved domain feature was the seemingly 
innocuous K201R substitution, which is modeled to lie between the two helices of the PLK LID

258

259

260

261

262

263

264

265

266

267

268

269

270

271

272

273

274

275

276

277

278

279

280

281

282 module (Fig. 4A).

\section{DcdV induced filamentation is due to impaired genome replication}

Filamentation is a phenotype often associated with thymineless death (TLD) [28] due to nucleotide starvation. A hallmark of TLD is an increased genomic origin to terminus (orilter) ratio resulting from repeated attempts to initiate replication from the origin that ultimately fail to reach the terminus due to a lack of dTTP substrate [44]. Hypothesizing that DcdV induced filamentation may be a consequence of replication inefficiency, analogous to TLD, we measured the ori/ter ratio of $V$. cholerae chromosome 1 from WT and $\Delta i g^{222} V$. cholerae grown to stationary phase overexpressing WT DcdV or a vector control. There was no significant difference in the ori/ter ratios following ectopic expression of WT DcdV in WT V. cholerae (Fig. 4E), consistent with the observation that these strains do not filament (Figs. 1D and 1E). However, ectopic expression of WT DcdV in the $\Delta i g^{222}$ mutant, which lacks difV, resulted in an orilter ratio $\sim 3$ times greater than the vector control (Fig. 4F), consistent with cell filamentation (Fig. 2B). We also measured the ori/ter ratio of the $\Delta i g^{222}$ mutant expressing $d c d V$ with mutations in the PLK or DCD domain. In agreement with an inability to induce filamentation (Fig. $4 \mathrm{C})$, the orilter ratio of these variants was not significantly different from the empty vector control (Fig. 4F). Therefore, DcdV corruption of DNA replication is dependent upon both the PLK and DCD domains.

\section{DcdV catalyzes the deamination of both dCMP and dCTP}

Based on the TLD-like genome instability driven by DcdV, we hypothesized this enzyme deaminates free nucleic acid substrates. Though we determined DcdV and DcdV variants were readily retained in $E$. coli lysates (Fig. S7), numerous attempts to purify active DcdV were unsuccessful. This suggested that an unknown cofactor or cellular condition may contribute to 
the activity of DcdV that was missing in our purification conditions. Soluble lysates from E. coli ectopically expressing DcdV or the DCD active site variant DcdVE384A were supplemented with amine containing nucleotides and monitored for the evolution of $\mathrm{NH}_{4}^{+}$, a product of nucleotide deamination. Lysates containing DcdV evolved significantly more ammonium when incubated with dCMP and dCTP, which was not detected in lysates containing the DCD active site variant DcdVE384A (Fig. 5A).

DCD enzymes are unique among the CDAs for their allosteric regulation by both dCTP and dTTP which activate and repress the catalytic deamination of dCMP, respectively, through a G[Y/W]NG allosteric site motif $[45,46]$. Such allosteric regulation ensures that nucleotide homeostasis is maintained even if DCD enzymes are present. The allosteric site found in DcdV is composed of a divergent GCND motif suggesting allosteric regulation by dNTPs may not be preserved. In support of this, the deamination of both dCMP and dCTP by soluble lysates containing DcdV were not inhibited by the addition of equimolar dTTP (Fig. S8).

To further understand the catalytic activity of DcdV we spiked $1 \mu \mathrm{M} d \mathrm{dTP}$ into soluble lysates collected from E. coli ectopically expressing either WT DcdV or a vector control and quantified the concentrations of dUTP and dUMP over 30 minutes using UPLC-MS/MS. Following addition of $1 \mu \mathrm{M}$ dCTP the concentrations of both dUTP (Fig. 5B) and dUMP (Fig. 5C) increased in lysates containing DcdV within the first minute while those found in vector control lysates did not dramatically change over the course of the entire experiment. The concentration of dUTP in DcdV containing lysates peaked after five minutes and slowly receded over time (Fig. 5B) while the concentration of dUMP in these lysates continued to increase to a final concentration of $\sim 1 \mu \mathrm{M}$ after 30 minutes (Fig. 5C). Importantly, the equimolar stoichiometry of the1 $\mu \mathrm{M}$ dCTP substrate spike and the $1 \mu \mathrm{M}$ dUMP detected at the conclusion of the experiment demonstrates that DcdV does not modify nucleotides in a unique manner which would alter their mass. Together these experiments indicate that DcdV deaminates both dCTP 
and dCMP substrates and DcdV containing lysates ultimately funnel dCTP to dUMP, indicating DcdV is likely to have profound effects on intracellular nucleotide metabolism.

\section{DcdV decreases intracellular dCTP, dCMP, and dUTP in E. coli}

Our genetic and in vitro evidence suggested that DcdV catalyzes the deamination of both dCMP and dCTP to the detriment of DNA replication. To quantify the impact of DcdV activity on the intracellular concentrations of deoxyribonucleotide species, we overproduced DcdV, DcdV $552 K, D c d V^{E 384 A}$, and an empty vector control in E. coli and measured the abundance of these molecules by UPLC-MS/MS. While all strains contained similar levels of dATP, dGTP, dTTP, and dUMP, the intracellular abundance of dCTP and dCMP were significantly reduced in E. coli expressing WT DcdV (Figs. 5D, S9). No dUTP was found following expression of WT DcdV while trace amounts of dUTP were detected in the vector and the two DcdV variant strains (Figs. 5D, S9). Unlike the results observed with the in vitro DcdV lysates (Fig. 5C), no increase in intracellular dUMP concentrations were observed when DcdV was expressed. We speculate the difference between dUMP detected in lysate versus in vivo extractions are due to compensatory metabolic pathways active in live cells which are lost in the lysates. Similar results were obtained when a DcdV homolog derived from enterotoxigenic E. coli (DcdVETEC), discussed later in this study, was overexpressed in the same heterologous E. coli host (Figs. 5D, S9). Importantly, inactivating amino acid substitutions in conserved features of the PLK $\left(\mathrm{DcdV}^{\mathrm{S} 52 \mathrm{~K}}\right)$ or DCD $\left(\mathrm{DcdV}^{\mathrm{E} 384 \mathrm{~A}}\right)$ domains blocked DcdV activity, indicating both domains are necessary for the DcdV dependent depletion of intracellular dC pools (Figs. 5D, S9).

\section{Conservation and evolution of DcdV}

To identify if DcdV is widely conserved, we used six DcdV homologs as starting points from V. cholerae, Vibrio parahaemolyticus, E. coli, Proteus mirabilis, Aeromonas veronii, and Enterobacter cloacae to perform homology searches across the tree of life (see Methods). We 
used a combination of protein domain and orthology databases, homology searches, and multiple sequence alignment for detecting domains, signal peptides, and transmembrane regions to reconstruct the domain architectures of the query DcdV proteins (Fig. S6). In agreement with the Phyre2 model of $V$. cholerae DcdV (Fig. 4A), we identified two distinct domains in all six DcdV homologs, the N-terminal PLK domain and the C-terminal DCD domain (Fig. S6).

We identified numerous homologs containing the core PLK+DCD architecture as well as other variations, which included multiple PLK domain fusions in proteobacteria (e.g., Klebsiella, Vibrio) and a nucleic acid binding domain (e.g., Mannheimia, Bibersteinia) (Table S4). Homologs of DcdV were identified in multiple bacterial phyla including Proteobacteria, Actinobacteria, Bacteroidetes, and Firmicutes (Figs. 6A, a few dominant clusters of homologs are labeled). Interestingly, we found DcdV-like proteins in Archaea (e.g., Thaumarchaeota) and

$347<30 \%$ for archaeal and eukaryotic homologs, respectively, we note these contain comparable domain architectures to the query proteins (Table S4).

\section{Identification and evaluation of Gram-negative DcdV-DifV system homologs}

To evaluate the conservation of enzymatic activity we selected three of the core DcdV

352 homologs used in the initial homolog search; $V$. parahaemolyticus O1:Kuk FDA_R31, $P$. mirabilis AR379, and E. coli H10407 ETEC (Figs. 6A and S10). Expression of all three DcdV

354 homologs in E. coli resulted in filamentous cells analogous to V. cholerae DcdV (Fig. 6B). These

$355 d c d V$ homologs are encoded 3' of a small ORF, annotated as a hypothetical protein, in an

356 orientation, size, and proximity consistent with $V$. cholerae difV. While there was no strong

357 amino acid or nucleotide sequence similarity among the small ORFs 5 ' of the dcdV homologs

358 (Figs. S11 and S12) we hypothesized these could encode cognate difV negative regulators.

359 Consistent with the inhibition of DcdV activity by DifV from V. cholerae, co-expression of the 
corresponding DifV with its DcdV partner suppressed the cell filamentation phenotype (Fig. 6B). Additionally, overexpression of DcdVETEC in a heterologous $E$. coli host also decreased the intracellular concentrations of dCMP, dCTP, and dUTP (Fig. 5D), indicating the catalytic activity of these DcdV homologs are analogous to V. cholerae DcdV.

To determine if DifV and the three ORFs encoded upstream of $d c d V$ homologs could provide cross-species inhibition of DcdV, we challenged each of the four $d c d V s$ with each of the four difVs in E. coli and looked for DcdV dependent filamentation. Cross-species inhibition of DcdV induced filamentation was observed between $V$. parahaemolyticus and $V$. cholerae when each species' difV was expressed in trans (Fig. 6C). However, difV from P. mirabilis and E. coli ETEC were only able to inhibit the activity of their own cognate DcdV (Fig. 6C). These data suggest that while the general mechanism of DifV inhibition of DcdV activity is conserved the specific molecular interactions that mediate this process are not.

\section{Ectopic expression of DcdV reduces phage titers and slows predation}

We initiated studies of $d c d V$ based on our discovery that this gene co-occurs in bacterial genomes with $d n c V$, a critical member of the CBASS antiphage abortive infection system [10, 47]. Additionally, cytidine deaminases are conserved anti-viral defense mechanisms in eukaryotes $[15,17,48]$. These connections led us to hypothesize that DcdV can also provide phage defense by manipulating cellular nucleotide concentrations. To test this hypothesis, we challenged $V$. cholerae WT and $\Delta d c d V$ with two $V$. cholerae lytic phage with dsDNA genomes, ICP1 and ICP3 $[49,50]$. However, we observed no differences in the ability of these phages to kill V. cholerae in these conditions (Figs S13A and S13B).

Because ICP1 and ICP3 have coevolved with EI Tor V. cholerae, it is likely that these phages have evolved mechanisms to counteract $d c d V$. Such resistance to other $V$. cholerae phage defense mechanisms by ICP-1 has been previously demonstrated [51-53]. Therefore, we selected the heterologous host Shigella flexneri, a Gram-negative human pathogen, and its 
bacteriophage Sf6 , a dsDNA phage from the Podoviridae family $[54,55]$, as a naïve host-phage pair to test the antiphage activity of DcdV and its homologs. Ectopic expression of $d c d V$ or its homologs did not impact the growth of $S$. flexneri before the onset of phage killing at $\sim 110$ minutes (Figs. 7A-D). S. flexneri strains ectopically expressing $d c d V$ or its homologs delayed the onset of population collapse caused by Sf6 predation, although the impact of the $V$. cholerae DcdV was more modest than the other three homologs (Figs. 7A-D). Additionally, induction of all four DcdV homologs significantly reduced Sf6 progeny following infection compared to the control strains lacking induction of DcdV (Fig. 7E). Together, these data indicate that DcdV enzymes confer defense against phage infection by delaying population collapse and reducing the proliferation of viable phage progeny.

\section{DISCUSSION}

Uncovering the contributions to bacterial fitness of the $\sim 36$ genes encoded within the El previously uncharacterized gene $d c d V$. The only function previously ascribed to $d c d V$ was an undefined involvement in quorum sensing controlled $V$. cholerae aggregate formation [56].

407 demonstrate that homologs of this protein are present across the tree of life. Collectively, both 408 domains are required for DcdV to disrupt deoxynucleotide pool homeostasis, which impairs

409 DNA replication and manifests in a filamentous cell morphology. DcdV activity is post-

410 translationally regulated by DifV, a sRNA encoded immediately 5' of the dcdV locus in VSP-1, 411 though the details of this inhibition remain to be fully elucidated. Finally, we demonstrate that 
412 DcdV and a set of homologs from other Gram-negative bacteria confer phage resistant

413 properties when expressed in a heterologous host.

Cell filamentation is a hallmark of TLD, observed in bacteria and eukaryotes, which arises from a sudden loss of thymine during robust cellular growth [31]. Interestingly, this phenomenon is not limited to dTTP as dGTP starvation elicits a similar response in $E$. coli and is

417 also hypothesized to occur when other deoxynucleotide substrates become disproportionately

418 scarce [29]. In the case of DcdV, it is conceivable the observed filamentation phenotype is a consequence of a TLD-like reduction in dCTP pools that can be termed 'cytosineless death'.

420 However, while DcdV activity also reduces the intracellular dC pool, it did not significantly

421 increase the intracellular concentrations of dTTP or dUMP in vivo, suggesting a cellular

422 compensatory pathway to combat DcdV activity is at work in intact cells. We speculate that the

423 DCD and PLK domains of DcdV are responsible for this conversion of dC nucleotides to dUMP

424 observed in the bacterial lysates, but we cannot rule out the contribution of other unknown

425 cellular factors. The deamination of dCTP is canonically performed by non-zinc dependent enzymes [57] making the dual substrate repertoire of dCMP and dCTP in DcdV a rare trait.

host nucleotide biosynthesis to ensure the appropriate ratio and quantities of deoxyribonucleotide precursors for replicating their own genomes [23, 24, 26, 27]. For example,

431 biDCD from chlorovirus PBCV-1, the only DCD previously reported to deaminate both dCMP

432 and dCTP substrates, rapidly catalyzes the conversion of host $\mathrm{dC}$ nucleic acids into dTTP thus

433 aiding replication of the A+T rich viral genome [23]. biDCD is allosterically regulated by dCTP

434 and dTTP to activate and inactivate the deaminase, respectively. This regulation provides a

435 means to fine-tune the pool of available dNTPs by preventing the enzyme from deaminating all 436 available dC substrates. Interestingly, DcdV does not appear to have maintained the allosteric 437 nucleotide binding site nor does excess dTTP added to cell lysates alter the catalytic activity of 
DcdV towards dCMP or dCTP (Fig. S8), and we propose these differences in enzyme activity are consistent with the function of DcdV as a phage defense mechanism that inhibits phage

440 replication by corrupting cellular nucleotide pools (graphical abstract). Altering pools of available

441 nucleotides has been shown to fend off biological attacks. For example, prokaryotic viperins

442 protect against T7 phage infection by producing modified ribonucleotides that ultimately inhibit

443 phage polymerase-dependent transcription [58]. The SAMHD1 phosphohydrolase enzyme in

444 eukaryotes also inhibits viral infections by depleting cellular nucleotide pools, although its structure and activity are different than DcdV [59-61].

In lieu of a conserved deoxynucleotide allosteric site, DcdV is regulated post-

translationally by the DifV untranslated RNA, which is unique among the CDA-family. The spacing, orientation, and relationship of $d i f V$ and $d c d V$ may have adapted to perform functions in a manner analogous to Type 2 and Type 3 Toxin-Antitoxin (TA) systems found across the bacterial phyla of which some are involved in antiphage defense and bacterial stress response [62]. While the RNA antitoxin of Type 3 TA systems encode nucleotide repeats [62] no repeat sequences are obvious in DifV indicating that DcdV/DifV may constitute a new TA class. We hypothesize that DcdV is activated upon phage infection by disruption of DifV inhibition, and we are currently preforming experiments to test this hypothesis (graphical abstract). Our systemic search for DcdV homologs containing at least a single PLK and DCD domain revealed hundreds of examples in a variety of bacteria beyond the Proteobacteria phylum including Bacteroidetes

457 and Actinobacteria and a few homologs in archaea and eukaryota. elements called defense islands $[63,64]$ and we speculate that the co-occurrence of DcdV and

460 DncV (along with the rest of the CBASS system) in bacterial genomes is a result of their shared 461 anti-phage activity. Our results indicate that DcdV reduces the available dC pool, and we 462 hypothesize that this activity delays phage genome replication potentially decreasing phage burst size. Although the $S$. flexneri host population expressing DcdV eventually collapses, we 
speculate that the delay in phage replication could provide an opportunity to prompt other phage defense systems, such as CBASS or a restriction modifications system to further target invading phages $[65,66]$.

Our study reveals that bacteria, like eukaryotes, also use CDA enzymes to protect against biological invasion although through different mechanisms. The eukaryotic APOBEC proteins deaminate ssRNA, leading to increased mutation and decreased genome stability of RNA viruses, whereas the substrates of DcdV are free deoxynucleotides. Further studies are required to determine if these two biological defense systems evolved from a common CDA ancestor.

\section{ACKNOWLEDGEMENTS}

We thank Shannon Manning (STEC Center, Michigan State University), Jessica Jones (U.S FDA), and Allison Brown (U.S. CDC), for providing us with E. coli ETEC, P. mirabilis, and V. parahaemolyticus strains, respectively. We thank Wei Leung $\mathrm{Ng}$ (Tuft University) for providing us V. cholerae ICP1 and ICP3 phages. We thank Kefei Yu and Dohun Pyeon for valuable suggestions and Dan Jones and Lijun Chen from the MSU RTSF mass spectrometry facility core for their technical support. This work was supported by National Institutes of Health (NIH) grants GM109259, GM110444, GM139537, Al143098, and Al158433 and National Science Foundation (NSF) grant DBI-0939454to C.M.W, the NIH grant GM110185 and the NSF CAREER Award 1750125 to K.N.P., and the NSF Graduate Research Fellowship Grant No. 1842399 to C.A.E. Any opinions, findings, and conclusions or recommendations expressed in this material are those of the author(s) and do not necessarily reflect the views of the National Science Foundation. 


\section{MATERIALS AND METHODS}

The strains, plasmids, and primers used in this study are listed in Supplementary Table S1, S2, and S3, respectively. Unless otherwise stated, cultures were grown in Luria-Bertani (LB) at $35^{\circ} \mathrm{C}$ and supplemented with the following as needed: ampicillin (100 $\left.\mu \mathrm{g} / \mathrm{mL}\right)$, kanamycin (100 $\mu \mathrm{g} / \mathrm{mL})$, tetracycline $(10 \mu \mathrm{g} / \mathrm{mL})$, and isopropyl- $\beta$-D-thiogalactoside (IPTG) $(100 \mu \mathrm{g} / \mathrm{mL})$. E. coli BW29427, a diaminopimelic acid (DAP) auxotroph, was additionally supplemented with 300 $\mu \mathrm{g} / \mathrm{mL}$ DAP. The $V$. cholerae El Tor biotype strain C6706str2 was utilized in this study and mutant strains were generated using the pKAS32 suicide vector [67] using three fragments: 500 $\mathrm{bp}$ of sequence upstream of the gene of interest, $500 \mathrm{bp}$ of sequence downstream of the gene of interest and cloned into the Kpnl and Sacl restriction sites of pKAS32 using by Gibson Assembly (NEB). $P_{\text {tac }}$ inducible expression vectors were constructed by Gibson Assembly with inserts amplified by PCR and pEVS143 [68] or pMMB67EH [69] each linearized by EcoRI and BamHI, as well as pET28b digested with Ncol and Xhol. pEVS141 [70] is used as an empty vector control for experiments using pEVS143 derived constructs. Site-directed mutagenesis was performed using the SPRINP method [71]. Plasmids were introduced into $V$. cholerae through biparental conjugation using an E. coli BW29427 donor. Transformation of E. coli for ectopic expression experiments was performed using electroporation with $\mathrm{DH} 10 \mathrm{~b}$ for expression of pEVS143 and pMMB67EH derived plasmids and BL21(DE3) for pET28b based constructs.

\section{Correlogy Bioinformatics Analysis}

Our Correlogy software package is built on Kim and Price's approach [32] to calculate genetic co-occurrence. The source code, documentation, and a Docker container for this Python3 package are available at https://github.com/clinte14/correlogy. While VSP-1 is used to simplify the description of the method detailed below, both VSP-1 and 2 were independently analyzed in the same fashion. To establish maximum related subnetworks (MRS) for the genomic region of the VSP-1 island, a BLASTP amino acid sequence was performed to search 
for each VSP-1 gene against the NCBI non-redundant protein database with an E-value cutoff

517 of $10^{-4}$. The BLAST results were limited to bacterial genomes, and all taxa belonging to the

518 genus Vibrio were removed to avoid bias from closely related vertical inheritance. The BLAST

519 results were used to generate a presence or absence matrix of VSP-1 homologues with all

520 species along one axis and VSP-1 genes along the other axis. Next, a pairwise Pearson

521 correlation value was calculated between all VSP-1 genes $i$ and $j$ using binary data from the

522 above-mentioned presence/absence matrix:

$$
r_{i j}=\frac{C_{i j} N-E_{i} E_{j}}{\sqrt{E_{i} E_{j}\left(N-E_{i}\right)\left(N-E_{j}\right)}}
$$

524 where $\mathrm{N}$ is the total number of unique species returned from the BLAST search and $C_{i j}$ the 525 number of species with co-occurrence of genes $i$ and $j$. While a Pearson correlation is warranted 526 for a normally distributed binary data set, it does not account for indirect correlation. For

527 example, if genes $i$ and $j$ individually associate with a third gene, a Pearson correlation will 528 incorrectly calculate a correlation between $i$ and $j$. To help correct for indirect correlation we calculate a partial correlation $w_{i j}$ from the Pearson $r_{i j}$ :

$$
w_{i j}=\frac{P_{i j}}{\sqrt{P_{i i} P_{i j}}}
$$

where the $(i, \jmath)$ element of the inverse matrix of Pearson $r_{i j}$ is $P_{i j}$ [32].

534 same species, while a value of 1 demonstrates genes $i$ and $j$ always co-occur in the same species. A $w_{i j}$ of 0 is the amount of co-occurrence expected between unrelated genes $i$ and $j$ drawn from a normal distribution. Using the above-mentioned approach, a partial correlation

537 value $w_{i j}$ was calculated for all genes $i$ to $j$ in VSP-1 and VSP-2 (Supplemental Files 1 and 2 ).

538 The single highest $w_{i j}$ value for each VSP-1 gene was represented as an edge (i.e., line) in our 
visualization (Fig. 1B, S1A, and S1B). Any set of genes that contains no further edges were assigned to a unique MRS that suggests functional association of the gene products within a

541 unique gene network.

\section{Genomic Identification, Structural, and Sequence Analyses of DcdV \& DifV Homologs}

DcdV from V. cholerae El Tor N16961 (WP 001901328.1) was identified as locus tag vc0175. DcdV and homologs profiles are performed using translated BLAST tblastn and run against the Nucleotide collection (nr/nt) database of National Center for Biotechnology Information (NCBI), using $>40 \%$ similarities cutoff. For previously annotated domains, the Pfam feature in KEGG $[72,73]$ were utilized as a guide to determine DcdV homologs. Out of all the sequence was submitted to Phyre2 [39] and structural visualization was performed using PyMol

557 (https://pymol.org). The amino acid and nucleotide alignments were analyzed using ClustalW

558 Omega from EMBL-EBI web services [74] and LocARNA [75], respectively.

\section{Identification and Characterization of Protein Homologs}

Homology searches: To ensure the identification of a comprehensive set of homologs

562 (close and remote), we started with six representative DcdV proteins across proteobacteria from

563 V. cholerae, V. parahaemolyticus, P. mirabilis, and E. coli described above along with $E$.

564 cloacae (WP 129996984.1), and A. veronii (WP 043825948.1) and performed homolog 
searches using DELTABLAST [76] against all sequenced genomes across the tree of life in the NCBI RefSeq database [77-79]. Homology searches were conducted for each protein and the search results were aggregated; the numbers of homologs per species and of genomes carrying each of the query proteins were recorded. These proteins were clustered into orthologous families using the similarity-based clustering program BLASTCLUST [76].

Characterizing homologous proteins: Phyre2, InterProScan, HHPred, SignalP, TMHMM, Phobius, Pfam, and custom profile databases [39-41, 80-85] were used to identify signal peptides, transmembrane (TM) regions, known domains, and secondary structures of proteins in every genome. Custom scripts were written to consolidate the results [86-91], and the domain architectures and protein function predictions were visualized using the MolEvolvR web-app (http://jravilab.org/molevolvr/).

Phylogenetic analysis (MSA and Tree): Thousands of homologs from all six starting points for DcdV proteins were consolidated and representatives were chosen from distinct Lineages and Genera, containing both the N- and C-terminal DcdV domains (PLK and DCD domains). Multiple sequence alignment (MSA) of the identified homologs was performed using Kalign [89] and MUSCLE [92, 93] (msa R package [94]). The phylogenetic trees were constructed using FastTree [95] FigTree [96] and the R package, ape [97].

\section{Growth Curve Assays}

Overnight cultures were diluted 1:1000 into LB supplemented with antibiotics and IPTG in a 96-well microplate (Costar®). Growth was monitored by measuring $\mathrm{OD}_{600}$ every 15 minutes for 15 hour $(h)$ using a BioTek plate reader with continuous, linear shaking.

\section{Fluorescence Microscopy and Analysis}

Cells were imaged as previously described [34]. Briefly, overnight cultures were diluted 1:1000 into LB supplemented with antibiotics and IPTG. Cultures were grown and induced for 7- 
$5918 \mathrm{~h}$, at which point cells were diluted to an $\mathrm{OD}_{600}$ of 0.5 in $1 \mathrm{X}$ PBS, then membrane stain FM4-

59264 dye (ThermoFisher Scientific) was added to a final concentration of $20 \mu \mathrm{g} / \mathrm{mL}$. $1 \%$ agarose

593 pads in deionized water were cut into squares of approximately $20 \times 20 \mathrm{~mm}$ and placed on

594 microscope slides. $2 \mu \mathrm{l}$ of diluted cultures were spotted onto a glass coverslip and then gently

595 placed onto the agarose pad. FM4-64 signal was visualized using a Leica DM5000b

596 epifluorescence microscope with a 100X-brightfield objective under RFP fluorescence channel.

597 Images were captured using a Spot Pursuit CCD camera and an X-cite 120 Illumination system.

598 Each slide was imaged with at least 20 fields of view for each biological replicate. Cell lengths

599 were processed using the Fiji plugin MicrobeJ [98, 99], and data were visualized and analyzed

600 using R [90] by quantifying the length of the curvilinear (medial) axis of detected cells.

601

602

\section{Construction and screening of mutant gene libraries}

DifV-insensitive DcdV constructs were generated by error-prone PCR (epPCR) using were collected from $\sim 30,000$ representative colonies for each $\mathrm{MnCl}_{2}$ concentration. Plasmid libraries were harvested using the Wizard® Plus SV Minipreps DNA purification Kit (Promega).

611 Plasmid libraries were subsequently electroporated to E. coli BW29427 which were again plated

612 and pooled to contain $~ 30,000$ representative colonies. The E. coli BW29427 random mutant

$613 \mathrm{pDcdV}$ libraries were conjugated with $\Delta d c d V V$. cholerae on LB agar plates for $8 \mathrm{~h}$, harvested,

614 diluted, and spread on LB agar plates containing 1 mM IPTG and antibiotics, and grown

615 overnight. $~ 5,000$ colonies were screened in each library and all colonies exhibiting a wrinkled

616 and small colony morphology, indicative of cell filamentation, were isolated and filamentation 
617 was confirmed by fluorescence microscopy. Mutant pDcdV plasmids recovered from cells

618 exhibiting cell filamentation were sequenced by Sanger sequencing. Mutations were

619 reintroduced individually into the WT pDcdV construct using SPRINP mutagenesis [71] and

620 reevaluated using fluorescence microscopy to confirm the DcdV variant's ability to remain

621 constitutively active in $\Delta d c d V V$. cholerae.

622

623

624

625

626

627

628

629

630

631

632

633

634

635

636

637

638

639

640

641

\section{RNA Isolation, qRT-PCR, and Co-transcription Analysis}

RNA isolation and qRT-PCR analysis were carried out as previously described [100, 101]. Briefly, triplicate overnight cultures were subcultured $1: 1000$ in $10 \mathrm{~mL}$ LB and grown to three different $\mathrm{OD}_{600}: 0.2$ (Early Exponential), 1.0 (Late Exponential), and 2.5 (Stationary). $1 \mathrm{~mL}$ of each replicate was pelleted, and RNA was extracted using TRIzol ${ }^{\circledR}$ reagent following the manufacturer's directions (Thermo Fischer Scientific). RNA quality and quantity were determined using a NanoDrop spectrophotometer (Thermo Fischer Scientific). $5 \mu \mathrm{g}$ of purified RNA was treated with DNase (Turbo ${ }^{\mathrm{TM}}$ DNase, Thermo Fischer Scientific). cDNA synthesis was carried out using SuperScript ${ }^{\mathrm{TM}}$ III Reverse Transcriptase (Thermo Fischer Scientific). cDNA was diluted 1:64 into molecular biology grade water and amplification was quantified using $2 x$ SYBR Green (Applied Biosystems ${ }^{\mathrm{TM}}$ ). For measuring gene expressions or determining orilter ratios, $25 \mu \mathrm{L}$ reactions consisted of $5 \mu \mathrm{L}$ each of $0.625 \mu \mathrm{M}$ primers 1 and $2,12.5 \mu \mathrm{L}$ of $2 \mathrm{X}$ SYBR master mix, and $2.5 \mu \mathrm{L}$ of template $(0.78 \mathrm{ng} / \mu \mathrm{L}$ cDNA for gene expression and $0.25 \mathrm{ng} / \mu \mathrm{L}$ genomic DNA for ori/ter). qRT-PCR reactions were performed in technical duplicates for biological triplicate samples and included no reverse transcriptase reaction controls ("no RT") to monitor for contaminating genomic DNA in purified RNA samples. qRT-PCR reaction thermo profile was $95^{\circ} \mathrm{C}$ for 20 seconds (s) then 40 cycles of $95^{\circ} \mathrm{C}$ for $2 \mathrm{~s}$ and $60^{\circ} \mathrm{C}$ for $30 \mathrm{~s}$ in the QuantStudio 3 Real-Time PCR system (Applied Biosystems ${ }^{\mathrm{TM}}$ ). The gyrA gene was used as an endogenous control to calculate relative quantification $\left(\Delta C_{t}\right)$. 
To determine the co-transcription of $d i f V$ and $d c d V$, PCR amplification was performed in

$64325 \mu \mathrm{L}$ volumes using Q5 polymerase (NEB), $0.5 \mu \mathrm{M}$ each of the forward and reverse primers as

644 indicated, $0.2 \mathrm{mM}$ dNTPs, and $3.5 \mu \mathrm{L}$ of cDNA or no RT control templates $(0.78 \mathrm{ng} / \mu \mathrm{L})$ from

645 RNA purified from WT and $\Delta \mathrm{ig}^{222} \mathrm{~V}$. cholerae grown to late exponential-phase in biological

triplicate. The thermal profile was $98^{\circ} \mathrm{C}$ for $30 \mathrm{~s}, 30$ cycles of $98^{\circ} \mathrm{C}$ for $10 \mathrm{~s}, 55^{\circ} \mathrm{C}$ for $30 \mathrm{~s}, 72^{\circ} \mathrm{C}$

for $10 \mathrm{sec}$ and one cycle of $72{ }^{\circ} \mathrm{C}$ for $2 \mathrm{~min}$. PCR products were loaded on a $1 \%$ agarose gel and stained with EZ-Vision® (VWR). Images were taken using the GelDoc system (Bio-Rad).

\section{In-vitro Nucleic Acid Deamination Assay}

Cell Lysate Preparation: Overnight cultures were subcultured 1:333 and grown to an

$652 \mathrm{OD}_{600}$ of $\sim 0.5-1.0$. Cultures were induced with $1 \mathrm{mM} \mathrm{IPTG}$, supplemented with $100 \mu \mathrm{M} \mathrm{ZnSO}$, and grown for an additional $3 \mathrm{hr}$. Cell pellets from $100 \mathrm{~mL}$ of induced cultures were harvested in two successive 15 min centrifugation steps at $4,000 \times \mathrm{g}$ and $4^{\circ} \mathrm{C}$. Supernatants were decanted thawed on ice and suspended in $2 \mathrm{~mL}$ of lysis buffer $\mathrm{A}\left(50 \mathrm{mM} \mathrm{NaPO}_{4}, \mathrm{pH} 7.3,300 \mathrm{mM} \mathrm{NaCl}, 2\right.$

$657 \mathrm{mM} \beta$-mercaptoethanol, 20\% glycerol and Roche cOmplete protease inhibitor (1 tablet per 10

$658 \mathrm{~mL})$ ). $1 \mathrm{~mL}$ of cell suspension was transferred to a microcentrifuge tube and sonicated on ice 659 using a Branson 450 Digital Sonifier (20\% amplitude, $20 \mathrm{sec}$ total, $2.5 \mathrm{sec}$ on, $2.5 \mathrm{sec}$ off).

660 Crude lysates were centrifuged at $15,000 \times \mathrm{g}$ for $10 \mathrm{~min}$ at $4^{\circ} \mathrm{C}$ and clarified lysates were

661 transferred to fresh microcentrifuge tubes on ice. Clarified lysates were normalized for total

662 protein to $1.9 \mathrm{mg} / \mathrm{mL}$ using Bradford reagents and a BSA standard. $26.5 \mu \mathrm{L}$ reactions composed 663 of lysis buffer A, nucleic acid substrates, and $3.5 \mu \mathrm{L}$ of normalized clarified lysates were assembled in PCR strip tubes, mixed by gentle pipetting, and incubated at room temperature buffer $\mathrm{A}$ and substituted for nucleic acid substrates as positive ammonium controls. 
Ammonium Detection: The evolution of $\mathrm{NH}_{4}{ }^{+}$by deamination of the nucleic acid

668

669

670

671

672

673

674

675

676

677

678

679

680

681

682

683

684

685

686

687

688

689

690

691

692

substrates was observed using a phenol-hypochlorite reaction to produce indophenol in a clear 96-well microtiter plate and modified from Dong et al. 2015 [102]. The work of Ngo et al. [103] was considered when designing the lysis buffer so as not to interfere with the phenolhypochlorite reaction. $50 \mu \mathrm{L}$ of Reagent $\mathrm{A}$ (composition below) was added to each well followed by $20 \mu \mathrm{L}$ of the completed in vitro deamination reaction described above. The phenolhypochlorite reaction was initiated by the addition and gentle mixing of $50 \mu \mathrm{L}$ Reagent $\mathrm{B}$ (composition below) to the wells. The reaction was incubated at $35^{\circ} \mathrm{C}$ for 30 min and the $\mathrm{ABS}_{630}$ was measured using a plate reader.

Reagent $A=1: 1(\mathrm{v} / \mathrm{v}), 6 \%(\mathrm{w} / \mathrm{v})$ sodium hydroxide (Sigma) in water: $1.5 \%(\mathrm{v} / \mathrm{v})$ sodium hypochlorite solution (Sigma, reagent grade) in water.

Reagent $B=1: 1: 0.04(\mathrm{v} / \mathrm{v} / \mathrm{v})$, water: $0.5 \%(\mathrm{w} / \mathrm{v})$ sodium nitroprusside (Sigma) in water: phenol solution (Sigma, P4557)

\section{Western Blot}

Strains containing DcdV- and variant- C-terminal 6x-histidine fusions were grown, induced, and harvested as described previously above (See In-vitro Nucleic Acid Deamination Assay: Cell Lysate Prep), except for the His-tag fusion (pGBS98) which are induced for only $2 \mathrm{~h}$ with $100 \mu \mathrm{M}$ IPTG and not subjected to sonication. The cell pellets were resuspended in $2 \mathrm{~mL}$ of chilled 1 X PBS and subsequently normalized to OD of $1.0 .1 \mathrm{~mL}$ aliquots were collected by centrifugation at $15 \mathrm{k} \times \mathrm{g}$ for $1 \mathrm{~min}$. Cell pellets were subsequently resuspended in $90 \mu \mathrm{L}$ of lysis buffer $\mathrm{A}$ and $30 \mu \mathrm{L}$ of $4 \mathrm{x}$ Laemmli buffer, denatured for 10 minutes at $65^{\circ} \mathrm{C}$, and centrifuged at $15 \mathrm{k} \times \mathrm{g}$ for 10 minutes. $5 \mu \mathrm{L}$ of samples were loaded into a precast $4-20 \%$ sodium dodecyl sulphate-polyacrylamide gel electrophoresis (SDS-PAGE) gels (Mini-PROTEAN TGX Precast Protein Gels, Bio-Rad) alongside size standards (Precision Protein Plus, Bio-Rad). Gels were run at room temperature for $90 \mathrm{~min}$ at $100 \mathrm{~V}$ in $1 \mathrm{x}$ Tris/glycine/SDS running buffer. Proteins 
were transferred to nitrocellulose membranes (Optitran). The membranes were blocked using 5\% skim milk and incubated with 1:5000 THE $^{\mathrm{TM}}$ His Tag Antibody, mAb, Mouse (GenScript) followed by 1:4000 Goat Anti-Mouse IgG Antibody (H\&L) [HRP], pAb (GenScript), treated with Pierce $^{\mathrm{TM}}$ ECL Western Blotting Substrate, and imaged using an Amersham ${ }^{\mathrm{TM}}$ Imager $600 .^{2}$

\section{UPLC-MS/MS Quantification of In Vitro and In Vivo Deoxynucleotides}

Deoxynucleotide concentrations were determined as previously described [104] with minor modifications. For measuring in vivo intracellular deoxynucleotide concentrations, overnight cultures were subcultured 1:1000 and grown to $\mathrm{OD}_{600}$ of $\sim 1.0$. Plasmid expression was induced by the addition of $1 \mathrm{mM} \mathrm{IPTG}$ for $1 \mathrm{~h}$, and $1 \mathrm{~mL}$ of cultures were collected by centrifugation at $15,000 \times \mathrm{g}$ for $1 \mathrm{~min}$. Cell pellets were resuspended in $200 \mu \mathrm{L}$ of chilled extraction buffer [acetonitrile, methanol, ultra-pure water, formic acid $(2: 2: 1: 0.02, \mathrm{v} / \mathrm{v} / \mathrm{v} / \mathrm{v})]$. To normalize in vivo nucleotide samples, an additional cell pellet was collected from $1 \mathrm{~mL}$ of culture by centrifugation at $15,000 \times \mathrm{g}$ for $1 \mathrm{~min}$, resuspended in $200 \mu \mathrm{L}$ lysis buffer $\mathrm{B}(20 \mathrm{mM}$ Tris $\cdot \mathrm{HCl}$, $1 \%$ SDS, $\mathrm{pH} 6.8$ ), and denatured for 10 minutes at $60^{\circ} \mathrm{C}$. Denatured lysates were centrifuged at $15,000 \times \mathrm{g}$ for $1 \mathrm{~min}$ to pellet cellular debris, and the supernatant was used to quantify the total protein concentration in the sample using the DC protein assay (Bio-Rad) a BSA standard curve [34]. The concentrations of deoxynucleotides detected by UPLC-MS/MS were then normalized to total protein in each sample.

For the quantification of deoxynucleotides in vitro E. coli BL21(DE3) clarified lysates were prepared as described for the deamination experiment above and normalized to $20 \mathrm{mg} / \mathrm{mL}$ of total protein and $200 \mu \mathrm{L}$ of normalized clarified lysates were assembled in PCR strip tubes. To measure abundance of dUMP and dUTP prior to the addition of $1 \mu \mathrm{M} \mathrm{dCTP}, 20 \mu \mathrm{L}$ of normalized clarified lysates were added to $200 \mu \mathrm{L}$ of chilled extraction buffer. $20 \mu \mathrm{L}$ of $10 \mu \mathrm{M}$ dCTP was then added to the remaining clarified lysates and $20 \mu \mathrm{L}$ lysates aliquots were 
718

719

720

721

722

723

724

725

726

727

728

729

730

731

732

733

734

735

736

737

738

739

740

741

742

743

removed $1,5,10$, and 30 minutes after the addition of dCTP and mixed in $200 \mu \mathrm{L}$ chilled extraction buffer.

All samples resuspended in extraction buffer, in vivo and in vitro, were immediately incubated at $-20^{\circ} \mathrm{C}$ for 30 minutes after collection and centrifuged at $15,000 \times \mathrm{g}$ for $1 \mathrm{~min}$. The supernatant was transferred to a new tube, dried overnight in a speed vacuum, and finally resuspended in $100 \mu \mathrm{L}$ ultra-pure water. Experimental samples and deoxynucleotides standards [1.9, 3.9, 7.8, 15.6, 31.3, 62.5, and $125 \mathrm{nM}$ of dATP (Invitrogen), dGTP (Invitrogen), dTTP, (Invitrogen), dCTP (Invitrogen), dCMP (Sigma), dUTP (Sigma), and dUMP (Sigma)] were analyzed by UPLC-MS/MS using an Acquity Ultra Performance LC system (Waters) coupled with a Xevo TQ-S mass spectrometer (Waters) with an ESI source in negative ion mode. The MS parameters were as follows: capillary voltage, $1.0 \mathrm{kV}$; source temperature, $150^{\circ} \mathrm{C}$; desolvation temperature, $400^{\circ} \mathrm{C}$; cone gas, $120 \mathrm{~L} / \mathrm{hr}$. Five microliter of each sample was separated in reverse phase using Acquity UPLC Premier BEH C18, 2.1 x 100 mm, $1.7 \mu \mathrm{m}$ particle size, VanGuard FIT at a flow rate of $0.3 \mathrm{~mL} / \mathrm{min}$ with the following gradient of solvent $A$ (8mM DMHA (N,N-dimethylhexylamine) $+2.8 \mathrm{mM}$ acetic acid in water, $\mathrm{pH}$ 9) to solvent $\mathrm{B}$ (methanol): $t=0 \mathrm{~min} ; \mathrm{A}-100 \%: \mathrm{B}-0 \%, t=10 \mathrm{~min} ; \mathrm{A}-60 \%: \mathrm{B}-40 \%, t=10.5 ; \mathrm{A}-100 \%: \mathrm{B}-0 \%, t=15$ min; A-100\%:B-0\% (end of gradient). The conditions of the MRM transitions were as follows [cone voltage (V), collision energy (eV)]: dATP, 490 > 159 (34, 34); dCTP, 466 > 159 (34, 34); dGTP, 506 > 159 (15, 46); dTTP, 481 > 159 (25, 34); dUTP, 467 > 159 (25, 34); dCMP, 306 > $97(43,22)$; dUMP, 306 > $111(22,22)$.

\section{Phage Infection and Plaque Assays}

V. cholerae phages ICP1 and ICP3 were provided by Wai-Leung Ng at Tuft University School of Medicine. ICP1 was propagated on V. cholerae E7946, while ICP3 were propagated on $V$. cholerae C6706str2 in LB, and their titer was determined using the small drop plaque assay method, as previously described [10]. Briefly, $1 \mathrm{ml}$ of overnight cultures were mixed with 9 
$744 \mathrm{ml}$ of $\mathrm{MMB}$ agar $(\mathrm{LB}+0.1 \mathrm{mM} \mathrm{MnCl} 2+5 \mathrm{mM} \mathrm{MgCl} 2+5 \mathrm{mM} \mathrm{CaCl} 2+0.5 \%$ agar $)$, tenfold serial

745 dilutions of phages in MMB were dropped on top of them, and incubated overnight at $35^{\circ} \mathrm{C}$. The

746 viral titer is expressed as plaque forming units per $\mathrm{mL}$ (pfu/mL). $4 \mathrm{~mL}$ of $V$. cholerae overnight

747 cultures were diluted 1:1000 in MMB medium. 145 $\mu \mathrm{L}$ of the diluted cultures, in three sets of

748 biological replicates, were transferred and incubated at $35^{\circ} \mathrm{C}$ in a 96 -well microplate (Costar $\AA$ ).

749 Once the $\mathrm{OD}_{600}$ reached $\sim 0.1,5 \mu \mathrm{L}$ of phages with a final $\mathrm{MOI}$ of 0.1 were added to each

750 biological replicate. Cultures were infected at room temperature $\left(\sim 23^{\circ} \mathrm{C}\right)$ for $12 \mathrm{~h}$ in a

751 SpectraMax M5 Plate Reader with continuous shaking and $\mathrm{OD}_{600}$ measurements taken every

$752 \quad 2.5 \mathrm{~min}$

Shigella flexneri strain PE577 [54] cells transformed with the pVector (pMMB67eh) and each of the associated pDcdV plasmids were grown in LB medium and incubated with aeration at $37^{\circ} \mathrm{C}$ overnight. The following day, $20 \mu \mathrm{L}$ of each of the overnight cultures were used to inoculate fresh medium in a 96-well microtiter plate with a final volume of $200 \mu \mathrm{L} /$ well. densities of the overnight cultures were experimentally determined by plating and found to be within a factor of two of one another. For all experiments, three biological replicates were tested. Additionally, the plates were set up with each unique condition having three technical replicates. Plate reader assays were conducted using a Molecular Devices FilterMax F5 plate reader, as previously described [105]. Briefly, the plates were incubated at $37^{\circ} \mathrm{C}$ for $6 \mathrm{~h}$. Every five minutes, the plate was mixed and aerated by orbital shaking before an absorbance (595 $\mathrm{nm})$ reading was taken. After the kinetic assay was complete an aliquot from each of the replicates was removed and used to determine the endpoint titer via plaque assay. 


\section{Statistical Analysis}

771 As specified in the figure legends, all of the statistical analyses for the violin plots were

772 performed with R statistical computing software [90], while other data were analyzed in

773 GraphPad Prism Software. Statistically significances denote as the following: a single asterisk

$774\left(^{*}\right)$ indicates $p<0.05$; double asterisks $\left({ }^{* *}\right)$ indicate $p<0.01$; triple asterisks $\left(^{* * *}\right)$ indicate $p<$

775

0.001 ; and quadruple asterisks $\left({ }^{* * * *}\right)$ indicate $p<0.0001$. Means \pm SEM and specific $n$ values

776 are reported in each figure legend.

777

778

\section{REFERENCE}

779 1. Thompson FL, lida T, Swings J (2004) Biodiversity of Vibrios. Microbiol Mol Biol Rev 68:403-431 . https://doi.org/10.1128/MMBR.68.3.403-431.2004

2. Son MS, Taylor RK (2011) Genetic Screens and Biochemical Assays to Characterize Vibrio cholerae O1 Biotypes: Classical and El Tor. Curr Protoc Microbiol 22:6A.2.1-

6A.2.17 . https://doi.org/10.1002/9780471729259.mc06a02s22

3. Dziejman M, Balon E, Boyd D, Fraser CM, Heidelberg JF, Mekalanos JJ (2002)

Comparative genomic analysis of Vibrio cholerae: Genes that correlate with cholera endemic and pandemic disease. Proc Natl Acad Sci 99:1556-1561 . https://doi.org/10.1073/pnas.042667999

4. Hu D, Liu B, Feng L, Ding P, Guo X, Wang M, Cao B, Reeves PR, Wang L (2016) Origins of the current seventh cholera pandemic. Proc Natl Acad Sci 113:E7730-E7739 . https://doi.org/10.1073/pnas.1608732113

791 5. O'Shea YA, Finnan S, Reen FJ, Morrissey JP, O'Gara F, Boyd EF (2004) The Vibrio seventh pandemic island-II is a $26.9 \mathrm{~kb}$ genomic island present in Vibrio cholerae El Tor and $\mathrm{O} 139$ serogroup isolates that shows homology to a $43.4 \mathrm{~kb}$ genomic island in $\mathrm{V}$. vulnificus. Microbiology 150:4053-4063 . https://doi.org/10.1099/mic.0.27172-0 
6. Murphy RA, Boyd EF (2008) Three Pathogenicity Islands of Vibrio cholerae Can Excise from the Chromosome and Form Circular Intermediates. J Bacteriol 190:636-647 . https://doi.org/10.1128/JB.00562-07

7. Nusrin S, Gil AI, Bhuiyan NA, Safa A, Asakura M, Lanata CF, Hall E, Miranda H, Huapaya B, Vargas G. C, Luna MA, Sack DA, Yamasaki S, Nair GB (2009) Peruvian Vibrio cholerae $\mathrm{O} 1 \mathrm{EI}$ Tor strains possess a distinct region in the Vibrio seventh pandemic island-II that differentiates them from the prototype seventh pandemic El Tor strains. J Med Microbiol 58:342-354 . https://doi.org/10.1099/jmm.0.005397-0

8. Beyhan S, Tischler AD, Camilli A, Yildiz FH (2006) Differences in Gene Expression between the Classical and El Tor Biotypes of Vibrio cholerae O1. Infect Immun 74:36333642 . https://doi.org/10.1128/IAI.01750-05

9. Davies BW, Bogard RW, Young TS, Mekalanos JJ (2012) Coordinated Regulation of Accessory Genetic Elements Produces Cyclic Di-Nucleotides for V. cholerae Virulence. Cell 149:358-370 . https://doi.org/10.1016/j.cell.2012.01.053

10. Cohen D, Melamed S, Millman A, Shulman G, Oppenheimer-Shaanan Y, Kacen A, Doron S, Amitai G, Sorek R (2019) Cyclic GMP-AMP signalling protects bacteria against viral infection. Nature 574:691-695 . https://doi.org/10.1038/s41586-019-1605-5

11. Severin GB, Ramliden MS, Hawver LA, Wang K, Pell ME, Kieninger A-K, Khataokar A, O’Hara BJ, Behrmann L V., Neiditch MB, Benning C, Waters CM, Ng W-L (2018) Direct activation of a phospholipase by cyclic GMP-AMP in El Tor Vibrio cholerae. Proc Natl Acad Sci 115:E6048-E6055 . https://doi.org/10.1073/pnas.1801233115

12. O'Donovan GA, Neuhard J (1970) Pyrimidine metabolism in microorganisms. Bacteriol Rev 34:278-343 . https://doi.org/10.1128/MMBR.34.3.278-343.1970

13. Weiss B (2007) The Deoxycytidine Pathway for Thymidylate Synthesis in Escherichia coli. J Bacteriol 189:7922-7926 . https://doi.org/10.1128/JB.00461-07

14. Weiss B, Wang L (1994) De novo synthesis of thymidylate via deoxycytidine in dcd 
(dCTP deaminase) mutants of Escherichia coli. J Bacteriol 176:2194-2199 . https://doi.org/10.1128/JB.176.8.2194-2199.1994

15. Krishnan A, lyer LM, Holland SJ, Boehm T, Aravind L (2018) Diversification of AID/APOBEC-like deaminases in metazoa: multiplicity of clades and widespread roles in immunity. Proc Natl Acad Sci 115:E3201-E3210 . https://doi.org/10.1073/pnas.1720897115

16. Chiu Y-L, Greene WC (2008) The APOBEC3 Cytidine Deaminases: An Innate Defensive Network Opposing Exogenous Retroviruses and Endogenous Retroelements. Annu Rev Immunol 26:317-353 . https://doi.org/10.1146/annurev.immunol.26.021607.090350

17. Lada AG, Frahm Krick C, Kozmin SG, Mayorov VI, Karpova TS, Rogozin IB, Pavlov YI (2011) Mutator effects and mutation signatures of editing deaminases produced in bacteria and yeast. Biochem 76:131-146 . https://doi.org/10.1134/S0006297911010135

18. Stavrou S, Ross SR (2015) APOBEC3 Proteins in Viral Immunity. J Immunol 195:456570 . https://doi.org/10.4049/jimmunol.1501504

19. Sharma S, Patnaik SK, Thomas Taggart R, Kannisto ED, Enriquez SM, Gollnick P, Baysal BE (2015) APOBEC3A cytidine deaminase induces RNA editing in monocytes and macrophages. Nat Commun 6:6881 . https://doi.org/10.1038/ncomms7881

20. Kreuzer KN, Brister JR (2010) Initiation of bacteriophage T4 DNA replication and replication fork dynamics: a review in the Virology Journal series on bacteriophage T4 and its relatives. Virol J 7:358 . https://doi.org/10.1186/1743-422X-7-358

21. You L, Suthers PF, Yin J (2002) Effects of Escherichia coli Physiology on Growth of Phage T7 In Vivo and In Silico. J Bacteriol 184:1888-1894 . https://doi.org/10.1128/JB.184.7.1888-1894.2002

22. Endy D, Kong D, Yin J (1997) Intracellular kinetics of a growing virus: A genetically structured simulation for bacteriophage T7. Biotechnol Bioeng 55:375-389 . https://doi.org/10.1002/(SICI)1097-0290(19970720)55:2<375::AID-BIT15>3.0.CO;2-G 
23. Zhang Y, Maley F, Maley GF, Duncan G, Dunigan DD, Van Etten JL (2007)

Chloroviruses Encode a Bifunctional dCMP-dCTP Deaminase That Produces Two Key Intermediates in dTTP Formation. J Virol 81:7662-7671 . https://doi.org/10.1128/jvi.00186-07

24. Graziani S, Xia Y, Gurnon JR, Van Etten JL, Leduc D, Skouloubris S, Myllykallio H, Liebl U (2004) Functional Analysis of FAD-dependent Thymidylate Synthase ThyX from Paramecium bursaria Chlorella Virus-1. J Biol Chem 279:54340-54347 . https://doi.org/10.1074/jbc.M409121200

25. Zhang Y, Moriyama H, Homma K, Van Etten JL (2005) Chlorella Virus-Encoded Deoxyuridine Triphosphatases Exhibit Different Temperature Optima. J Virol 79:99459953 . https://doi.org/10.1128/JVI.79.15.9945-9953.2005

26. Chiu CS, Ruettinger T, Flanegan JB, Greenberg GR (1977) Role of deoxycytidylate deaminase in deoxyribonucleotide synthesis in bacteriophage T4 DNA replication. J Biol Chem 252:8603-8608 . https://doi.org/10.1016/S0021-9258(19)75263-6

27. Miller ES, Kutter E, Mosig G, Arisaka F, Kunisawa T, Rüger W (2003) Bacteriophage T4 Genome. Microbiol Mol Biol Rev 67:86-156 . https://doi.org/10.1128/MMBR.67.1.86156.2003

28. Guzmán EC, Martín CM (2015) Thymineless death, at the origin. Front Microbiol 6:1-7 . https://doi.org/10.3389/fmicb.2015.00499

29. Itsko M, Schaaper RM (2014) dGTP Starvation in Escherichia coli Provides New Insights into the Thymineless-Death Phenomenon. PLoS Genet 10:e1004310 . https://doi.org/10.1371/journal.pgen.1004310

30. Kuong KJ, Kuzminov A (2010) Stalled replication fork repair and misrepair during thymineless death in Escherichia coli. Genes to Cells 15:619-634 . https://doi.org/10.1111/j.1365-2443.2010.01405.x

31. Ahmad SI, Kirk SH, Eisenstark A (1998) Thymine Metabolism and Thymineless Death in 
Prokaryotes and Eukaryotes. Annu Rev Microbiol 52:591-625.

https://doi.org/10.1146/annurev.micro.52.1.591

32. Kim PJ, Price ND (2011) Genetic co-occurrence network across sequenced microbes. PLoS Comput Biol 7: . https://doi.org/10.1371/journal.pcbi.1002340

33. Bartlett TM, Bratton BP, Duvshani A, Miguel A, Sheng Y, Martin NR, Nguyen JP, Persat A, Desmarais SM, VanNieuwenhze MS, Huang KC, Zhu J, Shaevitz JW, Gitai Z (2017) A Periplasmic Polymer Curves Vibrio cholerae and Promotes Pathogenesis. Cell 168:172185.e15 . https://doi.org/10.1016/j.cell.2016.12.019

34. Fernandez NL, Hsueh BY, Nhu NTQ, Franklin JL, Dufour YS, Waters CM (2020) Vibrio cholerae adapts to sessile and motile lifestyles by cyclic di-GMP regulation of cell shape. Proc Natl Acad Sci 117:29046-29054 . https://doi.org/10.1073/pnas.2010199117

35. Raabe CA, Hoe CH, Randau G, Brosius J, Tang TH, Rozhdestvensky TS (2011) The rocks and shallows of deep RNA sequencing: Examples in the Vibrio cholerae RNome. RNA 17:1357-1366 . https://doi.org/10.1261/rna.2682311

36. Papenfort K, Förstner KU, Cong J-P, Sharma CM, Bassler BL (2015) Differential RNAseq of Vibrio cholerae identifies the VqmR small RNA as a regulator of biofilm formation. Proc Natl Acad Sci 112:E766-E775 . https://doi.org/10.1073/pnas.1500203112

37. Krin E, Pierlé SA, Sismeiro O, Jagla B, Dillies M-AA, Varet H, Irazoki O, Campoy S, Rouy Z, Cruveiller S, Médigue C, Coppée J-YY, Mazel D (2018) Expansion of the SOS regulon of Vibrio cholerae through extensive transcriptome analysis and experimental validation. BMC Genomics 19:1-18 . https://doi.org/10.1186/s12864-018-4716-8

38. Short FL, Akusobi C, Broadhurst WR, Salmond GPC (2018) The bacterial Type III toxinantitoxin system, ToxIN, is a dynamic protein-RNA complex with stability-dependent antiviral abortive infection activity. Sci Rep 8:1013 . https://doi.org/10.1038/s41598-01718696-x

39. Kelley LA, Mezulis S, Yates CM, Wass MN, Sternberg MJE (2015) The Phyre2 web 
portal for protein modeling, prediction and analysis. Nat Protoc 10:845-58 .

900

901

902

903

904

905

906

907

908

909

910

911

912

913

914

915

916

917

918

919

920

921

922

923

924

https://doi.org/10.1038/nprot.2015.053

40. Jones P, Binns D, Chang H-Y, Fraser M, Li W, McAnulla C, McWilliam H, Maslen J, Mitchell A, Nuka G, Pesseat S, Quinn AF, Sangrador-Vegas A, Scheremetjew M, Yong S-Y, Lopez R, Hunter S (2014) InterProScan 5: genome-scale protein function classification. Bioinformatics 30:1236-1240 . https://doi.org/10.1093/bioinformatics/btu031

41. Finn RD, Attwood TK, Babbitt PC, Bateman A, Bork P, Bridge AJ, Chang H-Y, Dosztányi Z, El-Gebali S, Fraser M, Gough J, Haft D, Holliday GL, Huang H, Huang X, Letunic I, Lopez R, Lu S, Marchler-Bauer A, Mi H, Mistry J, Natale DA, Necci M, Nuka G, Orengo CA, Park Y, Pesseat S, Piovesan D, Potter SC, Rawlings ND, Redaschi N, Richardson L, Rivoire C, Sangrador-Vegas A, Sigrist C, Sillitoe I, Smithers B, Squizzato S, Sutton G, Thanki N, Thomas PD, Tosatto SCE, Wu CH, Xenarios I, Yeh L-S, Young S-Y, Mitchell AL (2017) InterPro in 2017-beyond protein family and domain annotations. Nucleic Acids Res 45:D190-D199 . https://doi.org/10.1093/nar/gkw1107

42. Leipe DD, Koonin E V., Aravind L (2003) Evolution and classification of P-loop kinases and related proteins. J Mol Biol 333:781-815 . https://doi.org/10.1016/j.jmb.2003.08.040

43. Walker JE, Saraste M, Runswick MJ, Gay NJ (1982) Distantly related sequences in the alpha- and beta-subunits of ATP synthase, myosin, kinases and other ATP-requiring enzymes and a common nucleotide binding fold. EMBO J 1:945-51. https://doi.org/10.1002/j.1460-2075.1982.tb01276.x

44. Khan SR, Kuzminov A (2019) Thymineless Death in Escherichia coli Is Unaffected by Chromosomal Replication Complexity. J Bacteriol 201: . https://doi.org/10.1128/JB.00797-18

45. Hou H-F, Liang Y-H, Li L-F, Su X-D, Dong Y-H (2008) Crystal structures of Streptococcus mutans 2'-deoxycytidylate deaminase and its complex with substrate analog and 
allosteric regulator dCTP x Mg2+. J Mol Biol 377:220-31 .

https://doi.org/10.1016/j.jmb.2007.12.064

46. Marx A, Alian A (2015) The first crystal structure of a dTTP-bound deoxycytidylate deaminase validates and details the allosteric-inhibitor binding site. J Biol Chem 290:682-90 . https://doi.org/10.1074/jbc.M114.617720

47. Lowey B, Whiteley AT, Keszei AFA, Morehouse BR, Mathews IT, Antine SP, Cabrera VJ, Kashin D, Niemann P, Jain M, Schwede F, Mekalanos JJ, Shao S, Lee ASY, Kranzusch PJ (2020) CBASS Immunity Uses CARF-Related Effectors to Sense 3'-5'- and 2'-5'Linked Cyclic Oligonucleotide Signals and Protect Bacteria from Phage Infection. Cell 182:38-49.e17 . https://doi.org/10.1016/j.cell.2020.05.019

48. Conticello SG, Thomas CJF, Petersen-Mahrt SK, Neuberger MS (2005) Evolution of the AID/APOBEC Family of Polynucleotide (Deoxy)cytidine Deaminases. Mol Biol Evol 22:367-377 . https://doi.org/10.1093/molbev/msi026

49. Seed KD, Bodi KL, Kropinski AM, Ackermann H-W, Calderwood SB, Qadri F, Camilli A (2011) Evidence of a Dominant Lineage of Vibrio cholerae-Specific Lytic Bacteriophages Shed by Cholera Patients over a 10-Year Period in Dhaka, Bangladesh. MBio 2:e0033410 . https://doi.org/10.1128/mBio.00334-10

50. Yen M, Cairns LS, Camilli A (2017) A cocktail of three virulent bacteriophages prevents Vibrio cholerae infection in animal models. Nat Commun 8:14187 . https://doi.org/10.1038/ncomms 14187

51. O'Hara BJ, Barth ZK, McKitterick AC, Seed KD (2017) A highly specific phage defense system is a conserved feature of the Vibrio cholerae mobilome. PLoS Genet 13:e1006838 . https://doi.org/10.1371/journal.pgen.1006838

52. McKitterick AC, Seed KD (2018) Anti-phage islands force their target phage to directly mediate island excision and spread. Nat Commun 9:2348 . https://doi.org/10.1038/s41467-018-04786-5 
951

952

953

954

955

956

957

958

959

960

961

962

963

964

965

966

967

968

969

970

971

972

973

974

975

976

53. Hays SG, Seed KD (2020) Dominant Vibrio cholerae phage exhibits lysis inhibition sensitive to disruption by a defensive phage satellite. Elife 9: .

https://doi.org/10.7554/eLife.53200

54. Morona R, Mavris M, Fallarino A, Manning PA (1994) Characterization of the rfc region of Shigella flexneri. J Bacteriol 176:733-747 . https://doi.org/10.1128/JB.176.3.733-

747.1994

55. Casjens SR (2004) The Chromosome of Shigella flexneri Bacteriophage Sf6: Complete Nucleotide Sequence, Genetic Mosaicism, and DNA Packaging*1. J Mol Biol 339:379_ 394 . https://doi.org/10.1016/S0022-2836(04)00377-8

56. Jemielita M, Wingreen NS, Bassler BL Quorum sensing controls Vibrio cholerae multicellular aggregate formation. Elife. https://doi.org/10.7554/eLife.42057

57. Johansson E, Fanø M, Bynck JH, Neuhard J, Larsen S, Sigurskjold BW, Christensen U, Willemoës M (2005) Structures of dCTP Deaminase from Escherichia coli with Bound Substrate and Product. J Biol Chem 280:3051-3059 .

https://doi.org/10.1074/jbc.M409534200

58. Bernheim A, Millman A, Ofir G, Meitav G, Avraham C, Shomar H, Rosenberg MM, Tal N, Melamed S, Amitai G, Sorek R (2020) Prokaryotic viperins produce diverse antiviral molecules. Nature. https://doi.org/10.1038/s41586-020-2762-2

59. Ayinde D, Casartelli N, Schwartz O (2012) Restricting HIV the SAMHD1 way: Through nucleotide starvation. Nat Rev Microbiol 10:675-680 .

https://doi.org/10.1038/nrmicro2862

60. Shepard C, Xu J, Holler J, Kim DH, Mansky LM, Schinazi RF, Kim B (2019) Effect of induced dNTP pool imbalance on HIV-1 reverse transcription in macrophages.

Retrovirology 16:29 . https://doi.org/10.1186/s12977-019-0491-0

61. Oo A, Kim DH, Schinazi RF, Kim B (2020) Viral protein X reduces the incorporation of mutagenic noncanonical rNTPs during lentivirus reverse transcription in macrophages. J 
978

979

980

981

982

983

984

985

986

987

988

989

990

991

992

993

994

995

996

997

998

999

1000

1001

1002

62. Harms A, Brodersen DE, Mitarai N, Gerdes K (2018) Toxins, Targets, and Triggers: An Overview of Toxin-Antitoxin Biology. Mol Cell 70:768-784 . https://doi.org/10.1016/j.molcel.2018.01.003

63. Makarova KS, Wolf YI, Snir S, Koonin E V. (2011) Defense Islands in Bacterial and Archaeal Genomes and Prediction of Novel Defense Systems. J Bacteriol 193:6039_ 6056 . https://doi.org/10.1128/JB.05535-11

64. Doron S, Melamed S, Ofir G, Leavitt A, Lopatina A, Keren M, Amitai G, Sorek R (2018) Systematic discovery of antiphage defense systems in the microbial pangenome. Science (80- ) 359:eaar4120 . https://doi.org/10.1126/science.aar4120

65. Bernheim A, Sorek R (2020) The pan-immune system of bacteria: antiviral defence as a community resource. Nat Rev Microbiol 18:113-119 . https://doi.org/10.1038/s41579019-0278-2

66. Westra ER, Swarts DC, Staals RHJ, Jore MM, Brouns SJJ, van der Oost J (2012) The CRISPRs, They Are A-Changin': How Prokaryotes Generate Adaptive Immunity. Annu Rev Genet 46:311-339 . https://doi.org/10.1146/annurev-genet-110711-155447

67. Skorupski K, Taylor RK (1996) Positive selection vectors for allelic exchange. Gene 169:47-52 . https://doi.org/10.1016/0378-1119(95)00793-8

68. Bose JL, Rosenberg CS, Stabb E V. (2008) Effects of luxCDABEG induction in Vibrio fischeri: Enhancement of symbiotic colonization and conditional attenuation of growth in culture. Arch Microbiol 190:169-183 . https://doi.org/10.1007/s00203-008-0387-1

69. Fürste JP, Pansegrau W, Frank R, Blöcker H, Scholz P, Bagdasarian M, Lanka E (1986) Molecular cloning of the plasmid RP4 primase region in a multi-host-range tacP expression vector. Gene 48:119-131 . https://doi.org/10.1016/0378-1119(86)90358-6

70. Dunn AK, Millikan DS, Adin DM, Bose JL, Stabb E V (2006) and pES213-Derived Tools for Analyzing Symbiotic. Society 72:802-810 . https://doi.org/10.1128/AEM.72.1.802 
1003 71. Edelheit O, Hanukoglu A, Hanukoglu I (2009) Simple and efficient site-directed

1004

1005

1006

1007

1008

1009

1010

1011

1012

1013

1014

1015

1016

1017

1018

1019

1020

1021

1022

1023

1024

1025

1026

1027

1028

mutagenesis using two single-primer reactions in parallel to generate mutants for protein structure-function studies. BMC Biotechnol 9:61 . https://doi.org/10.1186/1472-6750-9-61

72. Kanehisa M, Goto S (2000) KEGG: kyoto encyclopedia of genes and genomes. Nucleic Acids Res 28:27-30 . https://doi.org/10.1093/nar/28.1.27

73. Kanehisa M, Sato Y, Furumichi M, Morishima K, Tanabe M (2019) New approach for understanding genome variations in KEGG. Nucleic Acids Res 47:D590-D595 . https://doi.org/10.1093/nar/gky962

74. Madeira F, Madhusoodanan N, Lee J, Tivey ARN, Lopez R (2019) Using EMBL-EBI Services via Web Interface and Programmatically via Web Services. Curr Protoc Bioinforma 66:e74 . https://doi.org/10.1002/cpbi.74

75. Will S, Joshi T, Hofacker IL, Stadler PF, Backofen R (2012) LocARNA-P: accurate boundary prediction and improved detection of structural RNAs. RNA 18:900-14 . https://doi.org/10.1261/rna.029041.111

76. Camacho C, Coulouris G, Avagyan V, Ma N, Papadopoulos J, Bealer K, Madden TL (2009) BLAST+: architecture and applications. BMC Bioinformatics 10:421 . https://doi.org/10.1186/1471-2105-10-421

77. Tatusova T, Ciufo S, Federhen S, Fedorov B, McVeigh R, O'Neill K, Tolstoy I, Zaslavsky L (2015) Update on RefSeq microbial genomes resources. Nucleic Acids Res 43:D599_ D605 . https://doi.org/10.1093/nar/gku1062

78. O'Leary NA, Wright MW, Brister JR, Ciufo S, Haddad D, McVeigh R, Rajput B, Robbertse B, Smith-White B, Ako-Adjei D, Astashyn A, Badretdin A, Bao Y, Blinkova O, Brover V, Chetvernin V, Choi J, Cox E, Ermolaeva O, Farrell CM, Goldfarb T, Gupta T, Haft D, Hatcher E, Hlavina W, Joardar VS, Kodali VK, Li W, Maglott D, Masterson P, McGarvey KM, Murphy MR, O’Neill K, Pujar S, Rangwala SH, Rausch D, Riddick LD, Schoch C, Shkeda A, Storz SS, Sun H, Thibaud-Nissen F, Tolstoy I, Tully RE, Vatsan AR, Wallin C, 
Webb D, Wu W, Landrum MJ, Kimchi A, Tatusova T, DiCuccio M, Kitts P, Murphy TD, Pruitt KD (2016) Reference sequence (RefSeq) database at NCBI: current status, taxonomic expansion, and functional annotation. Nucleic Acids Res 44:D733-45 . https://doi.org/10.1093/nar/gkv1189

79. Federhen S (2012) The NCBI Taxonomy database. Nucleic Acids Res 40:D136-D143 . https://doi.org/10.1093/nar/gkr1178

80. Soding J, Biegert A, Lupas AN (2005) The HHpred interactive server for protein homology detection and structure prediction. Nucleic Acids Res 33:W244-W248 . https://doi.org/10.1093/nar/gki408

81. Nielsen H (2017) Predicting Secretory Proteins with SignalP. Methods Mol Biol 1611:59_ 73 . https://doi.org/10.1007/978-1-4939-7015-5_6

1040

1041

1042

1043

1044

1045

82. Krogh A, Larsson B, von Heijne G, Sonnhammer ELL (2001) Predicting transmembrane protein topology with a hidden markov model: application to complete genomes11Edited by F. Cohen. J Mol Biol 305:567-580 . https://doi.org/10.1006/jmbi.2000.4315

83. Käll L, Krogh A, Sonnhammer ELL (2004) A Combined Transmembrane Topology and Signal Peptide Prediction Method. J Mol Biol 338:1027-1036.

https://doi.org/10.1016/j.jmb.2004.03.016

84. Käll L, Krogh A, Sonnhammer ELL (2007) Advantages of combined transmembrane topology and signal peptide prediction-the Phobius web server. Nucleic Acids Res 35: . https://doi.org/10.1093/nar/gkm256

85. Mistry J, Finn R (2007) Pfam. Methods Mol Biol 396:43-58 . https://doi.org/10.1007/978$1-59745-515-2 \_4$

86. Wilkins D (2020) gggenes. available: https://github.com/wilkox/gggenes

87. Wickham H, Averick M, Bryan J, Chang W, McGowan L, François R, Grolemund G, Hayes A, Henry L, Hester J, Kuhn M, Pedersen T, Miller E, Bache S, Müller K, Ooms J, Robinson D, Seidel D, Spinu V, Takahashi K, Vaughan D, Wilke C, Woo K, Yutani H 
(2019) Welcome to the Tidyverse. J Open Source Softw 4:1686 . https://doi.org/10.21105/joss.01686

88. Müller K (2017) here: A Simpler Way to Find Your Files. available: https://cran.rproject.org/web/packages/here/index.html

89. Lassmann T (2019) Kalign 3: multiple sequence alignment of large datasets.

Bioinformatics. https://doi.org/10.1093/bioinformatics/btz795

90. R Core Team (2019) R: A language and environment for statistical computing. In: R Found. Stat. Comput. available: https://www.r-project.org/

91. RStudio Team (2020) RStudio: Integrated Development Environment for R. available: https://www.rstudio.com/

92. Edgar RC (2004) MUSCLE: Multiple sequence alignment with high accuracy and high throughput. Nucleic Acids Res. https://doi.org/10.1093/nar/gkh340

93. Edgar RC (2004) MUSCLE: A multiple sequence alignment method with reduced time and space complexity. BMC Bioinformatics. https://doi.org/10.1186/1471-2105-5-113

94. Bonatesta E, Horejs-Kainrath C, Bodenhofer U (2020) Multiple Sequence Alignment. available: https://www.bioinf.jku.at/software/msa/

95. Price MN, Dehal PS, Arkin AP (2010) FastTree 2 - Approximately maximum-likelihood trees for large alignments. PLoS One 5:e9490 .

https://doi.org/10.1371/journal.pone.0009490

96. Rambaut A (2009) FigTree. availabe: https://tree.bio.ed.ac.uk/software/figtree/

97. Paradis E, Blomberg S, Bolker B, Brown J, Claramunt S, Claude J, Cuong HS, Desper R, Didier G, Durand B, Dutheil J, Ewing R, Gascuel O, Guillerme T, Heibl C, Ives A, Jone B, Krah F, Lawson D, Lefort V, Legendre P, Lemon J, Louvel G, Marcon E, McCloskey R, Nylander J, Opgen-Rhein R, Popescu A-A, Royer-Carenzi M, Schliep K, Strimmer K, de Vienne D (2020) ape: Analyses of Phylogenetics and Evolution. available: https://apepackage.ird.fr/ 
1081

1082

1083

1084

1085

1086

1087

1088

1089

1090

1091

1092

1093

1094

1095

1096

1097

1098

1099

1100

1101

1102

1103

1104

1105

1106

98. Ducret A, Quardokus EM, Brun Y V. (2016) MicrobeJ, a tool for high throughput bacterial cell detection and quantitative analysis. Nat Microbiol 1:16077 .

https://doi.org/10.1038/nmicrobiol.2016.77

99. Schindelin J, Arganda-Carreras I, Frise E, Kaynig V, Longair M, Pietzsch T, Preibisch S, Rueden C, Saalfeld S, Schmid B, Tinevez J-Y, White DJ, Hartenstein V, Eliceiri K, Tomancak P, Cardona A (2012) Fiji: an open-source platform for biological-image analysis. Nat Methods 9:676-682 . https://doi.org/10.1038/nmeth.2019

100. Fernandez NL, Waters CM (2019) Cyclic di-GMP increases catalase production and hydrogen peroxide tolerance in Vibrio cholerae. Appl Environ Microbiol 85: . https://doi.org/10.1128/AEM.01043-19

101. Dryselius R, Izutsu K, Honda T, lida T (2008) Differential replication dynamics for large and small Vibrio chromosomes affect gene dosage, expression and location. BMC Genomics 9:559 . https://doi.org/10.1186/1471-2164-9-559

102. Dong H, Liu Y, Zu X, Li N, Li F, Zhang D (2015) An enzymatic assay for high-throughput screening of cytidine-producing microbial strains. PLoS One 10:e0121612 . https://doi.org/10.1371/journal.pone.0121612

103. Ngo TT, Phan APH, Yam CF, Lenhoff HM (1982) Interference in determination of ammonia with the hypochlorite-alkaline phenol method of Berthelot. Anal Chem 54:4649 . https://doi.org/10.1021/ac00238a015

104. Massie JP, Reynolds EL, Koestler BJ, Cong J-P, Agostoni M, Waters CM (2012) Quantification of high-specificity cyclic diguanylate signaling. Proc Natl Acad Sci 109:12746-12751 . https://doi.org/10.1073/pnas.1115663109

105. Dover JA, Burmeister AR, Molineux IJ, Parent KN (2016) Evolved populations of Shigella flexneri phage Sf6 acquire large deletions, altered genomic architecture, and faster life cycles. Genome Biol Evol 8:2827-2840 . https://doi.org/10.1093/gbe/evw177

106. Evans DJ, Evans DG (1973) Three Characteristics Associated with Enterotoxigenic 
Escherichia coli Isolated from Man. Infect Immun 8:322-328 .

https://doi.org/10.1128/IAI.8.3.322-328.1973

107. Helene Thelin K, Taylor RK (1996) Toxin-coregulated pilus, but not mannose-sensitive hemagglutinin, is required for colonization by Vibrio cholerae O1 El Tor biotype and 0139 strains. Infect Immun 64:2853-2856 . https://doi.org/10.1128/iai.64.7.2853-2856.1996

108. Miller VL, DiRita VJ, Mekalanos JJ (1989) Identification of toxS, a regulatory gene whose product enhances ToxR-mediated activation of the cholera toxin promoter. J Bacteriol

109. Lüdeke CHM, Kong N, Weimer BC, Fischer M, Jones JL (2015) Complete Genome Sequences of a Clinical Isolate and an Environmental Isolate of Vibrio parahaemolyticus. Genome Announc 3:e00216-15 . https://doi.org/10.1128/genomeA.00216-15

110. Lutgring JD, Machado M-J, Benahmed FH, Conville P, Shawar RM, Patel J, Brown AC (2017) FDA-CDC Antimicrobial Resistance Isolate Bank: a Publicly Available Resource To Support Research, Development, and Regulatory Requirements. J Clin Microbiol 56: . https://doi.org/10.1128/JCM.01415-17

1122 111. Parent KN, Erb ML, Cardone G, Nguyen K, Gilcrease EB, Porcek NB, Pogliano J, Baker TS, Casjens SR (2014) OmpA and OmpC are critical host factors for bacteriophage Sf6 entry in Shigella. Mol Microbiol 92:47-60 . https://doi.org/10.1111/mmi.12536

112. Vanbleu E, Marchal K, Vanderleyden J (2004) Genetic and physical map of the pLAFR1 vector. DNA Seq - J DNA Seq Mapp 15:225-227 . 
Fig. 1

A

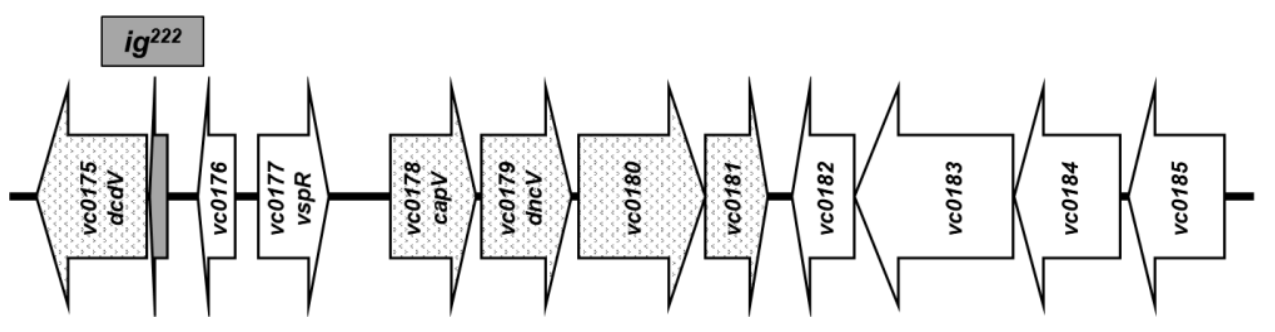

B

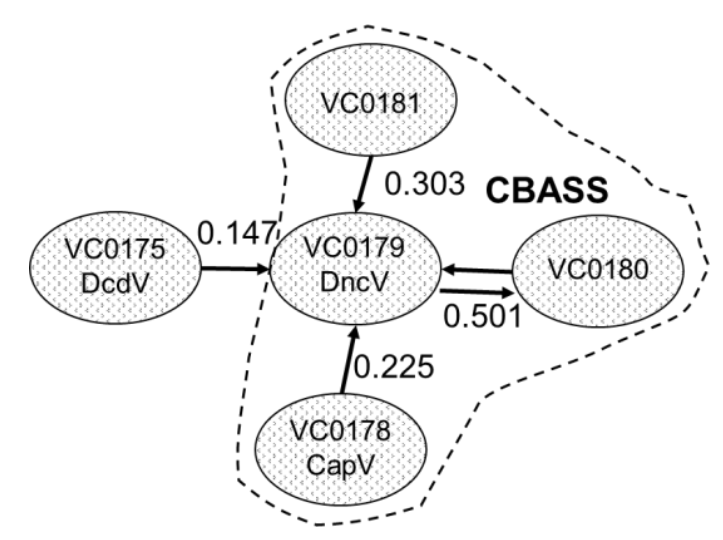

C

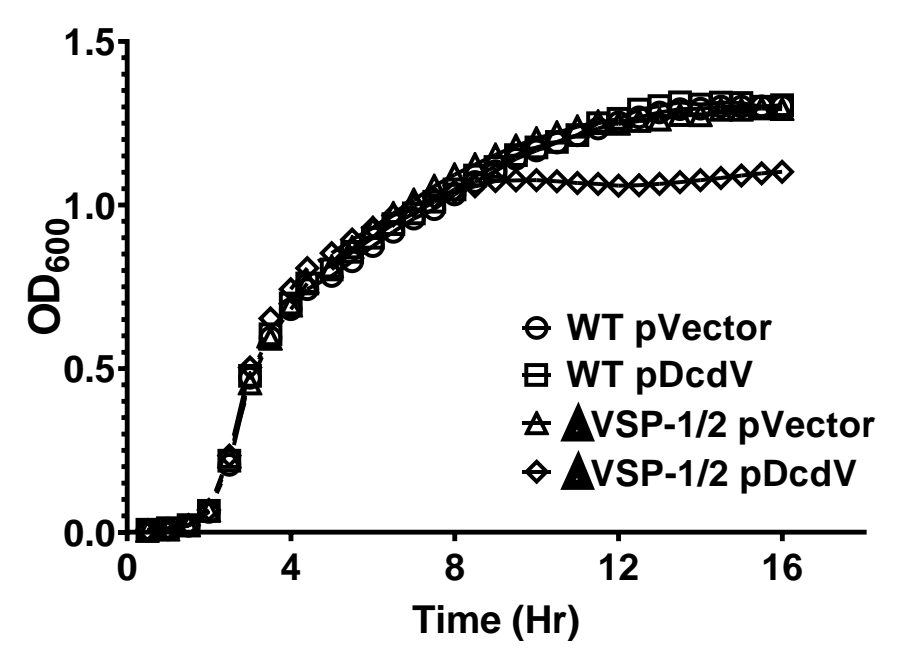

D

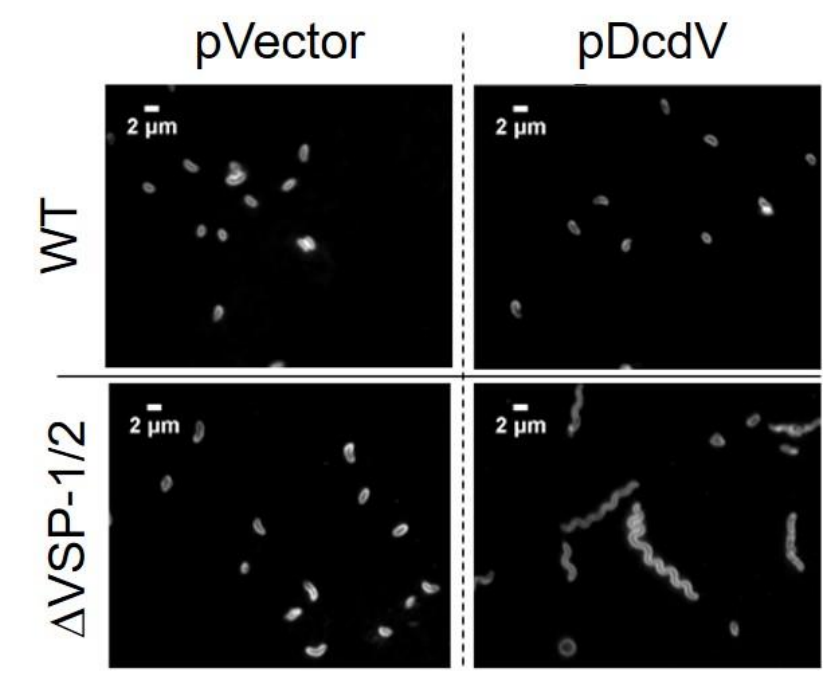

E

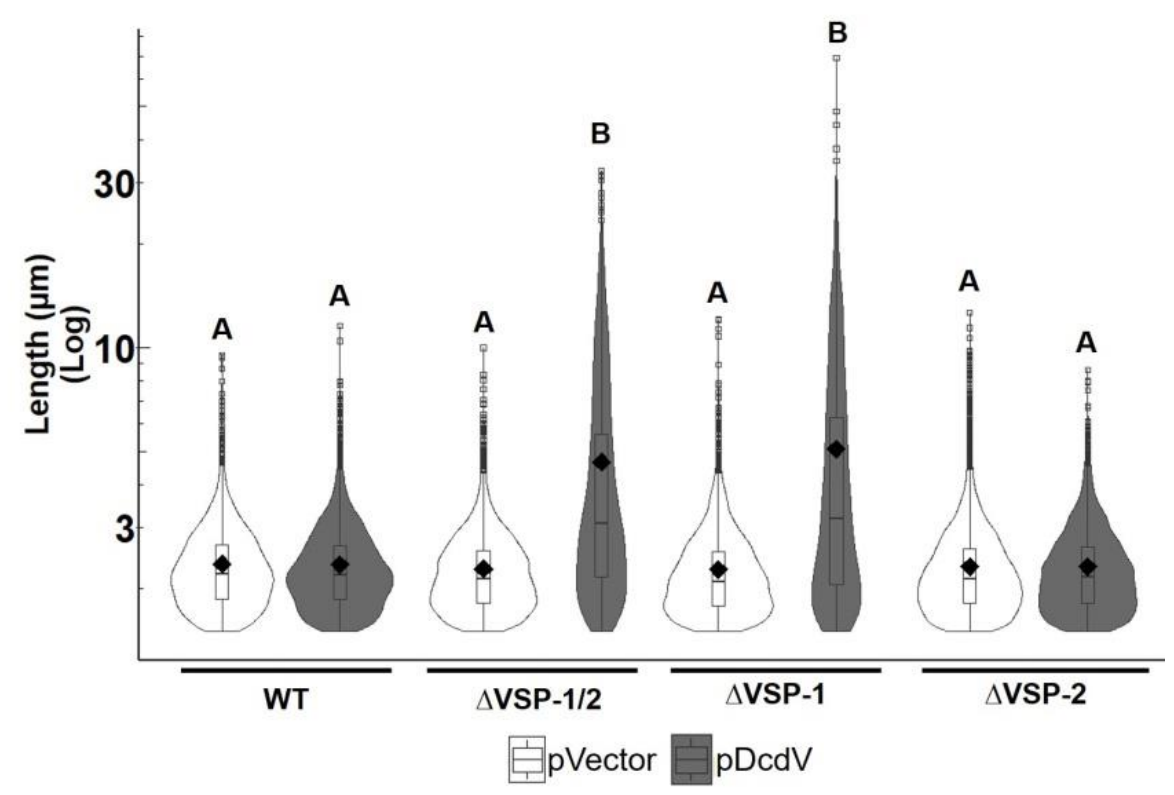




\section{Fig. 1: DcdV promotes filamentation in V. cholerae in the absence of VSP-1}

(A) Cartoon schematic of VSP-1 and (B) the Correlogy gene network prediction for $d n c V$ where arrows show the highest partial correlation $W_{i j}$ each individual VSP-1 gene has to another. (C) Growth of WT V. cholerae and $\Delta$ VSP-1/2 strains with the vector or pDcdV. Data represent the mean \pm SEM, $n=3$. (D) Representative images of WT and $\Delta \mathrm{VSP}-1 / 2$ strains with the vector or pDcdV. (E) Violin plots of cell length distributions of WT, $\Delta \mathrm{VSP}-1 / 2, \Delta \mathrm{VSP}-1$, and $\Delta \mathrm{VSP}-2$ strains with the vector or pDcdV: summary statistic for this and all following violin plots are mean (diamonds), median (horizontal black line), interquartile range (box), and data below and above the interquartile range (vertical lines). Different letters indicate significant differences $(n=3)$ at $p<0.05$, according to Tukey's post-hoc test. 


\section{Fig. 2}

A

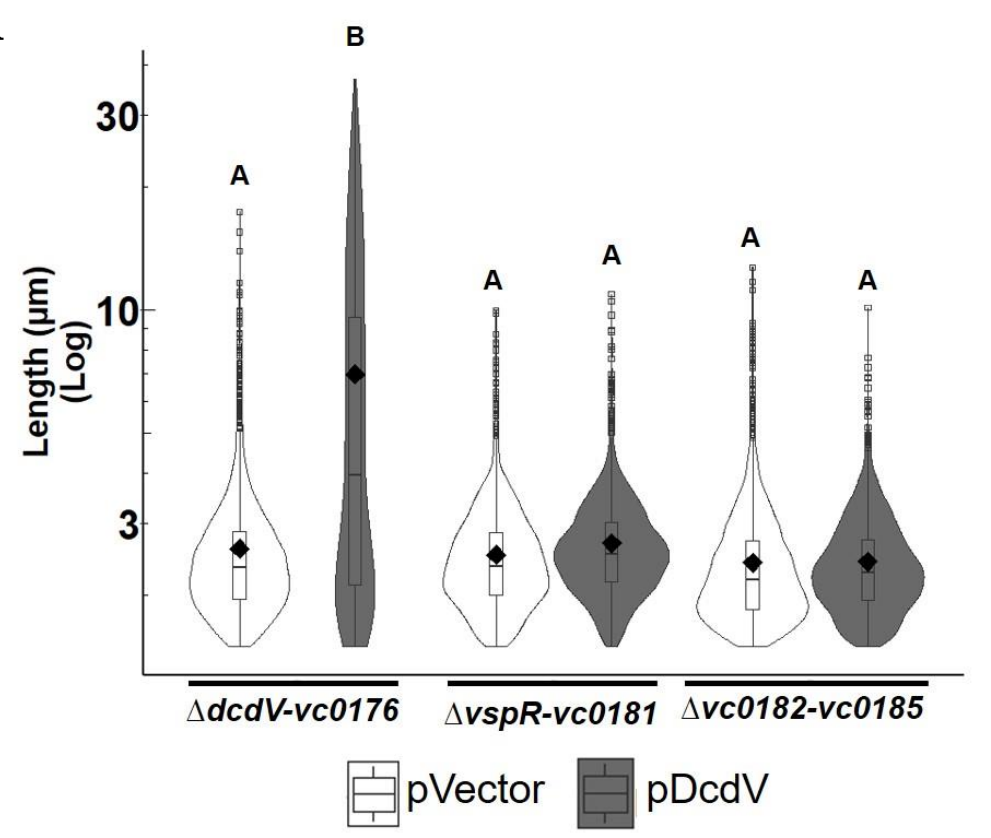

B

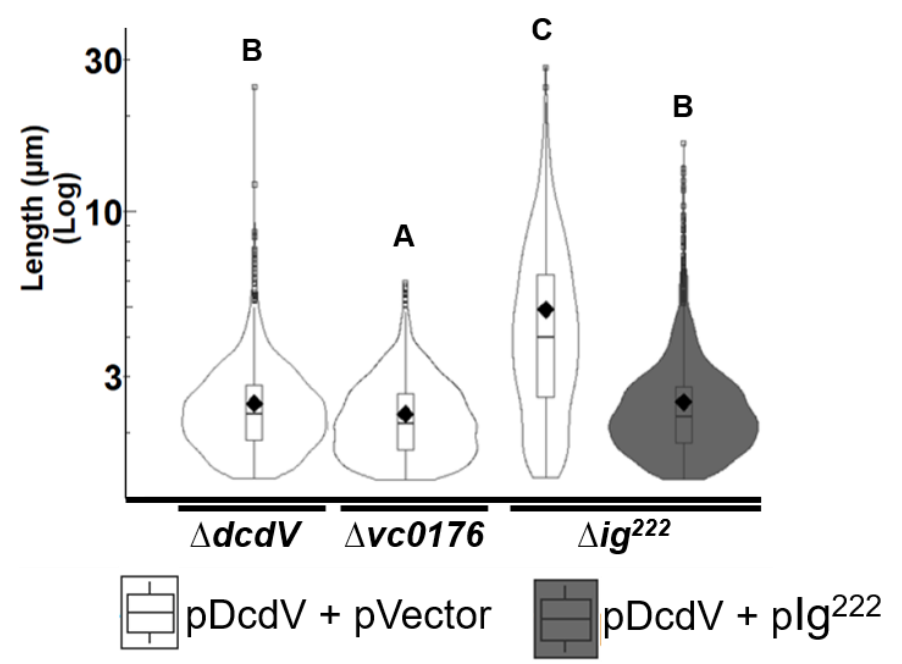

C

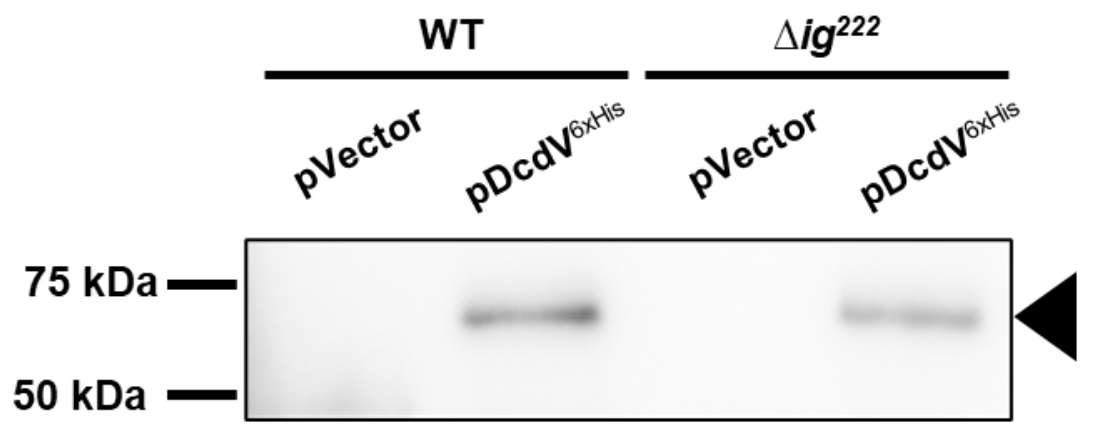

D

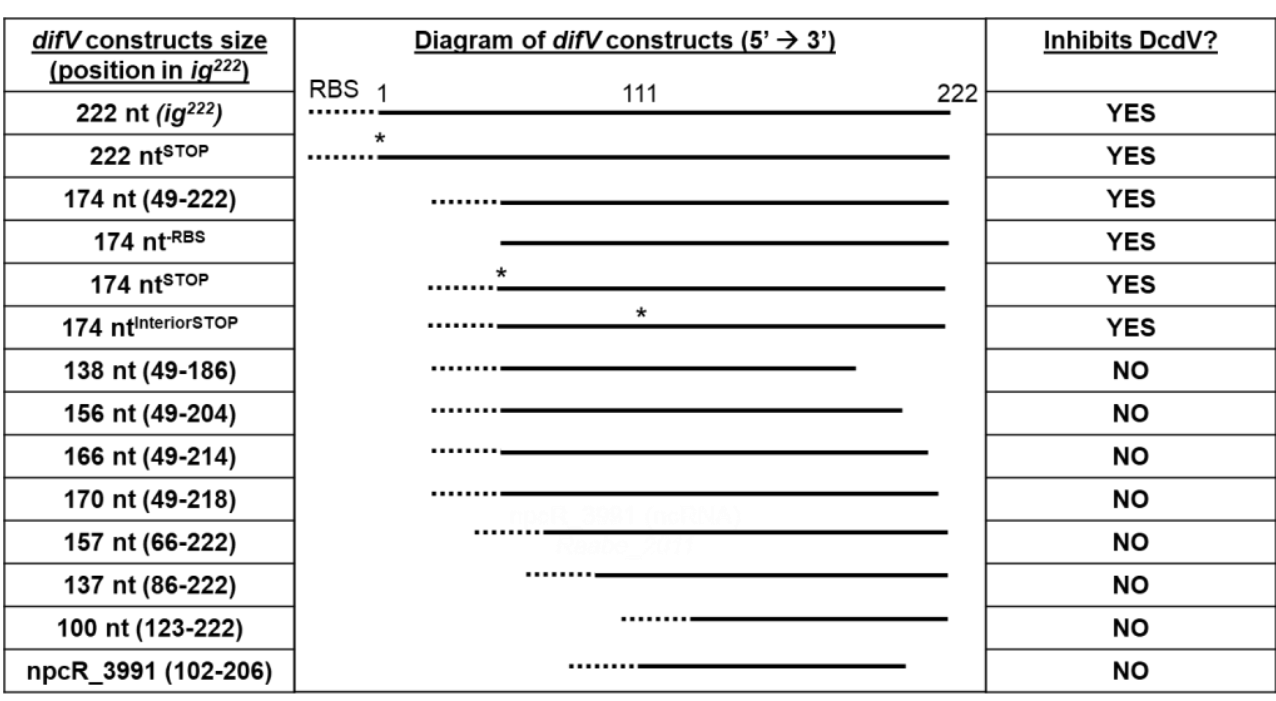




\section{Fig. 2: DifV is a sRNA that post-translationally regulates DcdV}

(A) Distribution of cell lengths measured from three biological replicates of gene deletions within VSP-1 or (B) individual gene deletions as indicated containing vector or pDcdV grown in the presence of $100 \mu \mathrm{M}$ IPTG for $8 \mathrm{~h}$. Different letters indicate significant differences $(n=3)$ at $p<0.05$, according to Tukey's post-hoc test. (C)

Representative anti-6x His antibody Western blot of whole cell lysates from $V$. cholerae WT and $\Delta i g^{222}$ cultures maintaining vector or pDcdV6xHis. Analysis was performed in

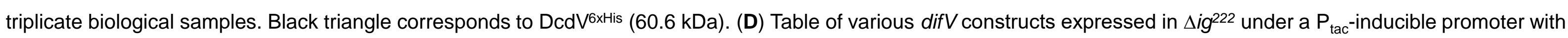
a non-native ribosomal binding site (RBS, denoted by dotted line). DcdV induced filamentation in the presence of these difV constructs was assessed using fluorescence microscopy in biological triplicate cultures. “*” indicates a stop codon introduced in place of a putative start codon. 
Fig. 3

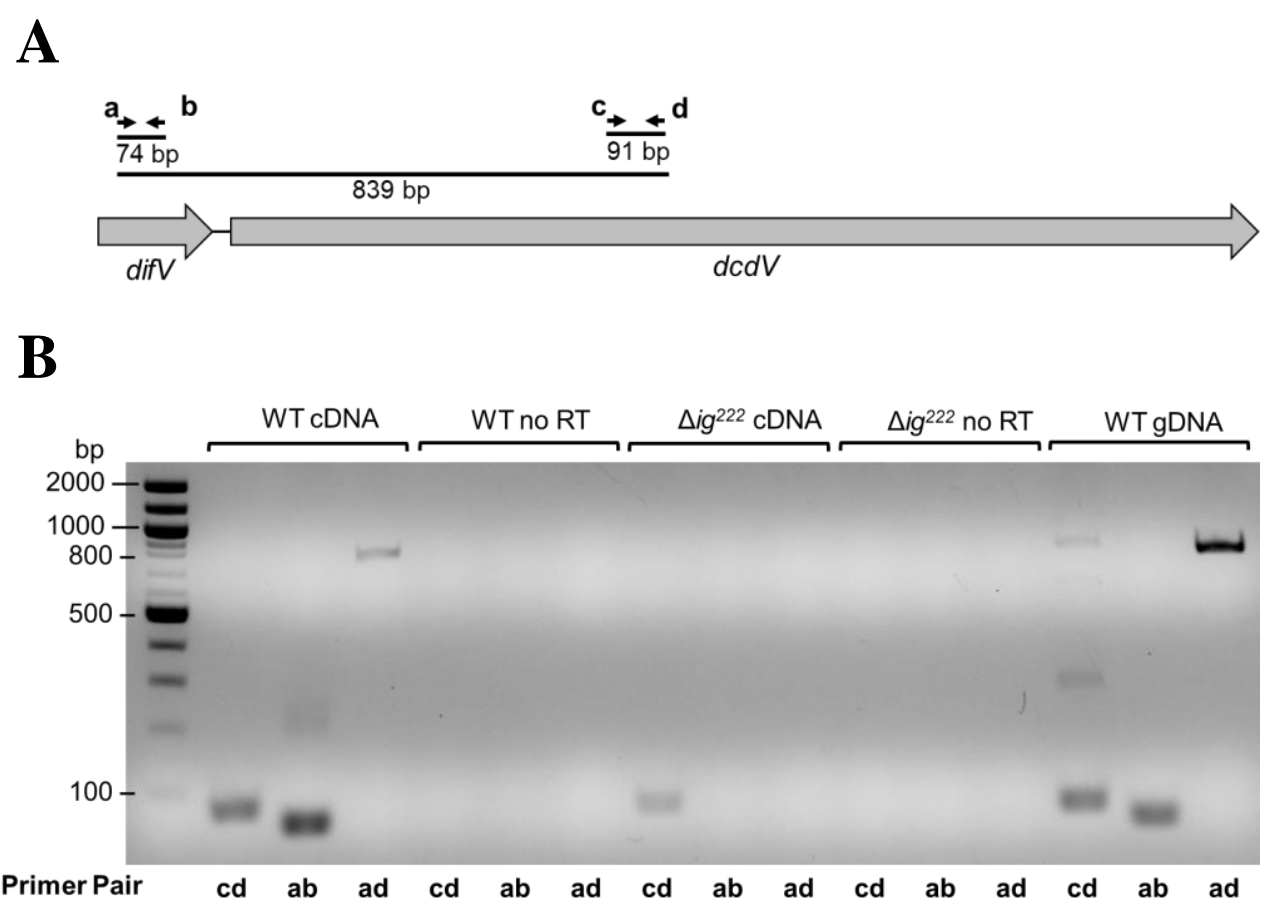

C

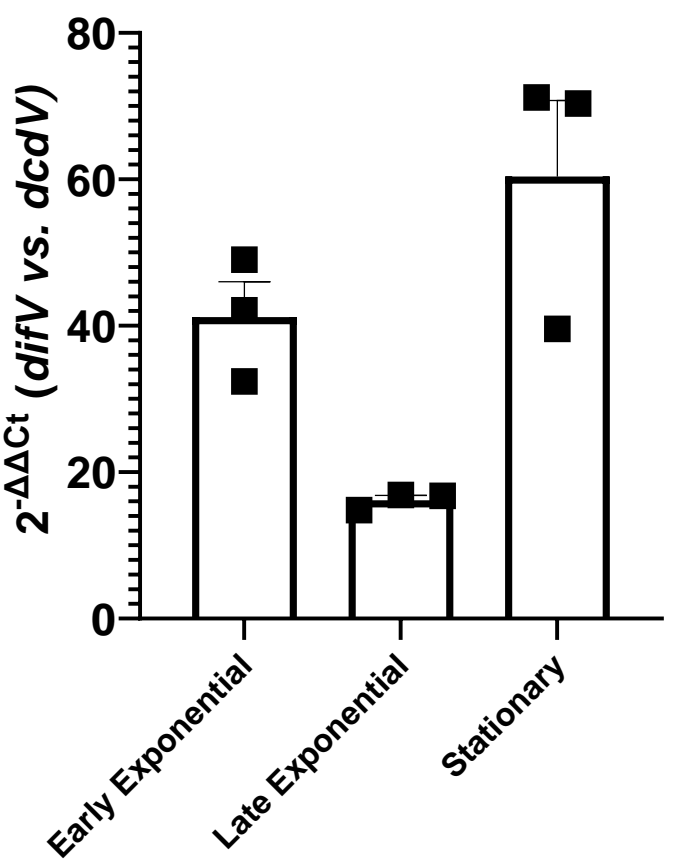


Fig. 3: difV and $d c d V$ are in an operon and difV expression exceeds dcdV

(A) Genomic diagram of $\operatorname{dif} V$ and $d c d V$ and the primers (a, b, c, and d) used for generating diagnostic PCR products. (B) PCR products amplified from nucleic acid templates (above) using the indicated primer pairs (below) resolved in a $1 \%$ agarose gel. All reactions were performed in duplicate using biologically independent samples with similar results. No RT = non-reverse transcribed RNA control. gDNA = genomic DNA control (C) qRT-PCR analysis of relative difference between difV transcript and $d c d V$ transcript levels at different growth phases in WT $V$. cholerae normalized to an endogenous gyrA control. Data are graphed as mean \pm SEM, $n=3$. 
Fig. 4

A

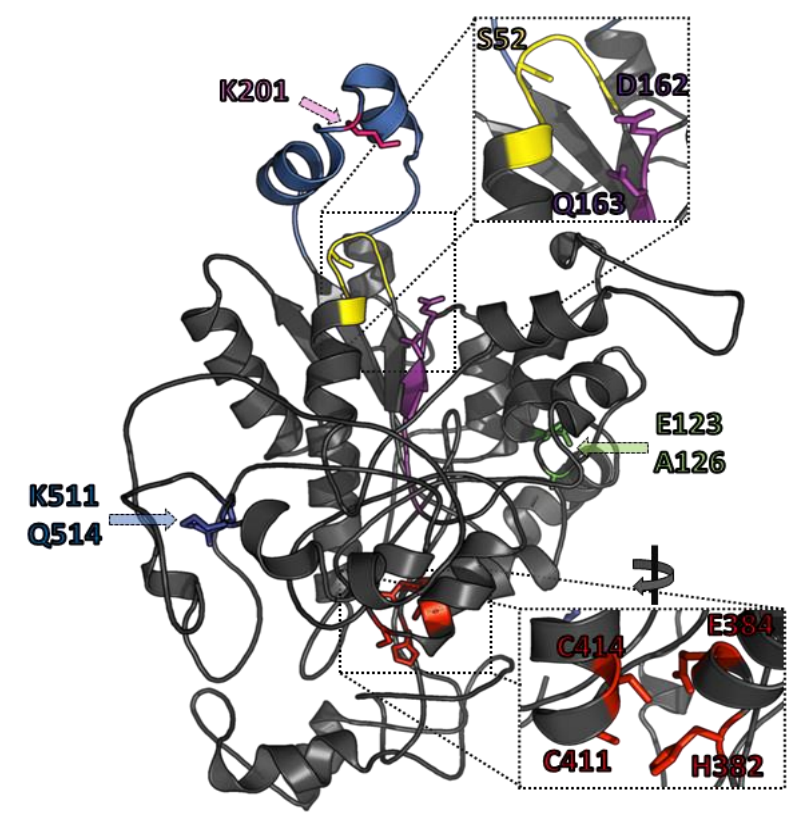

B

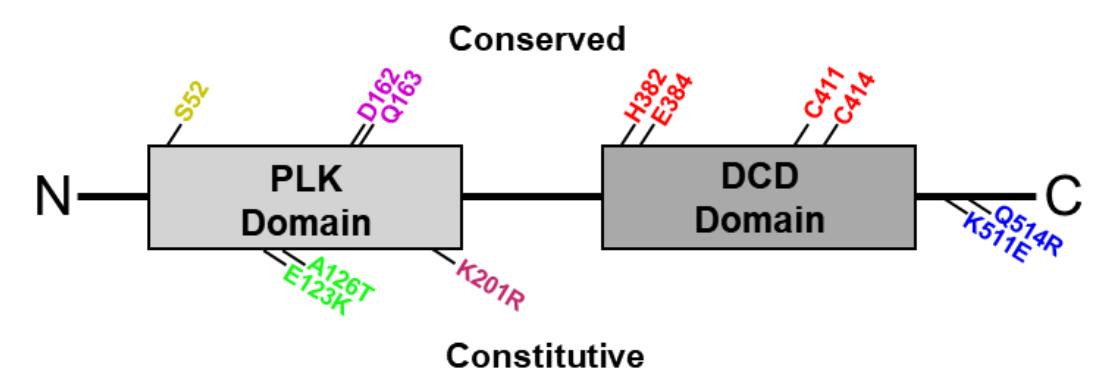

C

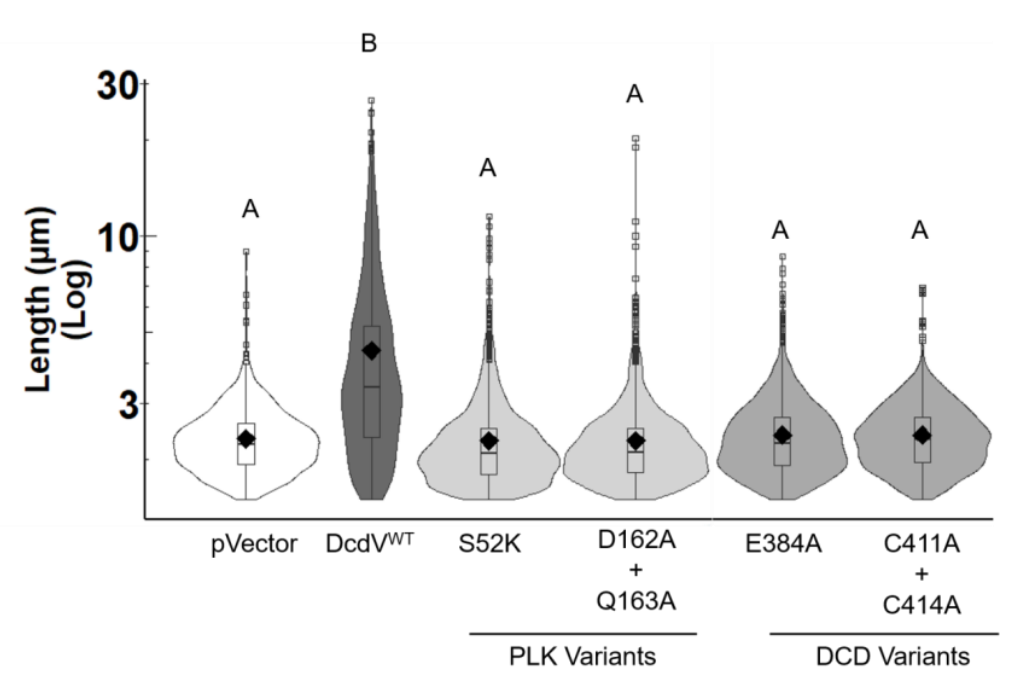

D

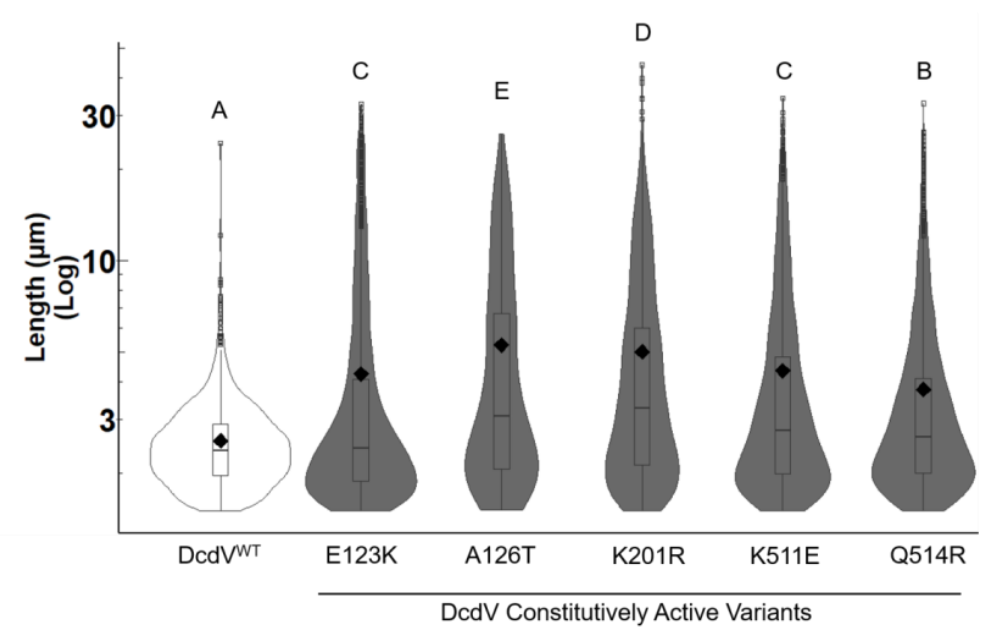

E

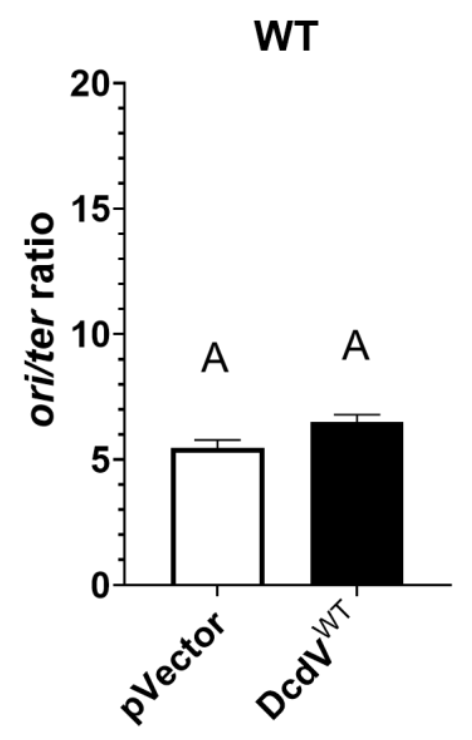

F

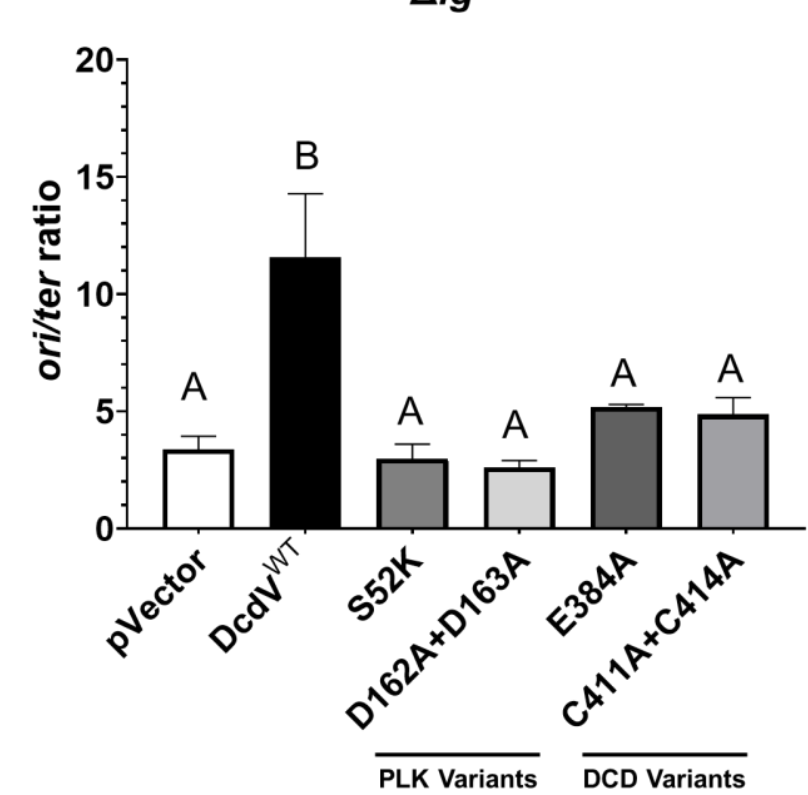




\section{Fig. 4: Both the PLK and DCD domains are required for DcdV induced filamentation}

(A) Phyre2 predicted structure of DcdV from V. cholerae El Tor. The inset shows the conserved residues of PLK (top) and DCD (bottom) domains. (B) Domain organization and conserved residues at each domain of DcdV. Top labeled residues indicate conserved features of both domains, and the bottom labeled residues indicate variants that render DcdV constitutively active. (C) Distribution of cell lengths measured from three biological replicates of WT E. coli as indicated. (D) Distribution of cell lengths measured from three biological replicates of the $\Delta d c d V V$. cholerae mutant expressing the indicated DcdV variants. ori/ter ratios of Chromosome 1 in $(\mathbf{E})$ WT and $(\mathbf{F}) \Delta i g^{222}$ $V$. cholerae strains expressing the indicated DcdV construct for $8 \mathrm{~h}$ and quantified using qRT-PCR. Each bar represents the mean \pm SEM, $n=3$. Different letters indicate significant differences $(n=3)$ at $p<0.05$, according to Tukey's post-hoc test. 
Fig. 5

A

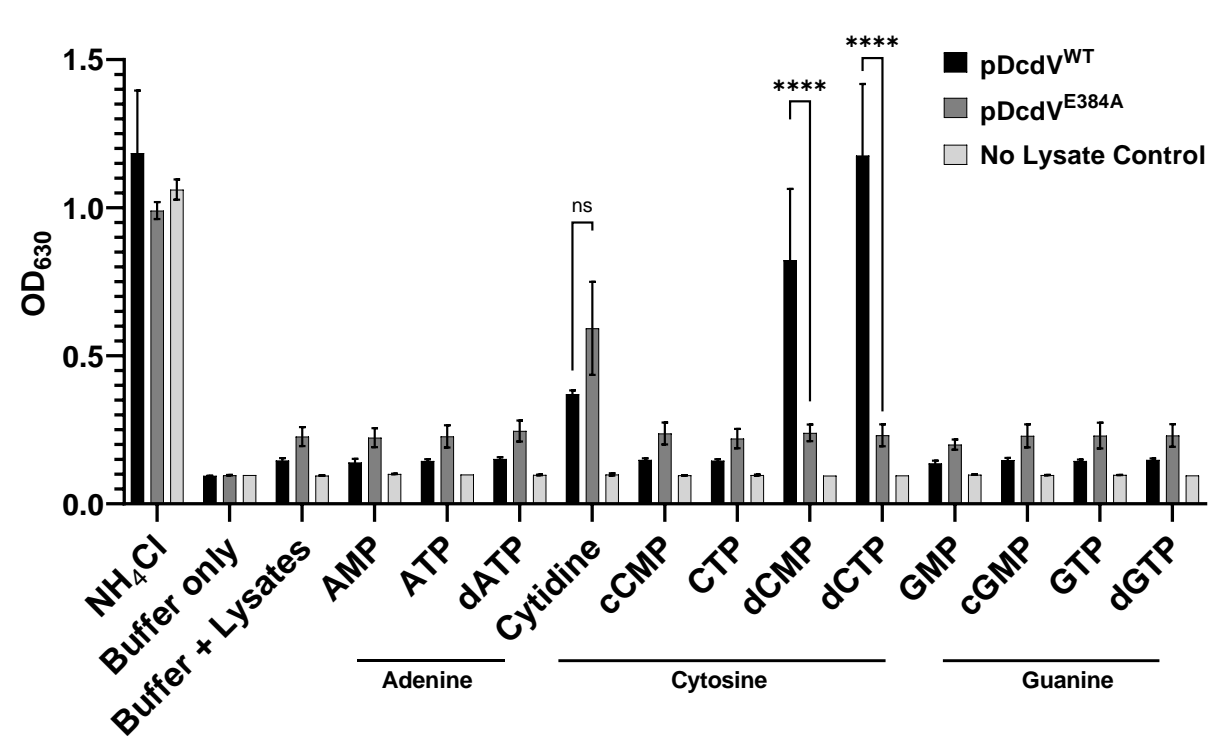

D

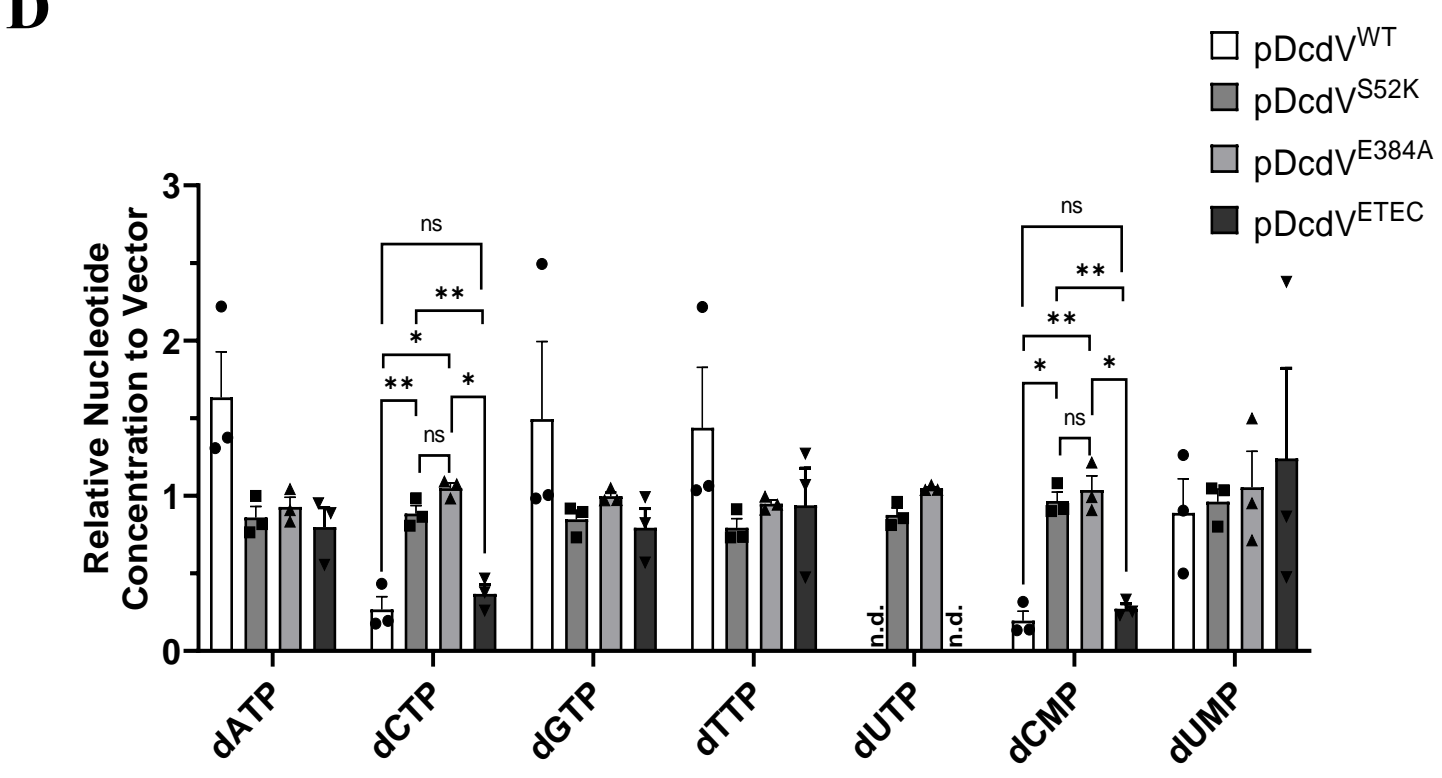

B

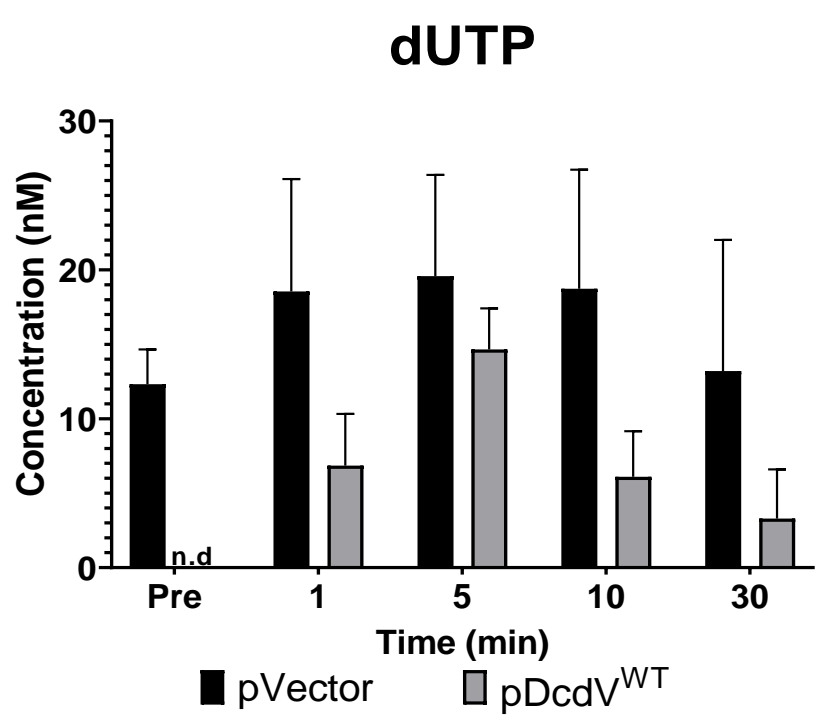

C

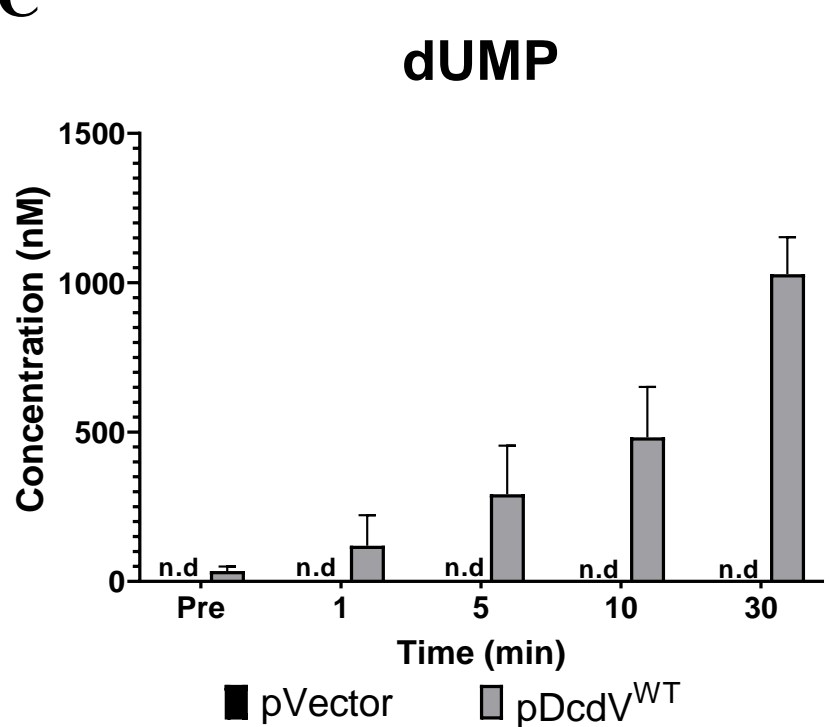




\section{Fig. 5: DcdV alters cellular nucleotide metabolism.}

(A) Lysates collected from E. coli expressing DcdV or DcdVE384A and a "no lysate" buffer control incubated with 12 nucleotide substrates (1.9 mM NH ${ }_{4} \mathrm{Cl}$ as a positive control, $37.7 \mathrm{mM}$ cytidine, and $7.5 \mathrm{mM}$ for all other substrates). Data represent the mean \pm SEM, $n=3$. Quantification of dUTP (B) and dUMP (C) using UPLC-MS/MS, in the indicated cell lysates before (Pre) and after addition of $1 \mathrm{mM} \mathrm{dCTP}$. Each lysate was normalized to $20 \mathrm{mg} / \mathrm{mL}$ total protein. Each bar represents mean \pm SEM, $n=3$. (D) Quantification of the indicated dNTPs in vivo using UPLC-MS/MS in strains expressing the four DcdV variants, as indicated, normalized to dNTP concentrations measured in a vector control. Data are graphed as mean \pm SEM, $n=3$, Two-way ANOVA with Tukey's multiple-comparison test, normalized to pVector, n.d. indicates "none detected", and ns indicates "not significant". 
Fig. 6

A

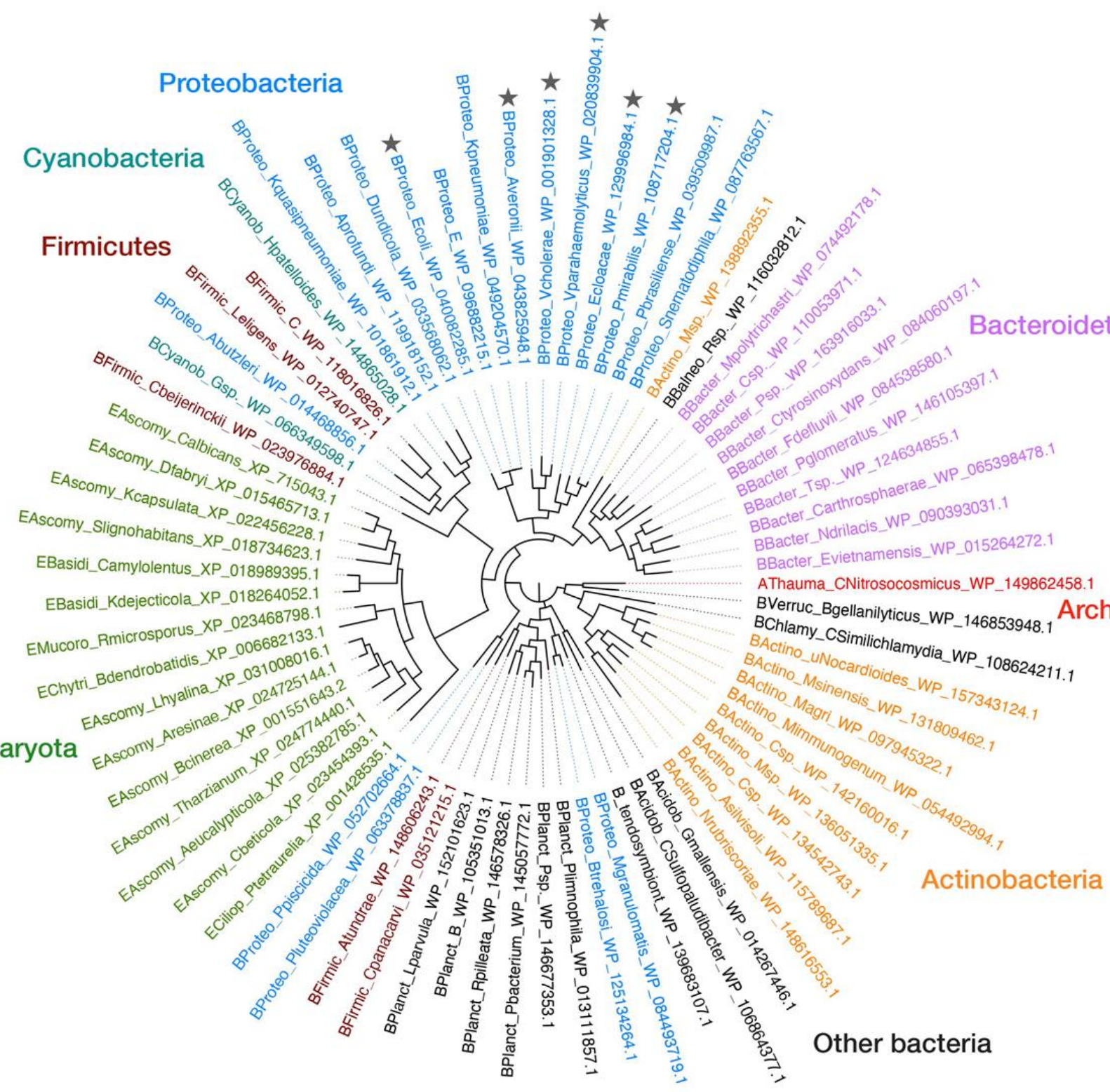

B

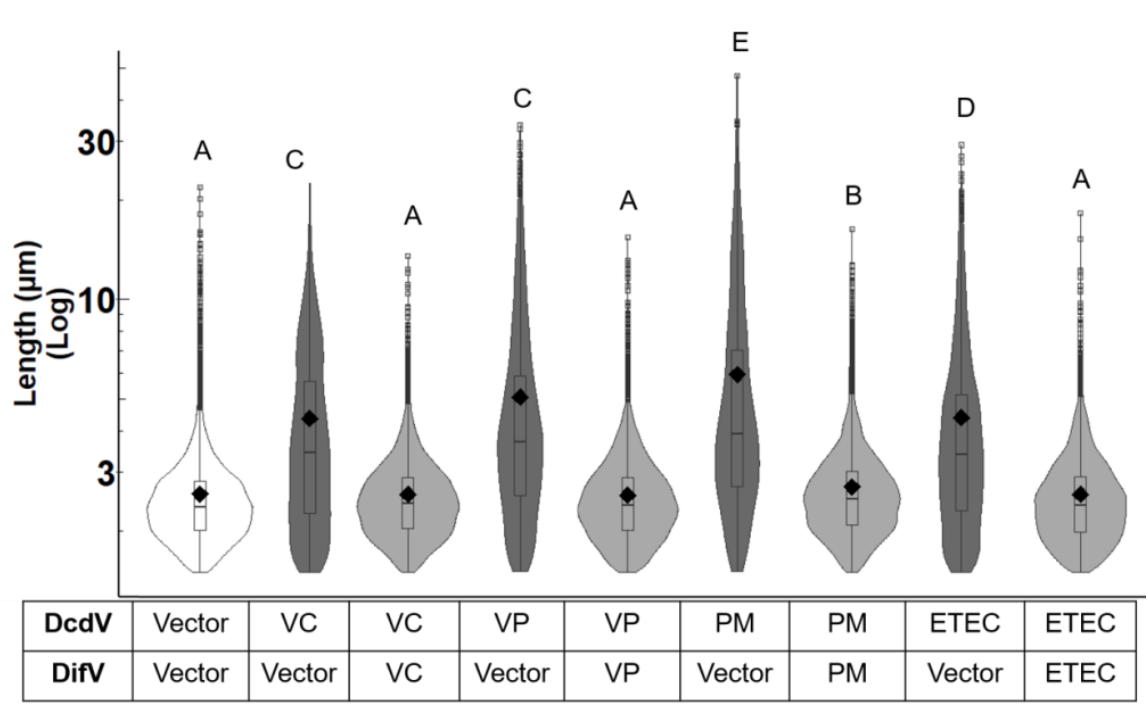

C

\begin{tabular}{|c|c|c|c|c|}
\hline$\Delta_{i j q} \delta_{c / q}$ & VC & VP & PM & ETEC \\
\hline VC & & & & \\
\hline VP & & & 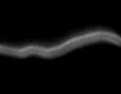 & \\
\hline PM & $\approx$ & & ${ }^{\circ}$ & \\
\hline ETEC & & & & \\
\hline
\end{tabular}




\section{Fig. 6: $d c d V$ and difV are widely conserved}

(A) Phylogenetic tree of DcdV homologs containing PLK and DCD domains from representative phyla across the tree of life. Stars indicate query proteins of interest in this study. (B) Distribution of cell lengths expressing the indicated DcdV homologs and their cognate DifV or vector control in $E$. coli ( $\mathrm{n}=3$ ). Different letters indicate significant differences $(n=3)$ at $p<0.05$, according to Dunnett's post-hoc test against the control (pVector ${ }^{\text {DadV }}+\mathrm{pVector}^{\mathrm{DifV}}$ ) strain. (C) Representative images of $E$. coli expressing $\mathrm{pDcdV} /$ homologs and $\mathrm{pDifV/homologs} \mathrm{combinations.} \mathrm{Scale} \mathrm{represents} 2 \mu \mathrm{m}$. 
Fig. 7

A.

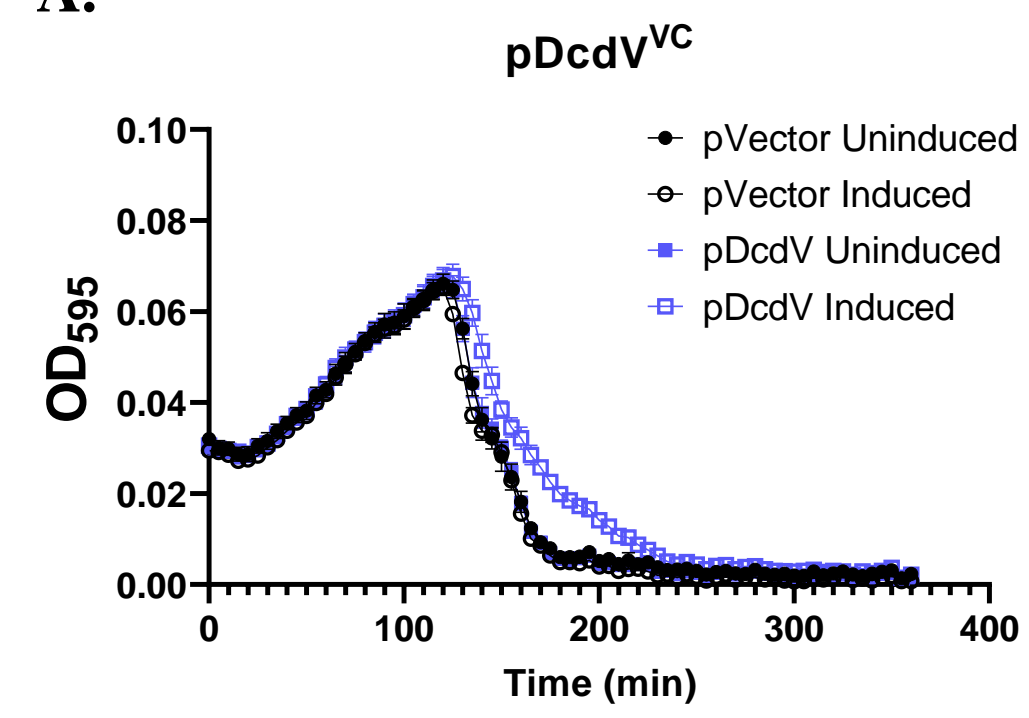

C.

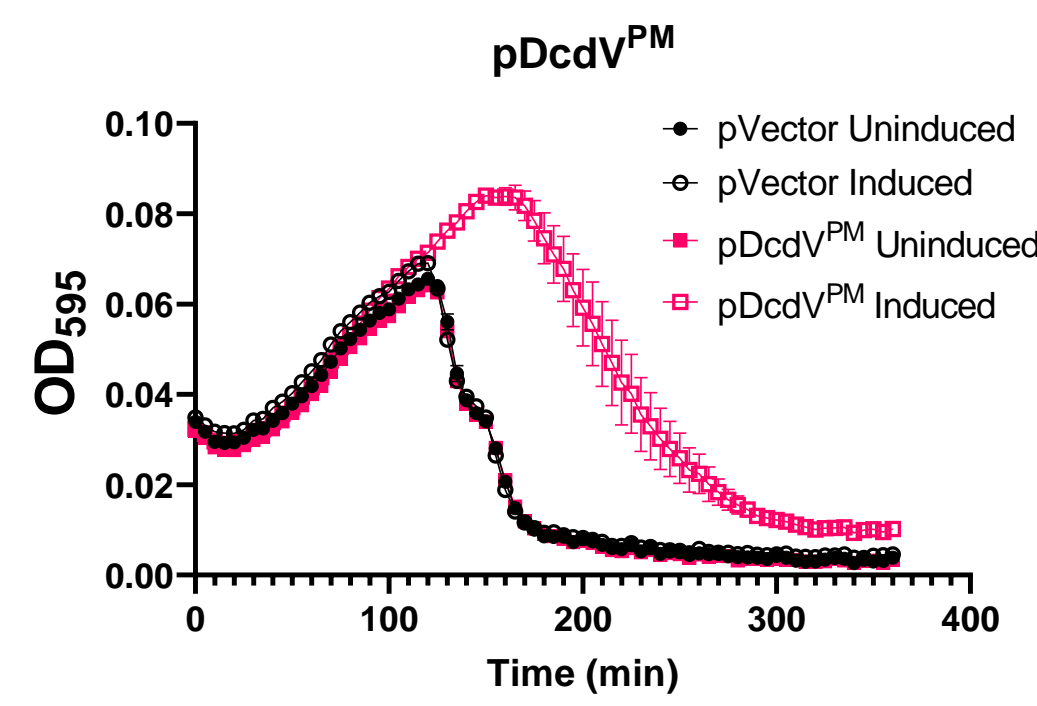

B.

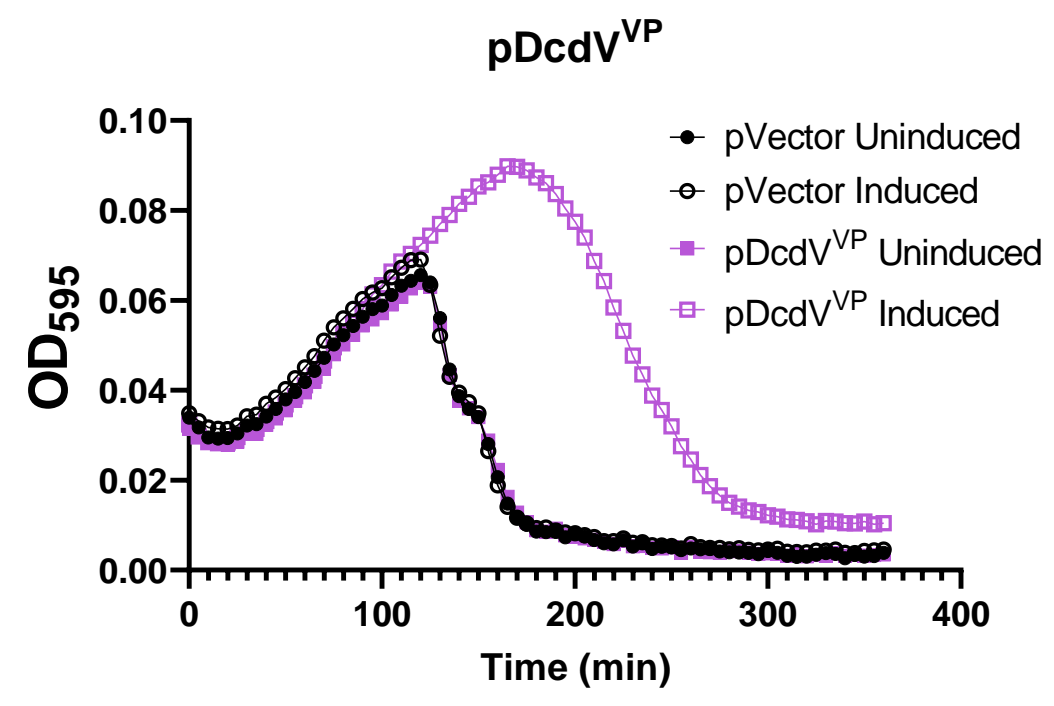

D.

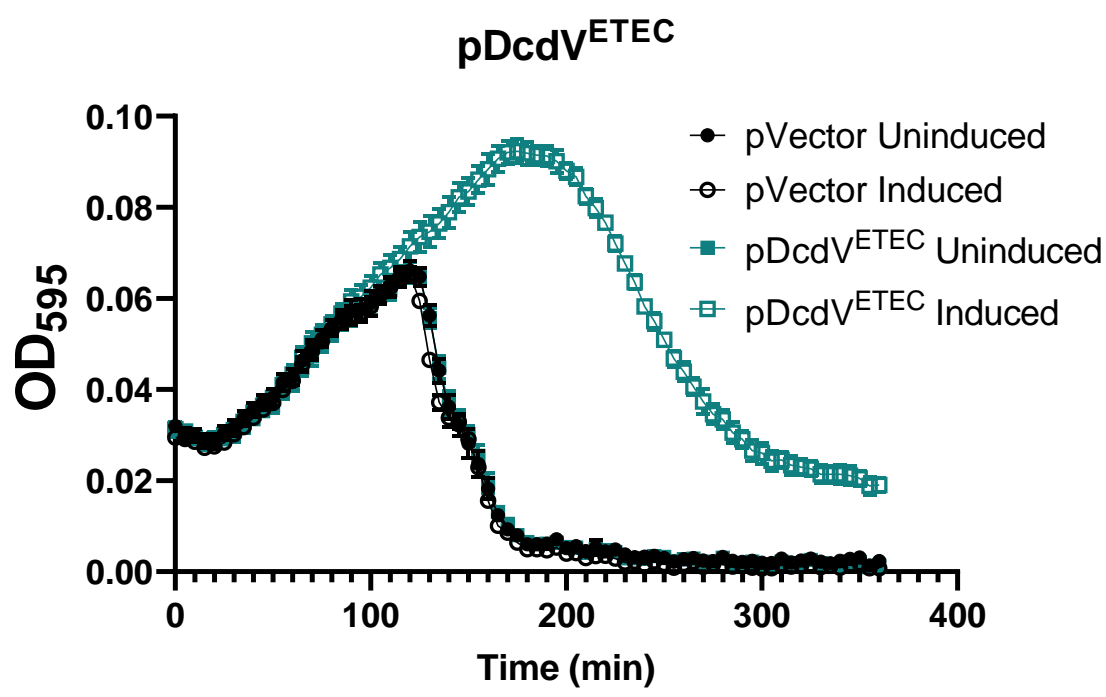

E.

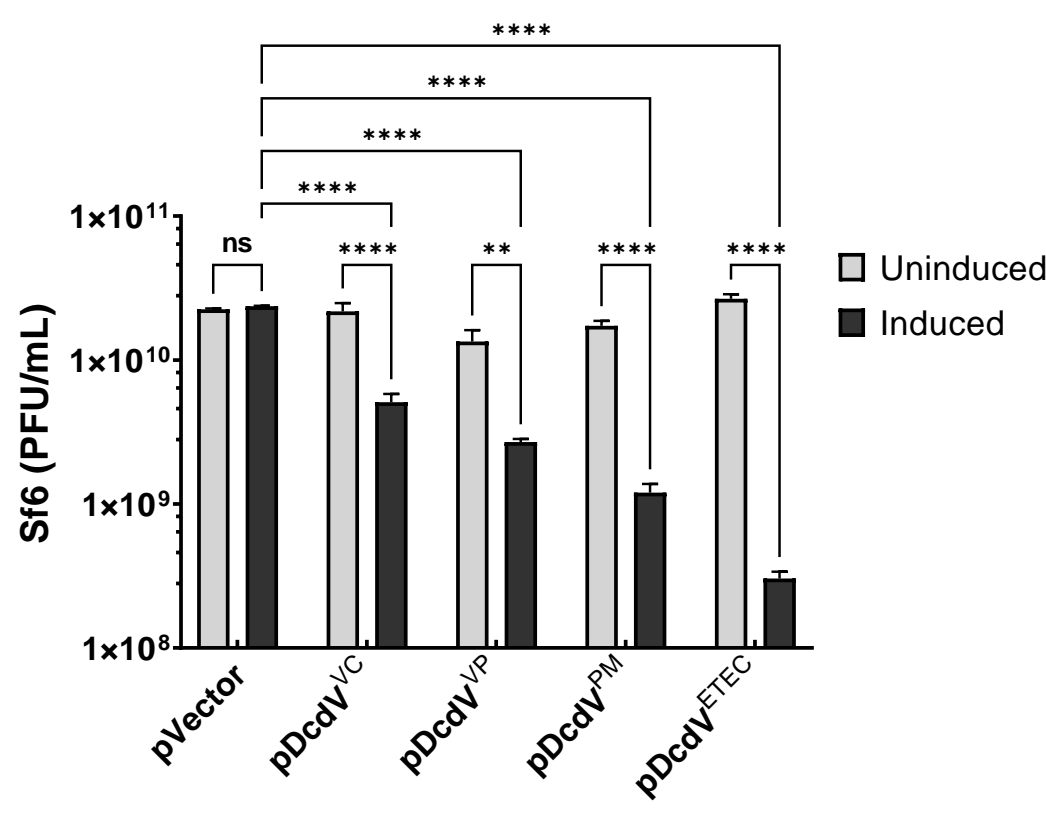




\section{Fig. 7: DcdV mediates phage defense}

(A-D) Growth curves for S. flexneri containing vector or pDcdV/homologs infected Sf6 at time 0 at an MOI of 0.1 in the presence or absence of $100 \mu \mathrm{M} \mathrm{IPTG.} \mathrm{Each} \mathrm{graph}$ represents three biological replicates each with three technical replicates. (B) Plaque-forming units (PFU) per mL of phage Sf6 measured at the conclusion of the $S$. flexneri growth curve experiment above. Results are represented as mean $\pm \mathrm{SEM}, n=3$, Two-way ANOVA with Tukey’s multiple-comparison test. 


\section{Graphical}

Abstract

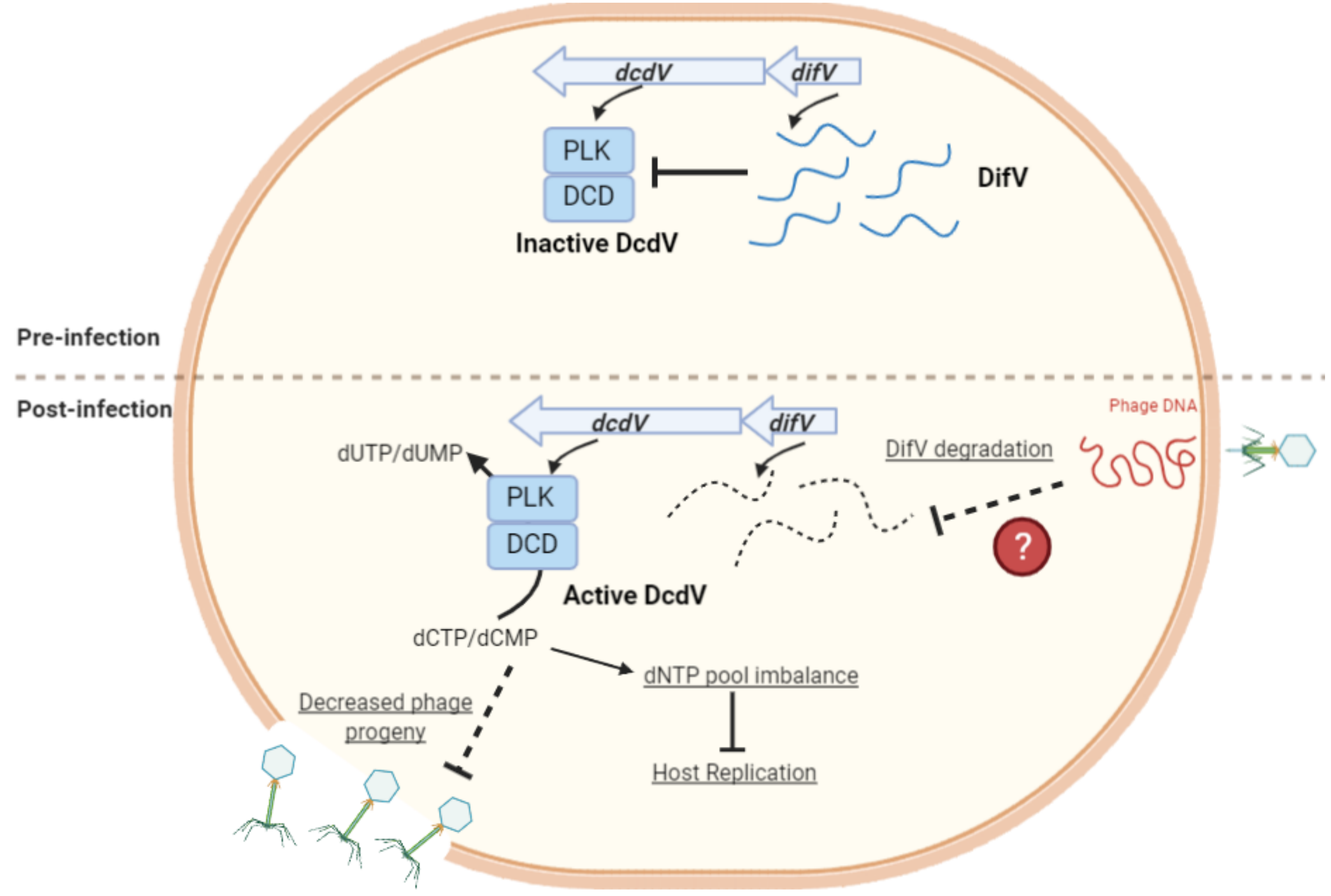


A

VSP-1 (vc0175-vc0185)

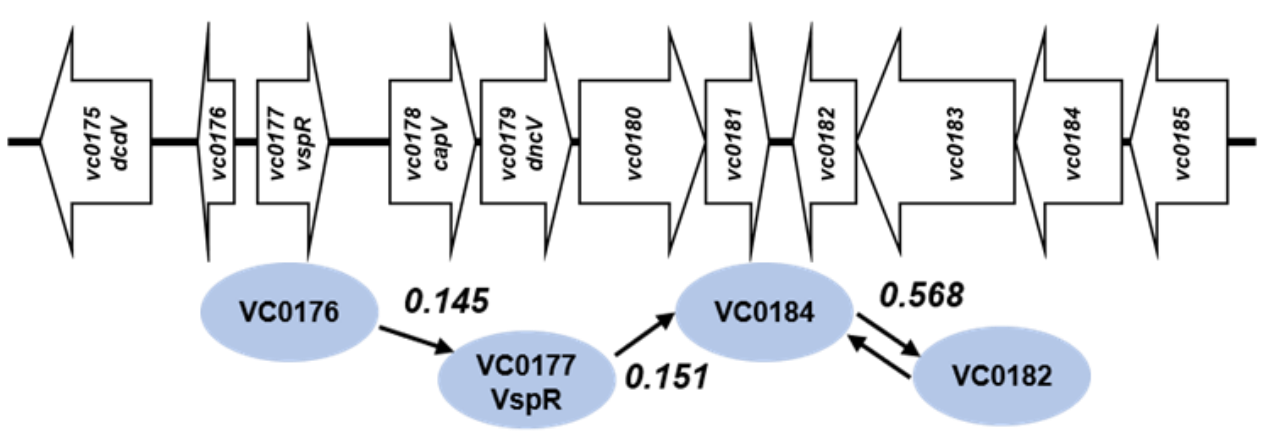

B

VSP-2 (vc0490-vc0516)

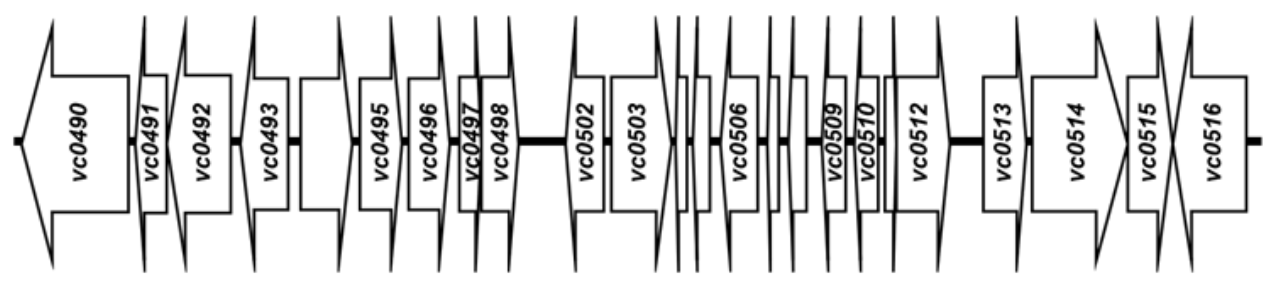

\section{Supplemental Figure 1. VSP-1 and VSP-2 schematic and predicted maximum} related subnetworks (MRS).

(A) Cartoon schematic and gene network predictions, other than DcdV and CBASS (see Figs. 1B and 1), of VSP-1 from El Tor V. cholerae N16961 (not to scale). (B) Cartoon schematic and gene network predictions of VSP-2 from El Tor V. cholerae N16961 (not to scale). Arrows indicate the highest partial correlation $\boldsymbol{W}_{\boldsymbol{i}}$ of each individual VSP gene to another (represented by ovals). Two arrows pointing in opposing directions indicates the two genes each have their highest correlation to each other. 
A

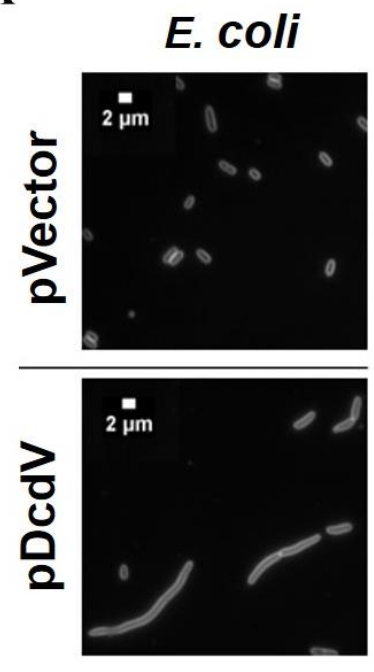

B

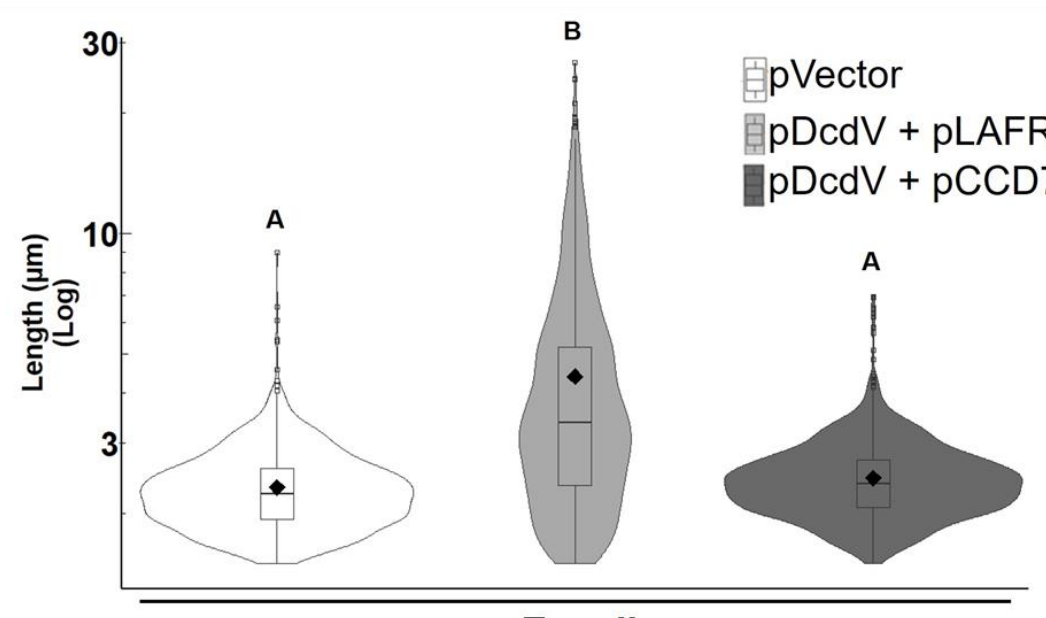

E. coli

Supplemental Figure 2. Ectopic expression of $d c d V$ leads to cell filamentation in E. coli that is alleviated by provision of a single copy cosmid containing VSP-1.

(A) Representative images of E. coli cultures maintaining an empty vector plasmid (pVector) or $\mathrm{P}_{\text {tac }}$-inducible $d c d V$ plasmid (pDcdV) grown in the presence of $100 \mu \mathrm{M}$ IPTG for $8 \mathrm{~h}$. Cells were stained with FM4-64 prior to imaging. Scale represents $2 \mu \mathrm{m}$. (B) Distribution of cell lengths measured from three biological replicates of $E$. coli cultures carrying an empty vector (Vector) or $P_{\text {tac }}$-inducible $d c d V$ plasmid ( $p D c d V$ ) in addition to either an empty vector single copy cosmid control (pLAFR) or pLAFR containing VSP-1 (pCCD7) grown in the presence of $100 \mu \mathrm{M}$ IPTG for $8 \mathrm{~h}$. Distributions represent $\sim 1000$ to 2000 cells measured per strain. Different letters indicate significant differences at $p<0.05$, according to Tukey's post-hoc test. 


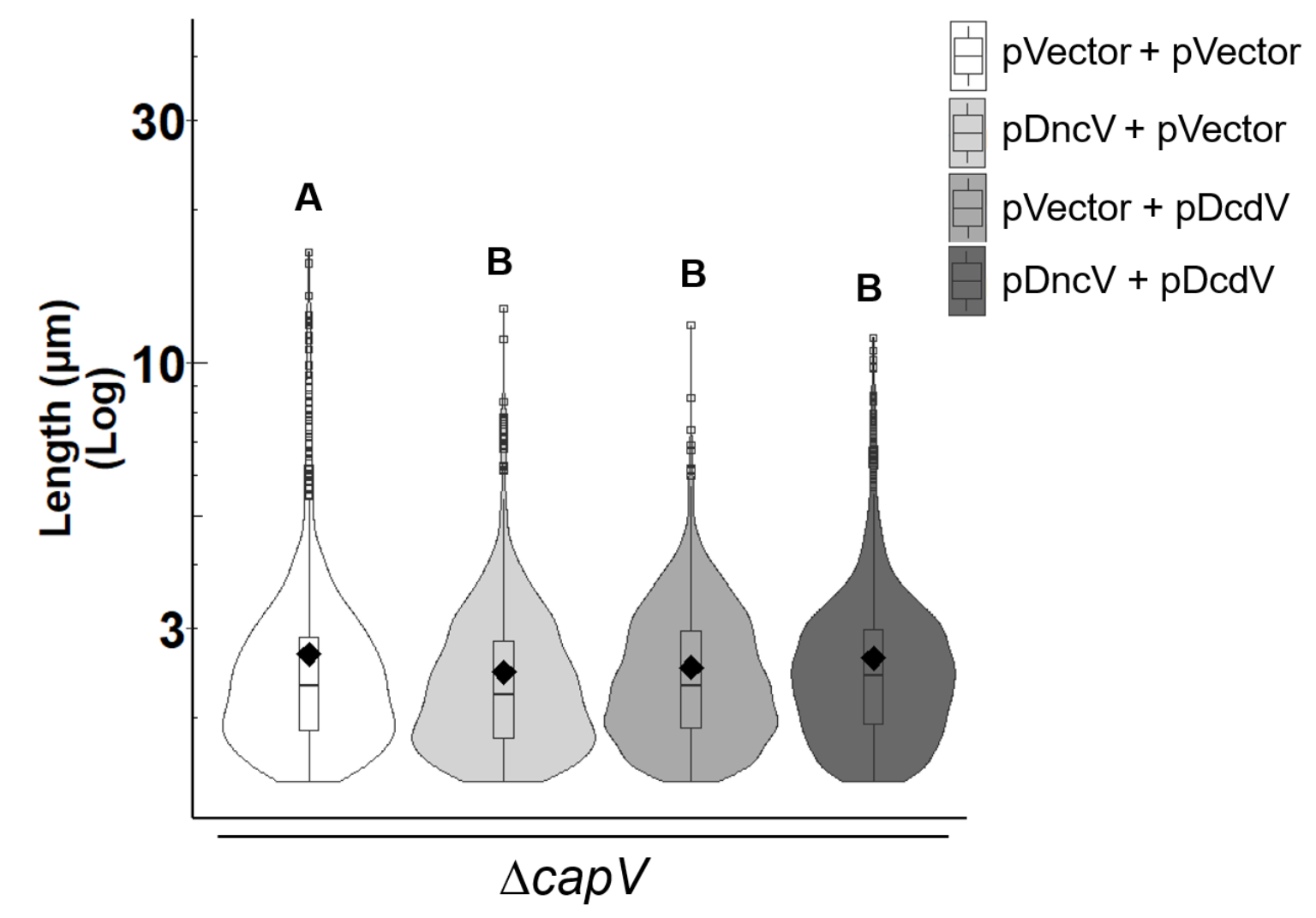

Supplemental Figure 3. Ectopic expression of DncV and DcdV does not lead to filamentation in the $\Delta c a p V$ mutant of $V$. cholerae.

Distribution of cell lengths measured from three biological replicates of $\Delta c a p V$ mutant cultures maintaining the indicated plasmids grown in the presence of $100 \mu \mathrm{M}$ IPTG for $8 \mathrm{~h}$. Distributions represent $\sim 1200-1700$ cells measured per strain. Different letters indicate significant differences at $p<0.05$, according to Tukey's post-hoc test. 


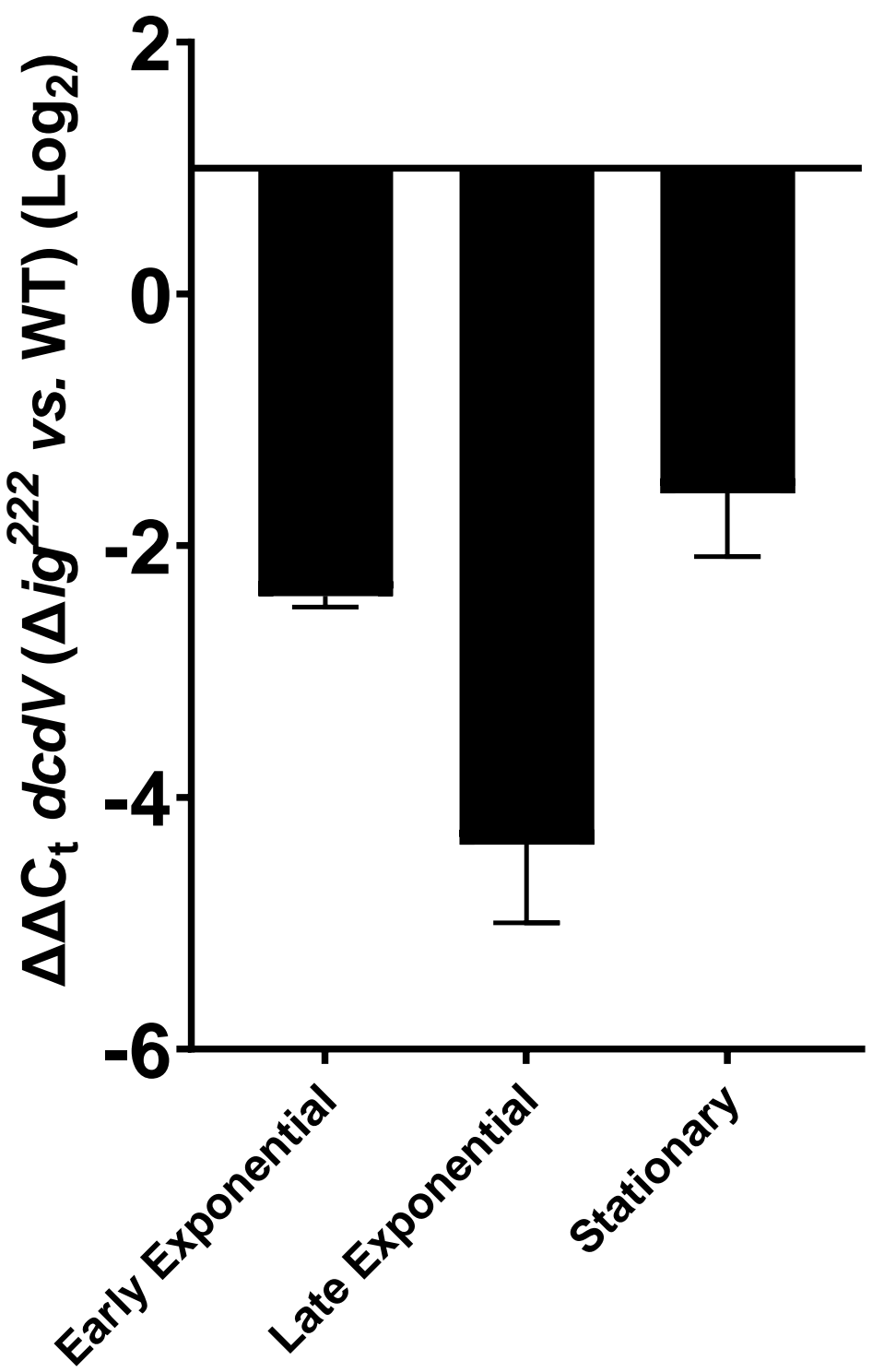
Relative difference in $d c d V$ expression between $\Delta i g^{222}$ and WT $V$. cholerae at three different growth phases using qRT-PCR and an endogenous gyrA control. Data represent the mean \pm SEM of three biological replicates. 


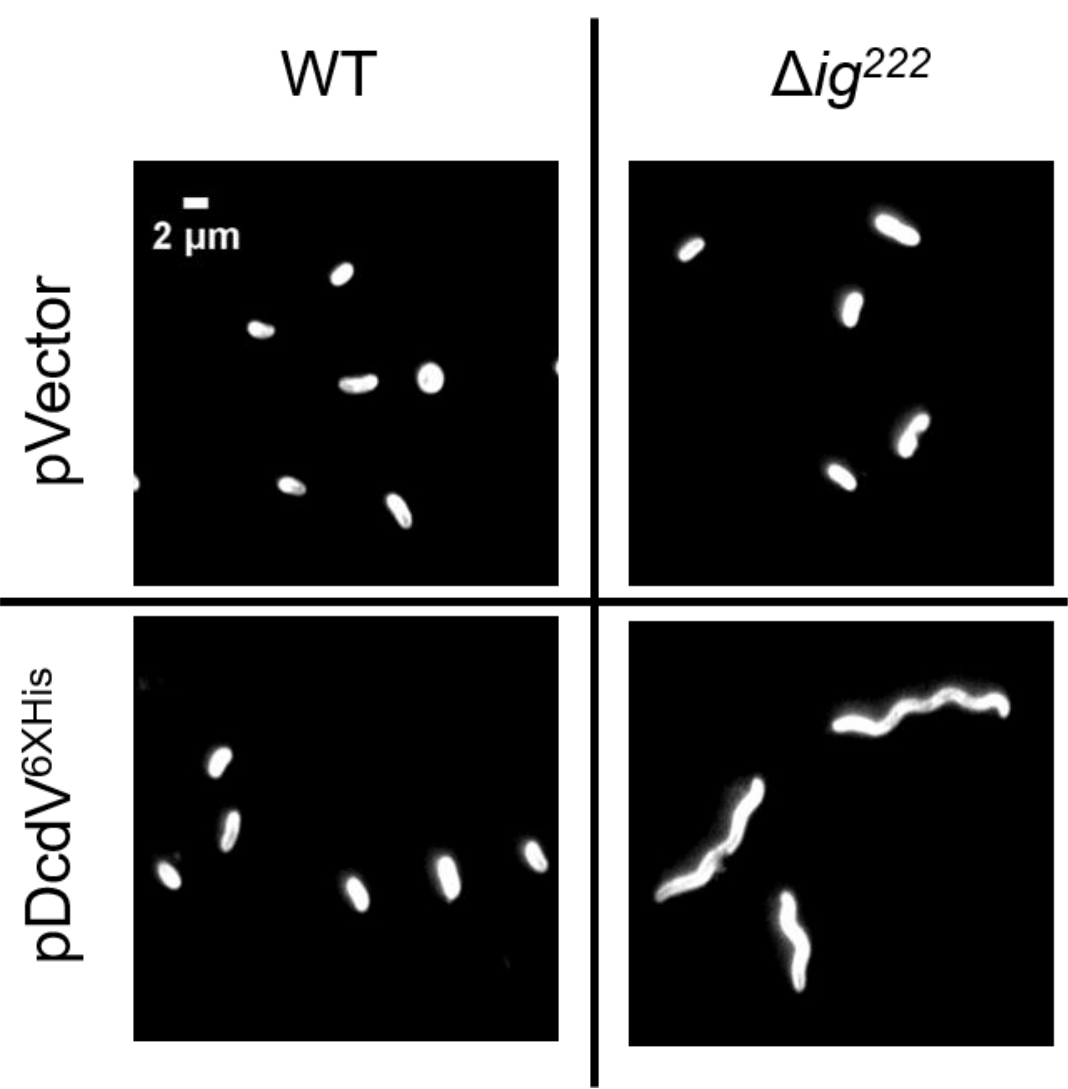

Supplemental Figure 5. DcdV C-terminal 6x Histidine fusion maintains the same activity as the WT DcdV enzyme.

Representative images of $V$. cholerae WT and $\Delta i g^{222}$ cultures maintaining an empty vector plasmid (pVector) or $\mathrm{P}_{\text {tac }}$-inducible $d c d V$-6xHIS plasmid (pDcdV6xHis) grown in the presence of 100 $\mu \mathrm{M}$ IPTG for $2 \mathrm{~h}$. Cells were stained with FM4-64 prior to imaging and performed in biological triplicate. 


\section{Supplemental Figure 6. Domain architectures of the six DcdV query proteins.}

Domain architecture and secondary structure predictions for the six proteobacterial starting points of interest (query proteins) using InterProScan [[40]; see Methods]. Results from six main analyses are shown here for the query proteins: Gene3D (including CATH structure database), Pfam, ProSiteProfiles, PANTHER, and SUPERFAMILY protein domain profile databases, and MobiDBLite for disorder prediction. No transmembrane regions (using TMHMM) or membrane/extracellular localization were predicted for any of the proteins (using Phobius); hence 

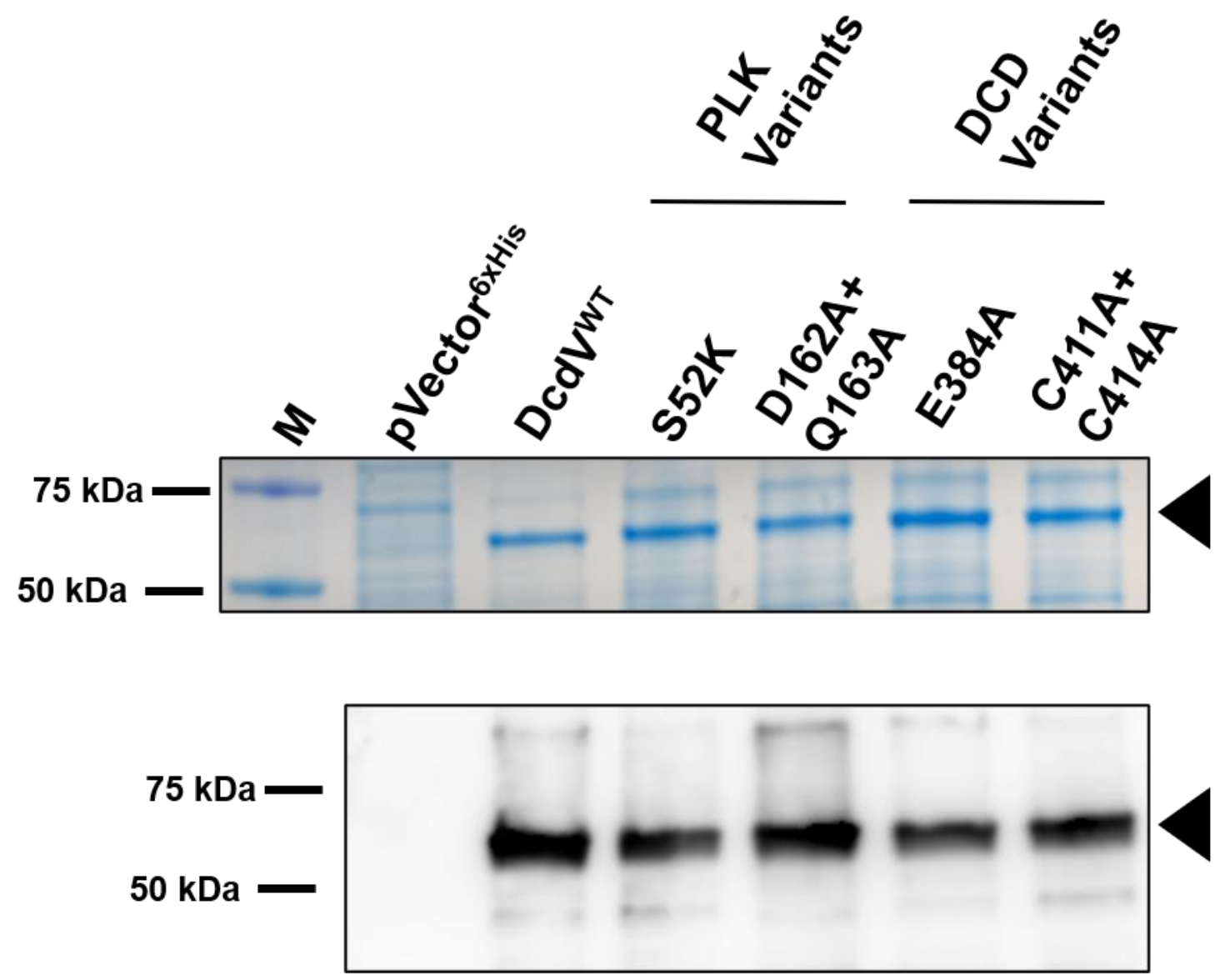

\section{Supplemental Figure 7. Cellular abundance of C-terminal $6 x$ histidine tagged DcdV variant fusions analyzed by Coomassie stain and Western blot.}

Representative Coomassie stained gel (top) and anti-6x His antibody Western blot (bottom) of whole cell lysates from E. coli BL21(DE3) cells maintaining an empty vector (pVector ${ }^{6 \times H i s}$ ), inducible C-terminal 6x histidine tagged $d c d V(\mathrm{WT})$ or $d c d V$ variants (S52K, D162A + Q163A, E384A, and C411A + C414A) grown in the presence of $1 \mathrm{mM}$ IPTG for $3 \mathrm{~h}$. Sample inputs were normalized by culture $\mathrm{OD}_{600}$ and resolved by SDS-PAGE. Three biological replicates of each strain were analyzed with similar results. Black triangles correspond to the predicted molecular weight of the DcdV tagged fusions $(60.6 \mathrm{kDa}) . \mathrm{M}=$ molecular weight marker. 


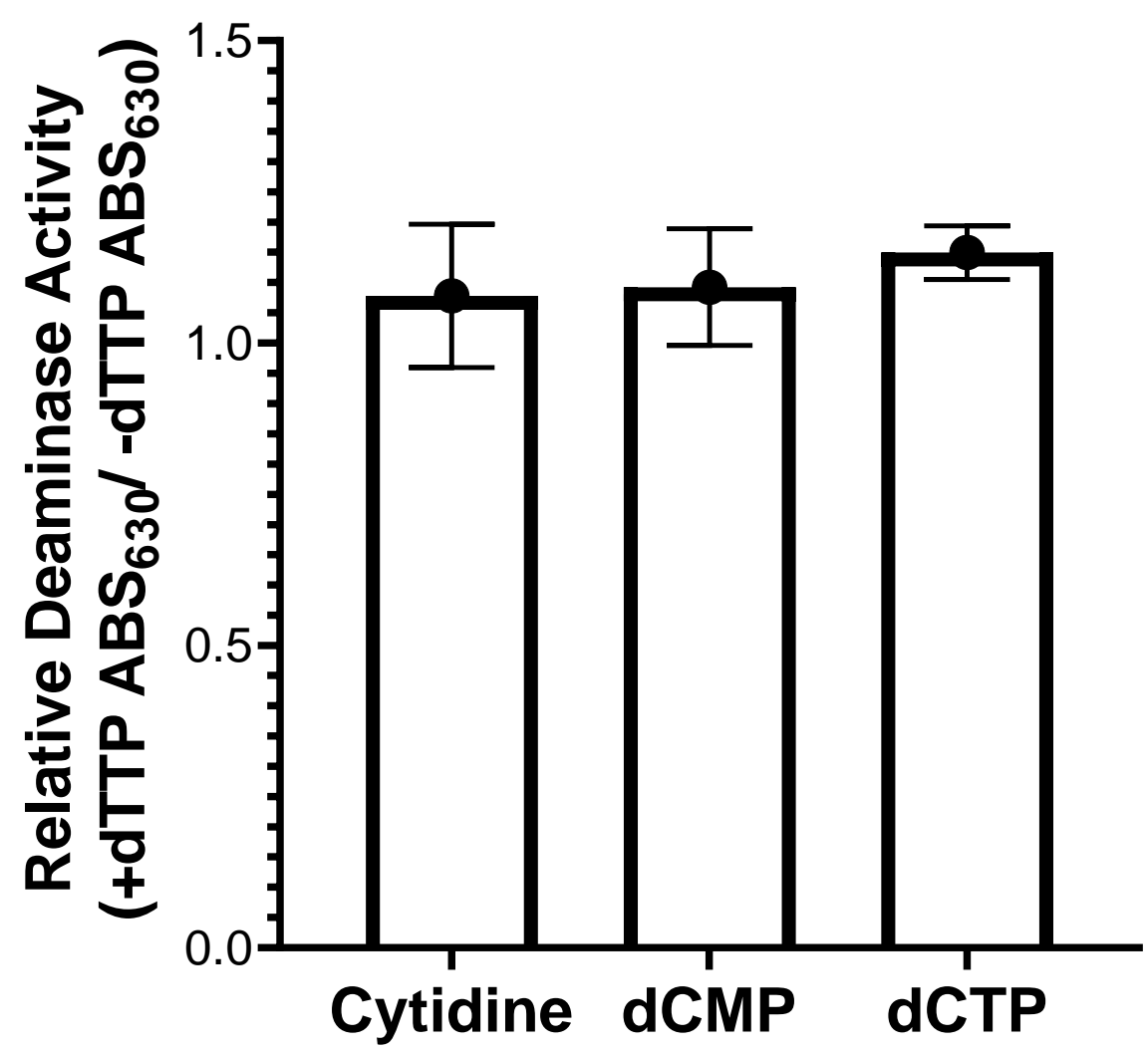

\section{Supplemental Figure 8. Addition of exogenous dTTP does not inhibit DcdV deaminase} activity in $E$. coli lysates.

69

Lysates collected from E. coli expressing WT DcdV incubated with or without exogenous $7.5 \mathrm{mM}$ dTTP and either $75 \mathrm{mM}$ cytidine, $7.5 \mathrm{mM}$ dCMP, or $7.5 \mathrm{mM}$ dCTP. The evolution of $\mathrm{NH}_{4}{ }^{+}$resulting from substrate deamination was detected by measuring the solution ABS $_{630}$ after a Berthelot's reaction in microtiter plates. The relative deaminase activity was calculated by dividing the $\mathrm{ABS}_{630}$ of the $+d T T P$ reaction by the no dTTP control reaction for each lysate. Data represent the mean \pm SEM of three biological replicate lysates. 
76

\begin{tabular}{|l|c|c|c|c|c|}
\hline & \multicolumn{5}{|c|}{ Absolute Intracellular dNTP Concentration in pmol/mg of Total Protein } \\
\hline Nucleotides & pVector & pDcdVWT & pDcdV552K & pDcdVE384A & pDcdVETEC \\
\hline dATP & $75.6 \pm 5.3$ & $121.9 \pm 18.1$ & $64.6 \pm 3.6$ & $70.1 \pm 5.7$ & $59.1 \pm 5.8$ \\
\hline dCTP & $6.6 \pm 0.7$ & $1.6 \pm 0.3$ & $5.8 \pm 0.3$ & $6.9 \pm 0.7$ & $2.4 \pm 0.2$ \\
\hline dGTP & $42.7 \pm 4.5$ & $59.9 \pm 13.9$ & $35.7 \pm 1.8$ & $42.4 \pm 3.7$ & $32.8 \pm 1.9$ \\
\hline dTTP & $11.4 \pm 0.7$ & $16.5 \pm 4.7$ & $9.0 \pm 0.3$ & $10.80 \pm 0.4$ & $10.4 \pm 2.2$ \\
\hline dUTP & $1.1 \pm 0.1$ & n.d. & $0.9 \pm 0.1$ & $1.1 \pm 0.10$ & n.d. \\
\hline dCMP & $7158.3 \pm 2485.5$ & $1185.7 \pm 227.9$ & $6859.4 \pm 2226.4$ & $7027.8 \pm 1950.4$ & $1945.1 \pm 636.2$ \\
\hline dUMP & $9.3 \pm 2.90$ & $7.1 \pm 0.3$ & $9.1 \pm 3.3$ & $8.7 \pm 1.1$ & $9.9 \pm 3.3$ \\
\hline
\end{tabular}

78

79

80

81

82

83

Supplemental Figure 9. Absolute intracellular concentration of deoxynucleotides.

84 Quantification of the indicated dNTPs in vivo, using UPLC-MS/MS, in strains expressing the

85 empty vector and four DcdV variants, as indicated. Data represents mean $\pm \mathrm{SEM}, n=3$.

86 
bioRxiv preprint doi: https://doi.org/10.1101/2021.03.31.437871; this version posted March 31,2021. The copyright holder for this preprint (which was not certified by peer review) is the author/funder, who has granted bioRxiv a license to display the preprint in perpetuity. It is made available under aCC-BY-NC-ND 4.0 International license.

87

V.cholerae
V.parahaemolyticus
P.mirabilis
E.coli
V.cholerae
V.parahaemolyticus
P.mirabilis
E.coli
V.cholerae
V.parahaemolyticus
P.mirabilis
E.coli
V.cholerae
V.parahaemolyticus
P.mirabilis
E.coli
V.cholerae
V.parahaemolyticus
P.mirabilis
E.coli

MFTMNKSSAKKILSTVPS--PTKSNSSSSNDLQKRILERRSRELVIGLCGAIGSGVKALKESLVSSLETYGYEWVIRISKIISEKTQ- -T---SLDGLSAFKRYNRLQDLGHSLRETHK ..-MGKSSTATKLKPLLQ - -SVSTDSSSTEDIQKRIQERRSOELIIGLCGAIGSGVKALKDNLIHSLESSGYQVQHIRISNIIAEKTN- - I - --VIDNIHGAERYITLQDKGDELRSEHK -.-MGNPAKVIDITNNLS--DVENFOSDFKDVESKIKERHSNELIIALCGTVGSGVRKLKESLIEQFENFNYKVKHIRISDLIAEONESPQ - - KIKMLSGYSRYEKLQDLGDELREKNT ..-MA-...-IALKKEVQKKGSLLDSNSNESPMQTIITRQSPDLFIGLCGFAGCGMKTVWSVLSKVAKSWWYOWHIRISDLMQOPLYFEKKVIEENDVLNKERHIRMQKLANGLLRRHYK

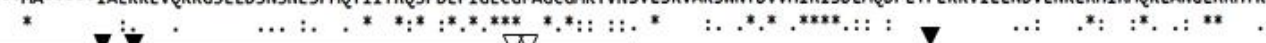
SS-ILAACAIEEIALERTLICQNEIDETSEENDNEPSLIKTTKKIAYIIDQL KHPDEIKFLRSVYPRUFYLIGLIRTEGERRLILEEEKISPSEIDTLMRRDRKD-VSHGQQVEKSLFNA TS-ILAACAIEEIAVARTIFCQDEIEE -....-DDQASVIKTTKKIAYVLDQLKHPDEVKLLRSWYPRNFYLLGLIRTEKERRLIILEEKMSLQEIDELIRRDRKG-VDHGQQVEKTLHNA IN-ICAOLAIRRINIWRHRTYGTELKE-...--NESPKHTKTLDKVYIIDQLKNPAEVGLFRTVYKNNFYLIGLLRNUNERERIULRADGLDDSEIKLLINURDRKNKASYGQQVEDTLQLS KKELLAEAAITYIKSDK-......-VKK-..........-EDKSVKTKTVYITDQLKRPEEIELLRIIYQHWFYLIGIVRDPEHTVRIILEEDSSLEDIYNIINVDDKSDDDFGQRTSKAILDS

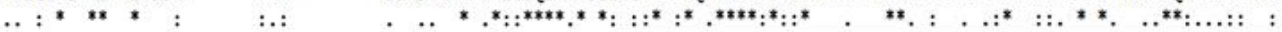
DYFIHNIHNQKQMLDKSVERFIKLVHGINGISPTIDEIGMHAAYSAALRSACLSRQVGAAILONQGNIISTGCNDVPSFGGGLYWSNS-LADFRCV-HTGRCSHDKHKDILKEEITDILK DYFIHIVHNHSOLLEKSVDRFIKLVHGVIGITPTIDEIGMHAAHSASLRSACLSRQVGAAITDEHGGVISTGCNDVPSFNGGLYNSNS-STDFRCV-HRGQCTNDKHKALLKEEIRDILS DYFIRNIEQLS-EINKSVNRFISLIHGVDHITPTKDEIGMFTAYNSSLRSACLSRQVGACIVDOEGNVLSTGCNDVPKFKGGLYNAES-VSDNRCH-NVGRCSNDLHKSMLRKQIIDILQ DVFIKNMQSQKNNLEKKINRFFGLIHGQNGLTPTIAEKGMYSAYAASLQSACLSRQVGAALLDDEGNLLAVGKNDVPKSGGGLYISDOGDNDHRCVYKSGKCYNIATKLKIKKRIADILI

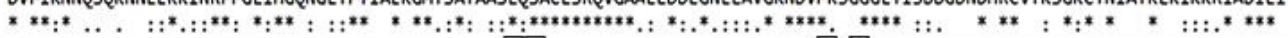
KSITNTLE-............. LKEIVIQITSETKIKTLIEYSRAVHAEMDSLIALARN NKETSVDKTLYVTTYPCHNCARHIVAAGIKKWWVEPYEKSLAMKLHDDSISDNADA-KN KELNMEVL -.................. LITLTDKITSGTKIKSLIEYSRAVHAEMDAIVALARINKESAVGKTLFATTYPCHNCARHIVAAGIKRWYIEPYEKSLAMKLHDDSITDSGE - - SE DESIDO DELKNNIGSOSNLDFLFKKISNNIDSIADAWSKSKISSVMEYSRSIHAEMDVITTMARK SSEGTKGKTLYTTTYPCHNCARHIVSSGMKKVIYIEPFOKSLALDLHDDAITTTED --PS

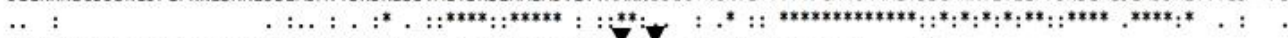
KVCFLPFEGVSSRRYEVFFOMHGDRKDOKTGKVLNINIQOSYHADSEFLDNYAEMEAKIAQSVNALLNVPSSEEESIQD 532 KVKLSPFEGVSPRRFEAFFRSNGNRKDD-DGRVIKIKVHOSYHADSEFIDNYPEMEAKVAQSVSDTFTKQQVEATI-E- $\quad 520$ KVLFANFEGVSPNRYSSFFKYHSARKDK-DGRVLNQKVITAKQVDPTGLDSYFDYEAKTVQDVNLRLGEERS -....... 517 RVIFSKFEGVAPRRYNKFFMPTDERKDEVTGEAYSFNVKYKRHIDVQFLDSYRTYEDIVAQRFLKDVAKVEPKQDDLI- 532

\section{Supplemental Figure 10. ClustalW multiple sequence alignment of DcdV homologs explored in this study.}

Amino acid alignment of DcdV and three homologs using webservice EMBL-EBI [74]. "*” indicates $100 \%$ identity, ":" indicates $>75 \%$, and "." Indicates $>50 \%$ similarity. Open triangles above the alignments indicate conserved residues of PLK and DCD domains. Closed triangles indicate amino acids where single amino acid substitutions were found to render $V$. cholerae DcdV insensitive to DifV inhibition (Figs. 6A, B, and D).

97 
98

V.cholerae
V.parahaemolyticus
P.mirabilis
E.coli_ETEC

V.cholerae

V.parahaemolyticus

P.mirabilis

E.coli_ETEC

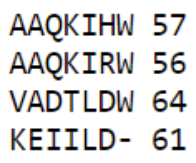

Supplemental Figure 11. DifV (174 nt) and the three ORFs encoded upstream of $d c d V$ homologs do not exhibit amino acid similarity.

103 Amino acid alignment of the $V$. cholerae $\lg ^{222}$ translated ORF and three ORFs 5' of the $d c d V$ 104 homologs using EMBL-EBI ClustalW [74]. "*” indicates 100\% identity, ":" indicates >75\%, and "." 105 Indicates $>50 \%$ similarity. 


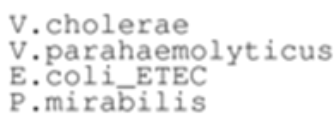

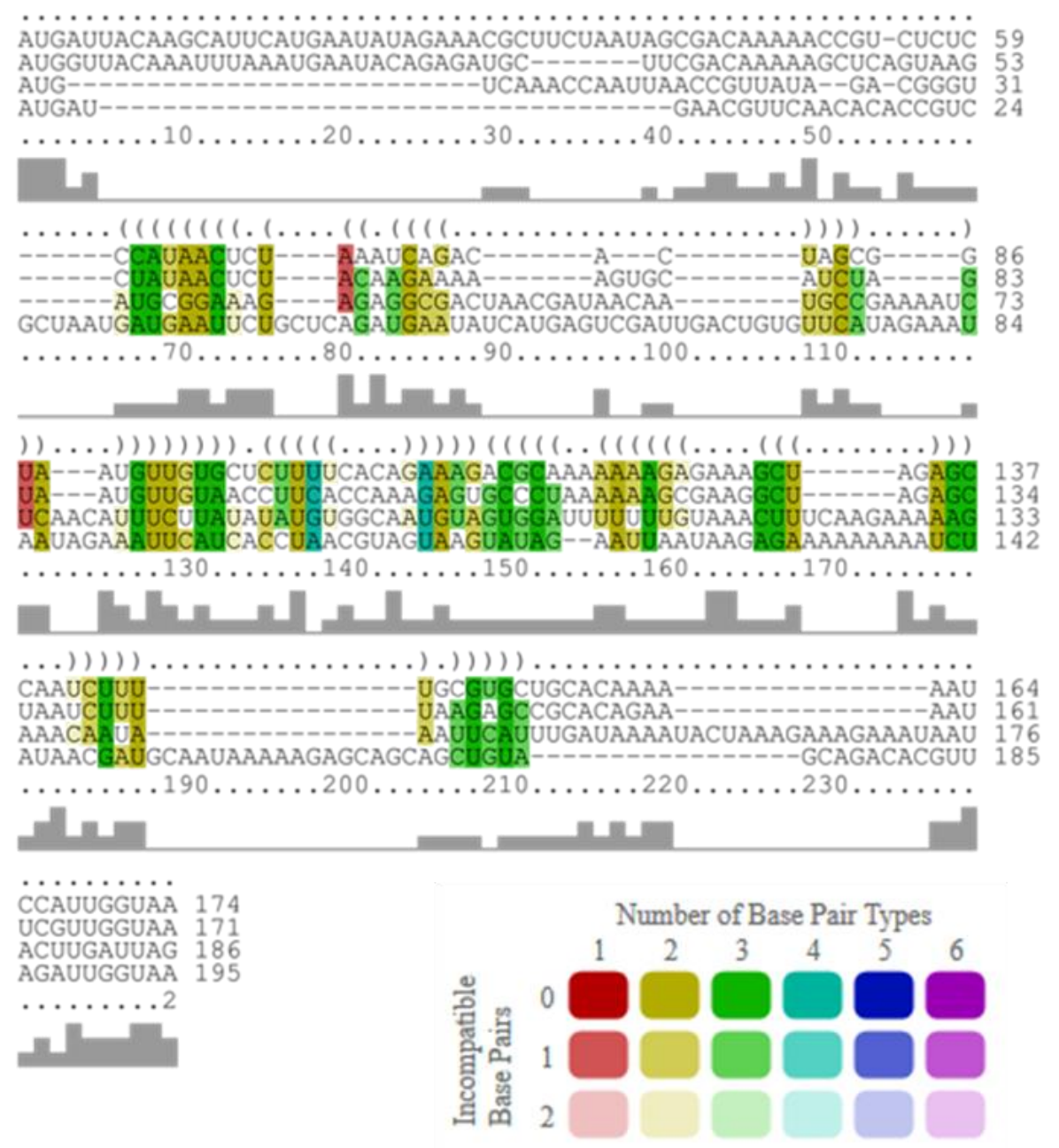

Supplemental Figure 12. DifV (174 nt) and the three ORFs encoded upstream of dcdV homologs do not have exhibit similarity.

Nucleotide alignment of the $V$. cholerae DifV and the ORFs 5' of $d c d V$ homologs using LocARNA [75]. Consensus identities are correlated with the height of the bars below the corresponding nucleotide (bottom). The average secondary structure is indicated in dot-bracket notation (top). Compatible base pairs are colored according to the number of different types C-G (1), G-C (2), A-U (3), U-A (4), G-U (5) or U-G (6) of compatible base pairs in the corresponding columns. The saturation decreases with the number of incompatible base pairs. 
A

ICP1

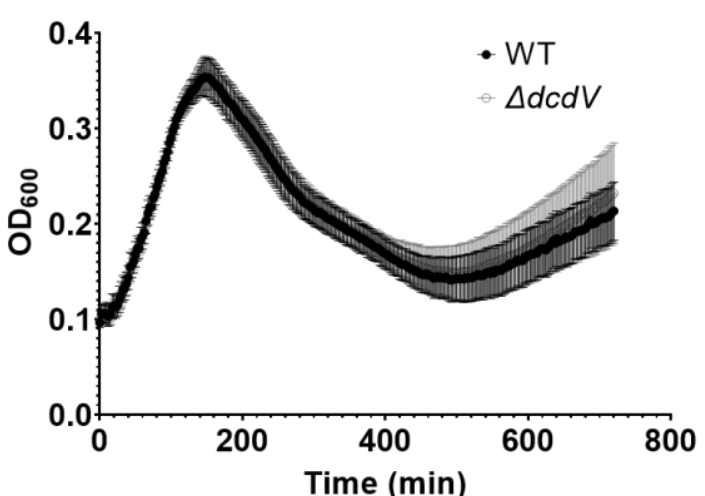

B

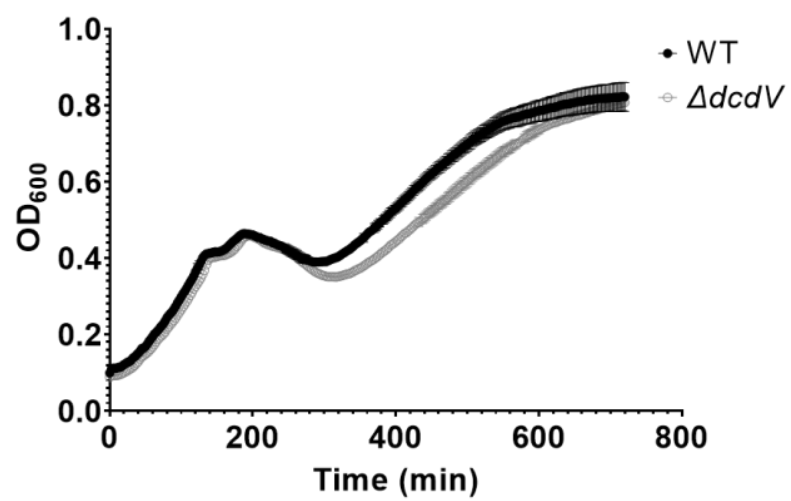

Supplemental Figure 13. $V$. cholerae lacking $d c d V$ do not exhibit enhanced susceptibility to predation by $V$. cholerae lytic phage ICP1 and ICP3.

Growth curves for $V$. cholerae WT and $\Delta d c d V$ infected by lytic phage ICP1 (A) and ICP3 (B). Bacteria were infected at time 0 at an $\mathrm{MOI}$ of 0.1 in microtiter plates. Data represent the mean \pm SEM, $n=3$. 
Supplementary Table 1. Strains and phages used in this study.

\begin{tabular}{|c|c|c|c|}
\hline Strains & $\begin{array}{l}\text { Name in this } \\
\text { Study }\end{array}$ & Relevant Characteristics & $\begin{array}{l}\text { Source or } \\
\text { reference }\end{array}$ \\
\hline \multicolumn{4}{|l|}{ E. coli } \\
\hline $\mathrm{DH} 10 \mathrm{~b}$ & & 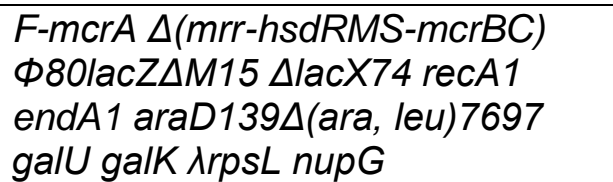 & $\begin{array}{c}\text { ThermoFisher } \\
\text { Scientific }\end{array}$ \\
\hline BW29427 & & $\begin{array}{l}\text { RP4- } \\
\text { 2(TetSkan1360::FRT), thrB1004, } \\
\text { lacZ58(M15), } \Delta \text { dapA1341::[erm } \\
\left.\text { pir }^{+}\right], \text {rpsL(strR), thi-, hsdS-, pro- }\end{array}$ & Lab Stock \\
\hline BL21(DE3) & & $\begin{array}{l}F-\text { ompT hsdSB }(r B-m B+) \text { gal dcm } \\
\text { (DE3) }\end{array}$ & Lab Stock \\
\hline $\begin{array}{l}\text { 078:H11 H10407 } \\
\text { (ETEC) }\end{array}$ & ETEC & Wild type & [106] \\
\hline \multicolumn{4}{|l|}{ V. cholerae } \\
\hline C6706str2 & WT & Wild type $01 \mathrm{El}$ Tor; Sm & [107] \\
\hline E7946 & & $\begin{array}{l}\text { Clinical isolate obtained in Bahrain } \\
\text { in 1978; } \mathrm{Sm}^{\mathrm{R}}\end{array}$ & [108] \\
\hline CR01 & $\Delta V S P-1$ & O1 El Tor $\Delta$ VSP-1 & This study \\
\hline CR02 & $\Delta \mathrm{VSP}-2$ & O1 El Tor $\Delta$ VSP-2 & This study \\
\hline CR03 & $\Delta \mathrm{VSP}-1 / 2$ & O1 El Tor $\Delta V S P-1 / 2$ & This study \\
\hline BYH206 & $\Delta i g^{222}$ & $\begin{array}{l}\text { O1 El Tor } \Delta i g^{222} \text { between vc0175- } \\
\text { vc0176 position in N16961 } \\
\text { chromosome I }[177,230-177,008]\end{array}$ & This study \\
\hline BYH207 & $\Delta v c 0176$ & O1 El Tor $\Delta v c 0176$ & This study \\
\hline BYH255 & $\Delta v c 0175-176$ & O1 El Tor $\Delta v c 0175-176$ & This study \\
\hline BYH256 & $\Delta v c 0177-181$ & O1 El Tor $\Delta v c 0177-181$ & This study \\
\hline $\mathrm{BYH} 257$ & $\Delta v c 0182-185$ & O1 El Tor $\Delta v c 0182-185$ & This study \\
\hline GS05 & $\Delta v c 0175$ & O1 El Tor $\Delta v c 0175(d c d V)$ & This study \\
\hline WLN5105 & $\Delta c a p V$ & O1 El Tor $\Delta c a p V$ & [11] \\
\hline \multicolumn{4}{|l|}{ V. parahaemolyticus } \\
\hline $\begin{array}{l}\text { O1:Kuk } \\
\text { str. FDA_R31 }\end{array}$ & VP & Wild type & [109] \\
\hline \multicolumn{4}{|l|}{ P. mirabilis } \\
\hline AR379 & PM & Wild type & {$[110]$} \\
\hline \multicolumn{4}{|l|}{ Shigella flexneri } \\
\hline PE577 & $\mathrm{Sf}$ & Wild type & {$[54]$} \\
\hline \multicolumn{4}{|l|}{ Phages } \\
\hline ICP1 & ICP1 & Wild type & [49] \\
\hline ICP3 & ICP3 & Wild type & [49] \\
\hline Sf6 & Sf6 & Wild type & [111] \\
\hline
\end{tabular}


Supplementary Table 2. Plasmids Descriptions

\begin{tabular}{|c|c|c|c|}
\hline Plasmids & $\begin{array}{l}\text { Name in this } \\
\text { Manuscript }\end{array}$ & Relevant characteristics & $\begin{array}{l}\text { Source or } \\
\text { Reference }\end{array}$ \\
\hline pEVS141 & pVector/pVector ${ }^{\text {DifV }}$ & pEVS143 without pTac; $\mathrm{Km}^{r}$ & [70] \\
\hline pEVS143 & & $\begin{array}{l}\text { Broad-host range pTac } \\
\text { overexpression vector; } \mathrm{Km}^{\mathrm{r}}\end{array}$ & [68] \\
\hline pMMB67EH & pVector DcdV & $\begin{array}{l}\text { Broad-host range pTac } \\
\text { overexpression vector; } \mathrm{Amp}^{\mathrm{r}}\end{array}$ & [69] \\
\hline pKAS32 & & $\begin{array}{l}\text { Suicide vector for mutant } \\
\text { construction, } \mathrm{Amp}^{r}\end{array}$ & [67] \\
\hline pET28b & pVector 6 xHis & T7 promoter; $\mathrm{Km}^{\mathrm{r}}$ & Novagen \\
\hline pLAFR & pLAFR & pLAFR; Tet $^{r}$ & [112] \\
\hline pCCD7 & pCCD7 & pLAFR::VSP-1; Tet ${ }^{r}$ & [11] \\
\hline pBRP353 & pDncV & pMMB67EH::dncV; Amp ${ }^{r}$ & [11] \\
\hline pCMW204 & pDcdV & pEVS143::dcdV; Km ${ }^{r}$ & This study \\
\hline pGBS87 & $\mathrm{pDcdV} / \mathrm{pDcdV} \mathrm{VC}^{\mathrm{N}}$ & pMMB67EH::dcdV; Amp ${ }^{r}$ & This study \\
\hline pGBS65 & $\mathrm{pDcdV}^{6 \times H i s}$ & $\begin{array}{l}\text { pET28b:::dcdV-6xHis C-term; } \mathrm{Km}^{r} \\
\text { ("only* in E. coli BL21(DE3)) }\end{array}$ & This study \\
\hline pGBS98 & $\mathrm{pDcdV}^{6 \times \mathrm{His}}$ & $\begin{array}{l}\text { pEVS143::dcdV-6xHis C-term; } \\
\mathrm{Km}^{\mathrm{r}}{ }^{*} \text { only* in V. cholerae) }\end{array}$ & This study \\
\hline pGBS71 & pDcdVE384A & pEVS143::dcdV-E384A; $\mathrm{Km}^{\mathrm{r}}$ & This study \\
\hline pGBS82 & pDcdVE384A & $\begin{array}{l}\text { pET28b::dcdV-E384A-6xHis C- } \\
\text { term; } \mathrm{Km}^{r} \text { ( }^{*} \text { only }{ }^{*} \text { for in vitro and } \\
\text { western blot) }\end{array}$ & This study \\
\hline pGBS81 & $\mathrm{pDcdV}$ C411A+C414A & $\begin{array}{l}\text { pEVS143::dcdV-C411A+C414A; } \\
\mathrm{Km}^{\mathrm{r}}\end{array}$ & This study \\
\hline pGBS75 & $\mathrm{pDcdV} \mathrm{V}^{\mathrm{C} 411 \mathrm{~A}+\mathrm{C} 414 \mathrm{~A}}$ & $\begin{array}{l}\text { pET28b::dcdV-C411A+C414A- } \\
6 x \text { His C-term; } \mathrm{Km}^{r}\end{array}$ & This study \\
\hline pGBS103 & pDcdVS52K & pEVS143::dcdV-S52K; Km & This study \\
\hline pGBS114 & pDcdV $552 K$ & $\begin{array}{l}\text { pET28b::dcdV-S52K-6xHis C- } \\
\text { term; Km }{ }^{r}\end{array}$ & This study \\
\hline pGBS106 & pDcdV ${ }^{D 162 A+Q 163 A ~}$ & $\begin{array}{l}\text { pEVS143::dcdV-D162A+Q163A; } \\
\mathrm{Km}^{\mathrm{r}}\end{array}$ & This study \\
\hline pGBS116 & pDcdV $162 A+Q 163 A$ & $\begin{array}{l}\text { pET28b::dcdV-D162A+Q163A- } \\
6 x H i s \text { C-term; } \mathrm{Km}^{\mathrm{r}}\end{array}$ & This study \\
\hline pGBS80 & $\operatorname{plg}^{222}$ & $\begin{array}{l}\text { pEVS143:: } \lg ^{222} \text {, (position in } \\
\text { N16961 chromosome I [177,230- } \\
\text { 177,008]); Km }{ }^{r}\end{array}$ & This study \\
\hline pGBS108 & $\mathrm{plg}^{222-S T O P}$ & pEVS143:: $i^{222}-1 \mathrm{C}>\mathrm{T}, 2 \mathrm{~T}>\mathrm{A} ; \mathrm{Km}^{\mathrm{r}}$ & This study \\
\hline pGBS110 & pDifV & $\begin{array}{l}\text { pEVS143::difV (position in } \\
\text { N16961 chromosome I [177,181- } \\
\text { 177,008]); Km }{ }^{r}\end{array}$ & This study \\
\hline pAW01 & pDifV $^{\text {RBS-less }}$ & pEVS143::difV without RBS; $\mathrm{Km}^{\mathrm{r}}$ & This study \\
\hline pGBS111 & pDifV STOP & $\begin{array}{l}\text { pEVS143::difV-1A>T, 2T>A, } \\
3 \mathrm{G}>\mathrm{A} ; \mathrm{Km}^{\mathrm{r}}\end{array}$ & This study \\
\hline pGBS118 & $\mathrm{pDifV}^{\text {InteriorSTOP }}$ & $\begin{array}{l}\text { pEVS143::difV-17A }>\mathrm{T}, 18 \mathrm{~T}>\mathrm{A} \text {, } \\
\text { 19G>A; } \mathrm{Km}^{r}\end{array}$ & This study \\
\hline
\end{tabular}




\begin{tabular}{|c|c|c|c|}
\hline pBYH49 & pDifV49-186 & pEVS143::difV (49-186 NT); Km ${ }^{r}$ & This study \\
\hline pBYH52 & pDifV $49-204$ & pEVS143::difV (49-204 NT); Km & This study \\
\hline pBYH53 & $\mathrm{pDifV}^{49-214}$ & pEVS143::difV (49-214 NT); $\mathrm{Km}^{\mathrm{r}}$ & This study \\
\hline pBYH54 & pDifV $49-218$ & pEVS143::difV (49-218 NT); Km & This study \\
\hline pBYH55 & pDifV $66-222$ & pEVS143::difV (66-222 NT); Km & This study \\
\hline pBYH56 & pDifV ${ }^{86-222}$ & pEVS143::difV (86-222 NT); Km & This study \\
\hline pBYH57 & $\mathrm{pDifV}^{123-222}$ & pEVS143::difV (123-222 NT); Km & This study \\
\hline pBYH50 & pNpcR_3991 & pEVS143::npcR_3991; Km & This study \\
\hline pGBS120 & pDcdV $V^{E 123 K}$ & pEVS143::dcdV-E123K; $\mathrm{Km}^{r}$ & This study \\
\hline pGBS131 & pDcdVA126T & pEVS143::dcdV-A126T; $\mathrm{Km}^{r}$ & This study \\
\hline pGBS128 & pDcdVK201R & pEVS143::dcdV-K201R; Km ${ }^{r}$ & This study \\
\hline pGBS129 & pDcdVK511R & pEVS143::dcdV-K511R; $\mathrm{Km}^{r}$ & This study \\
\hline pGBS130 & pDcdVQ514R & pEVS143::dcdV-Q514R; Km & This study \\
\hline pGBS124 & pDcdVETEC & $\begin{array}{l}\text { pEVS143::dcdV from Escherichia } \\
\text { coli O78:H11 H10407 (ETEC); } \\
\mathrm{Km}^{\mathrm{r}} \text { (*only* for mass spec } \\
\text { experiment) }\end{array}$ & This study \\
\hline pGBS125 & pDifVETEC & $\begin{array}{l}\text { pEVS143::difV from Escherichia } \\
\text { coli O78:H11 H10407 (ETEC); } \\
\mathrm{Km}^{\mathrm{r}}\end{array}$ & This study \\
\hline pGBS126 & pDcdVETEC & $\begin{array}{l}\text { pMMB67EH::dcdV from } \\
\text { Escherichia coli O78:H11 H10407 } \\
\text { (ETEC); Amp }{ }^{r}\end{array}$ & This study \\
\hline pAW07 & $\mathrm{pDifV}^{\mathrm{VP}}$ & $\begin{array}{l}\text { pEVS143::difV from } V . \\
\text { parahaemolyticus } 01: \text { Kuk str. } \\
\text { FDA_R31; Km }{ }^{r}\end{array}$ & This study \\
\hline pAW06 & pDcdVVP & $\begin{array}{l}\text { pMMB67EH::dcdV from } V \text {. } \\
\text { parahaemolyticus O1:Kuk str. } \\
\text { FDA_R31; Amp }{ }^{r}\end{array}$ & This study \\
\hline pAW02 & pDifVPM $^{P M}$ & $\begin{array}{l}\text { pEVS143::difV from } P \text {. mirabilis } \\
\text { AR379; } \mathrm{Km}^{r}\end{array}$ & This study \\
\hline pAW04 & pDcdVPM & $\begin{array}{l}\text { pMMB67EH::dcdV from } P . \\
\text { mirabilis AR379 }\end{array}$ & This study \\
\hline pCRR01 & & $\begin{array}{l}\text { Deletion construct for } \Delta \mathrm{VSP}-1 \text {, } \\
\text { Amp }^{r}\end{array}$ & This study \\
\hline pCRR02 & & $\begin{array}{l}\text { Deletion construct for } \Delta \text { VSP-2, } \\
\text { Amp }^{r}\end{array}$ & This study \\
\hline pBYH36 & & Deletion construct for $\Delta i g^{222}, \mathrm{Amp}^{r}$ & This study \\
\hline pBYH37 & & $\begin{array}{l}\text { Deletion construct for } \Delta v c 0176 \text {, } \\
\text { Amp }^{r}\end{array}$ & This study \\
\hline pBYH40 & & $\begin{array}{l}\text { Deletion construct for } \Delta d c d V \text { - } \\
v c 0176, \mathrm{Amp}^{r}\end{array}$ & This study \\
\hline pBYH41 & & $\begin{array}{l}\text { Deletion construct for } \Delta v c 0177- \\
v c 0181, \mathrm{Amp}^{r}\end{array}$ & This study \\
\hline pBYH42 & & $\begin{array}{l}\text { Deletion construct for } \Delta v c 0182- \\
\text { VC0185, } \mathrm{Amp}^{r}\end{array}$ & This study \\
\hline pGBS88 & & $\begin{array}{l}\text { Deletion construct for } \Delta d c d V, \\
\text { Amp }^{r}\end{array}$ & This study \\
\hline
\end{tabular}


Supplementary Table 3. Oligonucleotides used in this study.

\begin{tabular}{|c|c|c|c|}
\hline Name & Primer use & Sequence & Reference \\
\hline \multicolumn{4}{|c|}{ Vector Construction } \\
\hline CMW3009 & $\begin{array}{l}\text { dcdV } \mathrm{F}^{1} \mathrm{EcoRI}+\mathrm{RBS}^{3} \\
(\mathrm{pEV} S 143-\mathrm{DcdV})\end{array}$ & $\begin{array}{l}\text { GGAAACAGCCTCGACAGGCCTAGGAG } \\
\text { GAAGCTAAATTGTTTACAATGAATAAGT } \\
\text { CCTCCG }\end{array}$ & This study \\
\hline CMW3010 & $\begin{array}{l}\text { dcdV R² BamHI } \\
\text { (pEVS143-DcdV) }\end{array}$ & $\begin{array}{l}\text { CATAAAGCTTGCTCAATCAATCACCGG } \\
\text { ATCCTAGTCTTGGATGCTCTCTTC }\end{array}$ & This study \\
\hline CMW3025 & $\begin{array}{l}d c d V F \text { EcoRI + RBS } \\
\text { (pMMB67EH-DcdV) }\end{array}$ & $\begin{array}{l}\text { ATTTCACACAGGAAACAGAGGAGCTAA } \\
\text { GGAAGCTAAATTGTTTACAATGAATAAG } \\
\text { TCCTC }\end{array}$ & This study \\
\hline CMW3026 & $\begin{array}{l}d c d V \text { R BamHI } \\
\text { (pMMB67EH-DcdV) }\end{array}$ & $\begin{array}{l}\text { CCTGCAGGTCGACTCTAGAGCTAGTCT } \\
\text { TGGATGCTCTC }\end{array}$ & This study \\
\hline CMW3066 & $\begin{array}{l}d c d V+6 H i s \text { R BamHI } \\
\text { (pEVS143-DcdV-His })\end{array}$ & $\begin{array}{l}\text { GCTTGCTCAATCAATCACCGTTAGTGG } \\
\text { TGGTGGTGGTGGTGCTCGATGTCTTGG }\end{array}$ & This study \\
\hline CMW3079 & $\begin{array}{l}l g^{222} \mathrm{~F} \mathrm{EcoRI}+\mathrm{RBS} \\
\left(\mathrm{pEVS} 143-\mathrm{Ig}^{222}\right)\end{array}$ & $\begin{array}{l}\text { CAGCCTCGACAGGCCTAGGAGGAGCT } \\
\text { AAGGAAGCTAAACTGTTCGCAAATCAT } \\
\text { ACTTTAG }\end{array}$ & This study \\
\hline CMW3080 & $\begin{array}{l}l^{222} \mathrm{R} \text { BamHI } \\
\text { (pEVS143- } \text { Ig }^{222}, \\
\text { pEVS143-DifV \& } \\
\text { pEVS143-DifV 3' end } \\
\text { truncations and } \\
\text { interior stop codon) }\end{array}$ & $\begin{array}{l}\text { GCTTGCTCAATCAATCACCGTTACCAAT } \\
\text { GGATTTTTTGTG }\end{array}$ & This study \\
\hline CMW3081 & $\begin{array}{l}l g^{222-S T O P} \mathrm{~F} E \mathrm{ECORI}+ \\
\text { RBS (pEVS143- } \lg ^{222-} \\
\text { STOP) }\end{array}$ & $\begin{array}{l}\text { CAGCCTCGACAGGCCTAGGAGGAGCT } \\
\text { AAGGAAGCTAAATAGTTCGCAAATCAT } \\
\text { AGTTTAG }\end{array}$ & This study \\
\hline CMW3093 & $\begin{array}{l}d c d V F \text { Ncol } \\
\text { (pET28b-DcdV-His } 6)\end{array}$ & $\begin{array}{l}\text { AACTTTAAAGAAGGAGATATACATGTTTA } \\
\text { CAATGAATAAGTCCTCCGC }\end{array}$ & This study \\
\hline CMW3094 & $\begin{array}{l}\text { dcdV R Xhol } \\
\text { (pET28b-Dcdv-His } 6)\end{array}$ & $\begin{array}{l}\text { CTCAGTGGTGGTGGTGGTGGTGCTCG } \\
\text { ATGTCTTGGATGCTCTCTTCTTCACTCG } \\
\text { ATGG }\end{array}$ & This study \\
\hline CMW3102 & $\begin{array}{l}\text { difVF EcoRI + RBS } \\
\text { (pEVS143-DifV \& } \\
\text { pEVS143-DifV 5' end } \\
\text { truncations) }\end{array}$ & $\begin{array}{l}\text { CTCGACAGGCCTAGGAGGAGCTAAGG } \\
\text { AAGCTAAAATGATTACAAGCATTCATGA } \\
\text { ATATAG }\end{array}$ & This study \\
\hline CMW3103 & $\begin{array}{l}\text { difV F EcoRI + RBS } \\
\text { (pEVS143-DifVSTOP) }\end{array}$ & $\begin{array}{l}\text { CTCGACAGGCCTAGGAGGAGCTAAGG } \\
\text { AAGCTAAATAAATTACAAGCATTCATGA } \\
\text { ATATAG }\end{array}$ & This study \\
\hline CMW3128 & $\begin{array}{l}\text { difV } V^{49-186} \mathrm{~F} \mathrm{EcoRI} \mathrm{+} \\
\text { RBS (pEVS143-DifV } \\
\text { 186) }\end{array}$ & $\begin{array}{l}\text { ACAGCCTCGACAGGCCTAGGAGGAGC } \\
\text { TAAGGAAGCTAAAATGATTACAAG }\end{array}$ & This study \\
\hline CMW2129 & $\begin{array}{l}\text { difV'49-186 R BamHI } \\
\left(p E V S 143-D i f V^{49-186}\right)\end{array}$ & $\begin{array}{l}\text { GCTTGCTCAATCAATCACCGGGCTCTA } \\
\text { GCTTTCTCTTTTTTTGCGTCTTTC }\end{array}$ & This study \\
\hline CMW3130 & $\begin{array}{l}\text { npcR_3991 F EcoRI + } \\
\text { RBS (pEVS143- } \\
\text { npcR 3991) }\end{array}$ & $\begin{array}{l}\text { ACAGCCTCGACAGGCCTAGGAGGAGC } \\
\text { TAAGGAAGCTAAACTCTCCCATAACTC }\end{array}$ & This study \\
\hline
\end{tabular}




\begin{tabular}{|c|c|c|c|}
\hline CMW3131 & $\begin{array}{l}\text { npcR_3991 R BamHI } \\
\text { (pEVS143- } \\
\text { npcR_3991) }\end{array}$ & $\begin{array}{l}\text { GCTTGCTCAATCAATCACCGTGTGCAG } \\
\text { CACGCAAAAGATTGGCTCTAGCT }\end{array}$ & This study \\
\hline CMW3162 & $\begin{array}{l}d c d V^{\overline{E T E C}} \text { F EcoRI + } \\
\text { RBS (pEVS143- } \\
\text { DcdVETEC) }\end{array}$ & $\begin{array}{l}\text { ACAGCCTCGACAGGCCTAGGAGGAGC } \\
\text { TAAGGAAGCTAAAATGGCTATAGCTTT } \\
\text { GAAAAAG }\end{array}$ & This study \\
\hline CMW3163 & $\begin{array}{l}d c d V^{E T E C} \text { R BamHI } \\
\text { (pEVS143-DcdVETEC) }\end{array}$ & $\begin{array}{l}\text { GCTTGCTCAATCAATCACCGTTAAATCA } \\
\text { AGTCATCTTGTTTTG }\end{array}$ & This study \\
\hline CMW3164 & $\begin{array}{l}d c d V \text { ETEC F EcoRI + } \\
\text { RBS (pMMB67EH- } \\
\text { DcdVETEC) }\end{array}$ & $\begin{array}{l}\text { AATTTCACACAGGAAACAGAGGAGCTA } \\
\text { AGGAAGCTAAAATGGCTATAGCTTTGA } \\
\text { AAAAGG }\end{array}$ & This study \\
\hline CMW3165 & $\begin{array}{l}d c d V^{E T E C} \text { F BamHI } \\
\text { (pMMB67EH- } \\
\text { DcdVETEC) }\end{array}$ & $\begin{array}{l}\text { CCTGCAGGTCGACTCTAGAGTTAAATC } \\
\text { AAGTCATCTTGTTTTGG }\end{array}$ & This study \\
\hline CMW3166 & $\begin{array}{l}\text { difVETEC F EcoRI + } \\
\text { RBS (pEVS143- } \\
\text { DifVETEC) }\end{array}$ & $\begin{array}{l}\text { ACAGCCTCGACAGGCCTAGGAGGAGC } \\
\text { TAAGGAAGCTAAAATGTCAAACCAATTA } \\
\text { ACCG }\end{array}$ & This study \\
\hline CMW3167 & $\begin{array}{l}\text { dcdVETEC F BamHI } \\
\text { (pEVS143-DifVETEC) }\end{array}$ & $\begin{array}{l}\text { GCTTGCTCAATCAATCACCGCTAATCA } \\
\text { AGTATTATTTCTTTCTTTAGTATTTTATC }\end{array}$ & This study \\
\hline CMW3180 & $\begin{array}{l}\text { difV F F EcoRI + RBS } \\
\left(\text { pEVS143-DifV }{ }^{V P}\right)\end{array}$ & $\begin{array}{l}\text { ACAGCCTCGACAGGCCTAGGAGGAGC } \\
\text { TAAGGAAGCTAAAATGGTTACAAATTTA } \\
\text { AATG }\end{array}$ & This study \\
\hline CMW3181 & 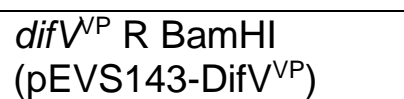 & $\begin{array}{l}\text { GCTTGCTCAATCAATCACCGTTACCAA } \\
\text { CGAATTTTCTGTGCGGCTCTTAAAAG }\end{array}$ & This study \\
\hline CMW3184 & $\begin{array}{l}d c d V^{N P} F \text { EcoRI + } \\
\text { RBS } \\
\left(\text { pMMB67EH-DcdV }{ }^{V P}\right)\end{array}$ & $\begin{array}{l}\text { CAATTTCACACAGGAAACAGAGGAGCT } \\
\text { AAGGAAGCTAAAATGGGAAAATCCTCT } \\
\text { A }\end{array}$ & This study \\
\hline CMW3185 & $\begin{array}{l}d c d V^{\mathrm{NP}} \mathrm{R} \text { BamHI } \\
(\text { pMMB67EH-DcdVVP) }\end{array}$ & $\begin{array}{l}\text { CCTGCAGGTCGACTCTAGAGTTATTCA } \\
\text { ATAGTGGCTTCTACTTGTTGCTTTGTGA } \\
\text { ATG }\end{array}$ & This study \\
\hline CMW3189 & $\begin{array}{l}\text { difVF EcoRI } \\
\text { (pEVS143-DifV) }\end{array}$ & $\begin{array}{l}\text { ACAGCCTCGACAGGCCTAGGATGATTA } \\
\text { CAAGCATTCATGAATATAGAAACGCTTC }\end{array}$ & This study \\
\hline CMW3192 & $\begin{array}{l}\text { difVPM F EcoRI + RBS } \\
(\mathrm{pEVS143-DifVPM})\end{array}$ & $\begin{array}{l}\text { ACAGCCTCGACAGGCCTAGGAGGAGC } \\
\text { TAAGGAAGCTAAAATGAACGTTCAAC }\end{array}$ & This study \\
\hline CMW3193 & $\begin{array}{l}\text { difVPM R BamHI } \\
\left(p E V S 143-D i f V^{P M}\right)\end{array}$ & $\begin{array}{l}\text { GCTTGCTCAATCAATCACCGTTACCAAT } \\
\text { CTAACGTGTCTGCTACAGCTGC }\end{array}$ & This study \\
\hline CMW3196 & $\begin{array}{l}d c d V^{\mathrm{NP}} \text { F EcoRI + } \\
\text { RBS } \\
(\text { pMMB67EH-DcdVPM) }\end{array}$ & $\begin{array}{l}\text { CAATTTCACACAGGAAACAGAGGAGCT } \\
\text { AAGGAAGCTAAAATGGGTAATCC }\end{array}$ & This study \\
\hline CMW3197 & $\begin{array}{l}d c d V^{\mathrm{NP}} \mathrm{R} \text { BamHI } \\
(\mathrm{pMMB67EH-DcdVPM})\end{array}$ & $\begin{array}{l}\text { CCTGCAGGTCGACTCTAGAGTTAACTT } \\
\text { CTCTCTTCACCTAAACGAAGATTTAC }\end{array}$ & This study \\
\hline CMW3200 & $\begin{array}{l}\text { difV }{ }^{49-204} \mathrm{R} \mathrm{BamHI} \\
\left(\mathrm{pEVS143-DifV}{ }^{49-204}\right)\end{array}$ & $\begin{array}{l}\text { GCTTGCTCAATCAATCACCGTGCAGCA } \\
\text { CGCAAAAGATTG }\end{array}$ & This study \\
\hline CMW3201 & 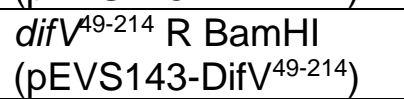 & $\begin{array}{l}\text { GCTTGCTCAATCAATCACCGGGATTTTT } \\
\text { TGTGCAGCAC }\end{array}$ & This study \\
\hline CMW3202 & $\begin{array}{l}\text { difV } 49-218 \text { R BamHI } \\
\left(p E V S 143-\text { DifV }^{49-218}\right)\end{array}$ & $\begin{array}{l}\text { GCTTGCTCAATCAATCACCGCAATGGA } \\
\text { TTTTTTGTGCAGCACGCAAAAGA }\end{array}$ & This study \\
\hline CMW3203 & $\begin{array}{l}\text { difV } 66-222 \mathrm{~F} \mathrm{EcoRI}+ \\
\text { RBS (pEVS143-DifV66- } \\
\text { 222) }\end{array}$ & $\begin{array}{l}\text { ACAGCCTCGACAGGCCTAGGAGGAGC } \\
\text { TAAGGAAGCTAAAGAATATAGAAACG }\end{array}$ & This study \\
\hline
\end{tabular}




\begin{tabular}{|c|c|c|c|}
\hline CMW3204 & $\begin{array}{l}\text { difVB6-222 F EcoRI + } \\
\text { RBS (pEVS143-DifV86- } \\
\text { 222) }\end{array}$ & $\begin{array}{l}\text { ACAGCCTCGACAGGCCTAGGAGGAGC } \\
\text { TAAGGAAGTAAAATAGCGACAAAAAC }\end{array}$ & This study \\
\hline CMW3205 & $\begin{array}{l}\text { difV } V^{123-222} \mathrm{~F} \text { EcoRI + } \\
\text { RBS (pEVS143- } \\
\text { DifV }^{123-222} \text { ) }\end{array}$ & $\begin{array}{l}\text { ACAGCCTCGACAGGCCTAGGAGGAGC } \\
\text { TAAGGAAGCTAAAAGACACTAGCG }\end{array}$ & This study \\
\hline \multicolumn{4}{|c|}{ Site-directed Mutagenesis } \\
\hline CMW3011 & $\begin{array}{l}d c d V(E 384 A) F \\
(p E V S 143-D c d V E 384 A \text { \& } \\
\text { pET28b-DcdVE384A })\end{array}$ & $\begin{array}{l}\text { CAAGAGCGGTTCATGCTGCAATGGATT } \\
\text { CTCTTATAGC }\end{array}$ & This study \\
\hline CMW3012 & $\begin{array}{l}d c d V(E 384 A) R \\
(p E V S 143-D c d V E 384 A \\
\text { pET28b-DcdVE384A })\end{array}$ & $\begin{array}{l}\text { GCTATAAGAGAATCCATTGCAGCATGA } \\
\text { ACCGCTCTTG }\end{array}$ & This study \\
\hline CMW3013 & $\begin{array}{l}d c d V(C 411 A+ \\
C 414 A) F(p E V S 143- \\
\text { DcdVC411A+C414A) }\end{array}$ & $\begin{array}{l}\text { TATATGTTACGACATATCCGGCTCACAA } \\
\text { CGCTGCGCGACACATCGTTGCTG }\end{array}$ & This study \\
\hline CMW3014 & $\begin{array}{l}d c d V(C 411 A+ \\
C 414 A) R(p E V S 143- \\
\text { DcdV } 411 A+C 414 A)\end{array}$ & $\begin{array}{l}\text { CAGCAACGATGTGTCGCGCAGCGTTGT } \\
\text { GAGCCGGATATGTCGTAACATATA }\end{array}$ & This study \\
\hline CMW3021 & $\begin{array}{l}d c d V(K 55 A) F \\
\left(p E V S 143-D c d V^{K 55 A}\right)\end{array}$ & $\begin{array}{l}\text { GCTATTGGCTCTGGTGTAGCGGCATTA } \\
\text { AAAGAGAGTTTAGTTAGTTCTCTTGAGA } \\
\text { CATAT }\end{array}$ & This study \\
\hline CMW3022 & $\begin{array}{l}d c d V(K 55 A) R \\
\left(p E V S 143-D c d V^{K 55 A}\right)\end{array}$ & $\begin{array}{l}\text { ATATGTCTCAAGAGAACTAACTAAACTC } \\
\text { TCTTTTAATGCCGCTACACCAGAGCCA } \\
\text { ATAGC }\end{array}$ & This study \\
\hline CMW3104 & $\begin{array}{l}d c d V(D 162 A+ \\
\text { Q163A) F (pEVS143- } \\
\text { DcdVD162A+Q163A) }\end{array}$ & $\begin{array}{l}\text { CGCATACATCATCGCGGCGTTAAAGCA } \\
\text { CCCTGATGAAATCAAATTCC }\end{array}$ & This study \\
\hline CMW3105 & $\begin{array}{l}d c d V(D 162 A+ \\
\text { Q163A) R (pEVS143- } \\
\text { DcdVQ162A+Q163A) }\end{array}$ & $\begin{array}{l}\text { GGAATTTGATTTCATCAGGGTGCTTTAA } \\
\text { CGCCGCGATGATGTATGCG }\end{array}$ & This study \\
\hline CMW3110 & $\begin{array}{l}d c d V(S 52 K) F \\
(p E V S 143-D c d V 552 K)\end{array}$ & $\begin{array}{l}\text { CCTCTGTGGGGCTATTGGCAAAGGTGT } \\
\text { AAAGGCATTAAAAGAGAG }\end{array}$ & This study \\
\hline CMW3111 & $\begin{array}{l}d c d V(S 52 K) R \\
\text { (pEVS143-DcdVs52K) }\end{array}$ & $\begin{array}{l}\text { CTCTCTTTTAATGCCTTTACACCTTTGC } \\
\text { CAATAGCCCCACAGAGG }\end{array}$ & This study \\
\hline CMW3112 & $\begin{array}{l}d c d V(S 52 P) F \\
(p E V S 143-D c d V 552 P)\end{array}$ & $\begin{array}{l}\text { CCTCTGTGGGGCTATTGGCCCGGGTG } \\
\text { TAAAGGCATTAAAAGAGAG }\end{array}$ & This study \\
\hline CMW3113 & $\begin{array}{l}d c d V(S 52 P) R \\
(p E V S 143-D c d V S 52 P)\end{array}$ & $\begin{array}{l}\text { CTCTCTTTTAATGCCTTTACACCCGGG } \\
\text { CCAATAGCCCCACAGAGG }\end{array}$ & This study \\
\hline CMW3114 & $\begin{array}{l}d c d V(S 52 W) F \\
(p E V S 143-D c d V s 52 W)\end{array}$ & $\begin{array}{l}\text { CCTCTGTGGGGCTATTGGCTGGGGTG } \\
\text { TAAAGGCATTAAAAGAGAG }\end{array}$ & This study \\
\hline CMW3115 & $\begin{array}{l}d c d V(S 52 K) R \\
(p E V S 143-D c d V 552 W)\end{array}$ & $\begin{array}{l}\text { CTCTCTTTTAATGCCTTTACACCCCAGC } \\
\text { CAATAGCCCCACAGAGG }\end{array}$ & This study \\
\hline CMW3118 & $\begin{array}{l}\text { difV (interior } \\
\text { alternative frame stop) } \\
F(p E V S 143- \\
\text { DifV17A>T, 18T>A, } \\
\text { 19G>A) }\end{array}$ & $\begin{array}{l}\text { AAGGAAGCTAAAATGATTACAAGCATT } \\
\text { CTAAAATATAGAAACGCTTCTAATAGCG }\end{array}$ & This study \\
\hline CMW3119 & $\begin{array}{l}\text { difV (interior } \\
\text { alternative frame stop) }\end{array}$ & $\begin{array}{l}\text { CGCTATTAGAAGCGTTTCTATATTTTAAG } \\
\text { AATGCTTGTAATCATTTTAGCTTCCTT }\end{array}$ & This study \\
\hline
\end{tabular}




\begin{tabular}{|c|c|c|c|}
\hline & $\begin{array}{l}R(p E V S 143- \\
\text { DifV17A }>T, 18 T>A \\
19 G>A)\end{array}$ & & \\
\hline CMW3124 & $\begin{array}{l}\text { dcdV }(\mathrm{E} 123 \mathrm{~K}) \mathrm{F} \\
\left(\mathrm{pEVS143-DcdV}{ }^{123 K}\right)\end{array}$ & $\begin{array}{l}\text { GCAGCCTGTGCTATCAAAGAAATTGCG } \\
\text { CTGG }\end{array}$ & This study \\
\hline CMW3125 & $\begin{array}{l}\text { dcdV (E123K) R } \\
\text { (pEVS143-DcdVE123K) }\end{array}$ & $\begin{array}{l}\text { CCAGCGCAATTTCTTTGATAGCACAGG } \\
\text { CTGC }\end{array}$ & This study \\
\hline CMW3172 & $\begin{array}{l}d c d V(\mathrm{~A} 126 \mathrm{~T}) \mathrm{F} \\
\left(\mathrm{pEVS143-DcdV}{ }^{\mathrm{A} 26 \mathrm{~T}}\right)\end{array}$ & $\begin{array}{l}\text { GCTATCGAAGAAATTACGCTGGAAAGA } \\
\text { ACATTAATCTGTC }\end{array}$ & This study \\
\hline CMW3173 & $\begin{array}{l}\text { dcdV (A126T) R } \\
\text { (pEVS143-DcdV } \\
\text { p126T) }\end{array}$ & $\begin{array}{l}\text { GACAGATTAATGTTCTTTCCAGCGTAAT } \\
\text { TTCTTCGATAGC }\end{array}$ & This study \\
\hline \multicolumn{4}{|c|}{ Gene Deletion } \\
\hline CMW2794 & $\begin{array}{l}\text { AVSP-2 up } \text { Fr; }^{4} \\
\text { CR02 \& CR03 }\end{array}$ & $\begin{array}{l}\text { GTGGAATTCCCGGGAGAGCTCGGCTT } \\
\text { GTTCACTATCGTAATAATGC }\end{array}$ & This study \\
\hline CMW2795 & $\begin{array}{l}\text { AVSP-2 up R; } \\
\text { CR02 \& CR03 }\end{array}$ & $\begin{array}{l}\text { GGAGGGGCCACCACTGGGAGGGCACC } \\
\text { AGATTC }\end{array}$ & This study \\
\hline CMW2796 & $\begin{array}{l}\triangle V S P-2 \text { down }{ }^{5} \mathrm{~F} \\
\text { CR02 \& CR03 }\end{array}$ & $\begin{array}{l}\text { GCCCTCCCAGTGGTGGCCCCTCCCAG } \\
\text { GT }\end{array}$ & This study \\
\hline CMW2797 & $\begin{array}{l}\triangle V S P-2 \text { down R; } \\
\text { CR02 \& CR03 }\end{array}$ & $\begin{array}{l}\text { AGCTATAGTTCTAGAGGTACGGGCATT } \\
\text { AAGGTGGTGGAAACCG }\end{array}$ & This study \\
\hline CMW2814 & $\begin{array}{l}\triangle V S P-1 \text { up F; } \\
\text { CR01 \& CR03 }\end{array}$ & $\begin{array}{l}\text { GTGGAATTCCCGGGAGAGCTGGCTTTA } \\
\text { CTGTTATTCGC }\end{array}$ & This study \\
\hline CMW2815 & $\begin{array}{l}\Delta \text { VSP-1 up R; } \\
\text { CR01 \& CR03 }\end{array}$ & $\begin{array}{l}\text { TACCATGTAGTAGCGGTATCGAGATTC } \\
\mathrm{C}\end{array}$ & This study \\
\hline CMW2816 & $\begin{array}{l}\triangle V S P-1 \text { down F; } \\
\text { CR01 \& CR03 }\end{array}$ & $\begin{array}{l}\text { GATACCGCTACTACATGGTAACGAACT } \\
\text { CTTC }\end{array}$ & This study \\
\hline CMW2817 & $\begin{array}{l}\triangle V S P-1 \text { down R; } \\
\text { CR01 \& CR03 }\end{array}$ & $\begin{array}{l}\text { AGCTATAGTTCTAGAGGTACCGCTAAG } \\
\text { TTTGTGGATGC }\end{array}$ & This study \\
\hline CMW2970 & $\begin{array}{l}\Delta v c 0176 \text { up F; } \\
\text { BYH207 }\end{array}$ & $\begin{array}{l}\text { ATAACAATTTGTGGAATTCCCGGGAGA } \\
\text { GCTGGGAATCGAATATTGAGAG }\end{array}$ & This study \\
\hline CMW2971 & $\begin{array}{l}\Delta v c 0176 \text { up R; } \\
\text { BYH207 }\end{array}$ & $\begin{array}{l}\text { ATATAGTGTCTCTATTTATGGCTCATAA } \\
\text { TCTTGAAG }\end{array}$ & This study \\
\hline CMW2972 & $\begin{array}{l}\Delta v c 0176 \text { down } F ; \\
\text { BYH207 }\end{array}$ & $\begin{array}{l}\text { GATTATGAGCCATAAATAGAGACACTAT } \\
\text { ATTTAGTGTTTAATTAAC }\end{array}$ & This study \\
\hline CMW2973 & $\begin{array}{l}\triangle v c 0176 \text { down } \mathrm{R} ; \\
\mathrm{BYH} 207\end{array}$ & $\begin{array}{l}\text { TGCGCATGCTAGCTATAGTTCTAGAGG } \\
\text { TACTATGAAACTTATTTCTATACTCTCA } \\
\text { G }\end{array}$ & This study \\
\hline CMW3035 & $\begin{array}{l}\Delta v c 0176-v c 0175 \text { up F; } \\
\text { BYH255 }\end{array}$ & $\begin{array}{l}\text { ATAACAATTTGTGGAATTCCCGGGAGA } \\
\text { GCTGGGAATCGAATATTGAGAG }\end{array}$ & This study \\
\hline CMW3036 & $\begin{array}{l}\Delta v c 0176-v c 0175 \text { up R; } \\
\text { BYH255 }\end{array}$ & $\begin{array}{l}\text { TTTTCCAGACTAAAGTTATGGCTCATAA } \\
\text { TCTTGAAG }\end{array}$ & This study \\
\hline CMW3037 & $\begin{array}{l}\Delta v c 0176-v c 0175 \text { down } \\
\text { F; BYH255 }\end{array}$ & $\begin{array}{l}\text { GATTATGAGCCATAACTTTAGTCTGGAA } \\
\text { AATTCACTTTTC }\end{array}$ & This study \\
\hline CMW3038 & $\begin{array}{l}\Delta v c 0176-v c 0175 \text { down } \\
\text { R; BYH255 }\end{array}$ & $\begin{array}{l}\text { TGCGCATGCTAGCTATAGTTCTAGAGG } \\
\text { TACACATGGAGCATGATCAGG }\end{array}$ & This study \\
\hline CMW3039 & $\begin{array}{l}\Delta v c 0177-v c 0181 \text { up F; } \\
\text { BYH256 }\end{array}$ & $\begin{array}{l}\text { ATAACAATTTGTGGAATTCCCGGGAGA } \\
\text { GCTGTTTGTATGTTTGGGGTG }\end{array}$ & This study \\
\hline CMW3040 & $\begin{array}{l}\Delta v c 0177-v c 0181 \text { up R; } \\
\text { BYH256 }\end{array}$ & $\begin{array}{l}\text { AATGAATTAGTATACGTATTTCTAATAC } \\
\text { CACTAAAAACTAAG }\end{array}$ & This study \\
\hline
\end{tabular}




\begin{tabular}{|c|c|c|c|}
\hline CMW3041 & $\begin{array}{l}\Delta v c 0177-v c 0181 \text { down } \\
\text { F; BYH256 }\end{array}$ & $\begin{array}{l}\text { TGGTATTAGAAATACGTATACTAATTCA } \\
\text { TTCACTGTACTTC }\end{array}$ & This study \\
\hline CMW3042 & $\begin{array}{l}\Delta v c 0177-v c 0181 \text { down } \\
\text { R; BYH256 }\end{array}$ & $\begin{array}{l}\text { TGCGCATGCTAGCTATAGTTCTAGAGG } \\
\text { TACAAAGTTCTCCACAAATTTCAG }\end{array}$ & This study \\
\hline CMW3043 & $\begin{array}{l}\Delta v c 0182-v c 0185 \text { up F; } \\
\text { BYH257 }\end{array}$ & $\begin{array}{l}\text { ATAACAATTTGTGGAATTCCCGGGAGA } \\
\text { GCTGCTGACTCCGGTGGCCGT }\end{array}$ & This study \\
\hline CMW3044 & $\begin{array}{l}\Delta v c 0182-v c 0185 \text { up R; } \\
\text { BYH257 }\end{array}$ & $\begin{array}{l}\text { CTTAGGTATACTAATTGTATTTGATATA } \\
\text { CATAGAGGCTAGTATGGTTTCCAGAGT } \\
\text { TTAC }\end{array}$ & This study \\
\hline CMW3045 & $\begin{array}{l}\Delta v c 0182-v c 0185 \text { down } \\
\text { F; BYH257 }\end{array}$ & $\begin{array}{l}\text { TGTATATCAAATACAATTAGTATACCTA } \\
\text { AGATTCGATTTTC }\end{array}$ & This study \\
\hline CMW3046 & $\begin{array}{l}\Delta v c 0182-v c 0185 \text { down } \\
\text { R; BYH257 }\end{array}$ & $\begin{array}{l}\text { TGCGCATGCTAGCTATAGTTCTAGAGG } \\
\text { TACTTCTCAGGATGTAATATTTGTG }\end{array}$ & This study \\
\hline CMW3067 & $\Delta v c 0175$ up F; GS05 & $\begin{array}{l}\text { GTGGAATTCCCGGGAGAGCTACTATAT } \\
\text { TTAGTGTTTAATTAACAAAAAAC }\end{array}$ & This study \\
\hline CMW3068 & $\Delta v c 0175$ up R; GS05 & $\begin{array}{l}\text { CAGACTAAAGCCTGAAATTATGAAACTT } \\
\text { ATTTCTATAC }\end{array}$ & This study \\
\hline CMW3069 & $\begin{array}{l}\Delta v c 0175 \text { down } F \\
\text { GS05 }\end{array}$ & $\begin{array}{l}\text { TAATTTCAGGCTTTAGTCTGGAAAATTC } \\
\text { ACTTTTC }\end{array}$ & This study \\
\hline CMW3070 & $\begin{array}{l}\Delta v c 0175 \text { down } \mathrm{R} \\
\text { GS05 }\end{array}$ & $\begin{array}{l}\text { AGCTATAGTTCTAGAGGTACACATGGA } \\
\text { GCATGATCAGG }\end{array}$ & This study \\
\hline CMW3071 & $\Delta / g^{222}$ up F; BYH206 & $\begin{array}{l}\text { ATAACAATTTGTGGAATTCCCGGGAGA } \\
\text { GCTTCTCAAAGAAGCACGTAAAAAAG }\end{array}$ & This study \\
\hline CMW3072 & $\Delta / g^{222}$ up R; BYH206 & $\begin{array}{l}\text { CAAGAATTAACGTGGTAAAGTGCGCAC } \\
\text { ATTCTAC }\end{array}$ & This study \\
\hline CMW3073 & $\begin{array}{l}\Delta l g^{222} \text { down } \mathrm{F} ; \\
\text { BYH206 }\end{array}$ & $\begin{array}{l}\text { AATGTGCGCACTTTACCACGTTAATTCT } \\
\text { TGATTAGC }\end{array}$ & This study \\
\hline CMW3074 & $\begin{array}{l}\Delta l g^{222} \text { down } \mathrm{R} ; \\
\text { BYH206 }\end{array}$ & $\begin{array}{l}\text { TGCGCATGCTAGCTATAGTTCTAGAGG } \\
\text { TACTCATTTTCTTCTGAGGTTTC }\end{array}$ & This study \\
\hline \multicolumn{4}{|l|}{ qRT-PCR } \\
\hline CMW2926 & gyrA F & TGGCCAGCCAGAGATCAAG & This study \\
\hline CMW2927 & gyrA R & ACCCGCAGCGGTACGA & This study \\
\hline CMW3206 & $d c d V F$ & TCGACCAGTTAAAGCACCCT & This study \\
\hline CMW3207 & $d c d V \mathrm{R}$ & CCTTCTGTACGGATCAAGCCA & This study \\
\hline CMW3208 & $\operatorname{difVF}$ & GTGAATGGATATTTCGGTGGA & This study \\
\hline CMW3209 & $\operatorname{difVR}$ & TTGTCGCTATTAGAAGCGTT & This study \\
\hline CMW3288 & ori $\mathrm{F}$ & CAGGTGAACCAGCAAAATCGA & [101] \\
\hline CMW3289 & ori $\mathrm{R}$ & TGGTATTGAAGCTCAATGCGG & [101] \\
\hline CMW3290 & $\operatorname{ter} \mathrm{F}$ & TTCAAGCTGAGGCGGATTTG & [101] \\
\hline CMW3291 & $\operatorname{ter} \mathrm{R}$ & GCTCATTGGCTTCTTGTGCTT & [101] \\
\hline
\end{tabular}


142 Supplementary Table 4. This table sorts the indicated lineages by the DcdV homolog in that 143 group with the maximum amino acid similarity to $V$. cholerae DcdV.

\begin{tabular}{|c|c|c|}
\hline \multicolumn{3}{|c|}{$\begin{array}{l}\text { DcdV homologs summary table } \\
\text { Lineages and percentage similarities of DcdV homologs containing both DCD and } \\
\text { PLK domains }\end{array}$} \\
\hline DomArch.Gene3D & Lineage & Max\%Positive \\
\hline $\mathrm{PLK}+\mathrm{DCD}$ & Bacteria >Proteobacteria & 100.00 \\
\hline PLK+DCD & Bacteria>Bacteroidetes & 58.80 \\
\hline PLK+DCD & Bacteria>Balneolaeota & 56.02 \\
\hline PLK+DCD & Bacteria>Actinobacteria & 55.63 \\
\hline PLK+DCD & Archaea $>$ Thaumarchaeota & 53.65 \\
\hline PLK+DCD & Bacteria >Firmicutes & 52.27 \\
\hline PLK+DCD & Bacteria>Planctomycetes & 52.27 \\
\hline PLK+DCD & Bacteria & 51.88 \\
\hline $\mathrm{NABP}+\mathrm{PLK}+\mathrm{DCD}$ & Bacteria >Proteobacteria & 51.09 \\
\hline PLK+DCD & Bacteria $>$ Acidobacteria & 49.70 \\
\hline $\mathrm{PLK}+\mathrm{DCD}$ & Bacteria $>$ Verrucomicrobia & 48.69 \\
\hline PLK+DCD & Bacteria>Chlamydiae & 45.25 \\
\hline $\mathrm{PLK}+\mathrm{DCD}+\mathrm{NABP}$ & Bacteria>Proteobacteria & 42.48 \\
\hline $\mathrm{PLK}+\mathrm{DCD}+\mathrm{NABP}+\mathrm{NABP}$ & Bacteria >Proteobacteria & 39.85 \\
\hline PLK+PLK+DCD & Bacteria >Proteobacteria & 36.75 \\
\hline PLK+DCD & Bacteria $>$ Cyanobacteria & 34.63 \\
\hline PLK+DCD & Eukaryota $>$ Ascomycota & 27.63 \\
\hline PLK+DCD & Eukaryota>Ciliophora & 27.57 \\
\hline PLK+DCD & Eukaryota>Basidiomycota & 25.10 \\
\hline PLK+DCD & Eukaryota $>$ Chytridiomycota & 23.77 \\
\hline $\mathrm{PLK}+\mathrm{DCD}$ & Eukaryota>Mucoromycota & 22.63 \\
\hline PLK+DCD & Eukaryota>Apicomplexa & 19.96 \\
\hline PLK+DCD & Eukaryota>Streptophyta & 19.39 \\
\hline PLK+Znf_CCHC+DCD & Eukaryota>Ascomycota & 16.92 \\
\hline
\end{tabular}

Abbreviations. PLK, P-loop containing nucleotide triphosphate hydrolases; DCD, Cytidine Deaminase domain 2; NABP, Nucleic acid-binding proteins; Znf_CCHC, 
Partial Correlation Value $\mathrm{w}_{\mathrm{ij}}$ of VSP-1 Genes $i$ to $j$ (Supplemental File 1)

\begin{tabular}{|c|c|c|c|c|c|c|c|c|c|c|c|}
\hline & VC0175 & VC0176 & VC0177 & VC0178 & VC0179 & VC0180 & VC0181 & VC0182 & VC0183 & VC0184 & VC0185 \\
\hline VC0175 & 1 & -0.301 & -0.034 & -0.459 & 0.147 & -0.085 & -0.072 & 0.089 & -0.068 & 0.02 & -0.099 \\
\hline VC0176 & -0.301 & 1 & 0.145 & -0.394 & 0.116 & -0.048 & -0.036 & 0.077 & -0.055 & 0.028 & -0.031 \\
\hline VC0178 & -0.459 & -0.394 & -0.043 & 1 & 0.225 & -0.098 & -0.057 & 0.086 & -0.11 & 0.027 & -0.146 \\
\hline VC0179 & 0.147 & 0.116 & 0.026 & 0.225 & 1 & 0.501 & 0.303 & -0.035 & 0.059 & -0.002 & 0.062 \\
\hline VC0180 & -0.085 & -0.048 & -0.038 & -0.098 & 0.501 & 1 & 0.293 & 0.025 & -0.024 & 0.001 & -0.008 \\
\hline VC0181 & -0.072 & -0.036 & 0.03 & -0.057 & 0.303 & 0.293 & 1 & 0.042 & -0.005 & 0.007 & -0.035 \\
\hline VC0182 & 0.089 & 0.077 & 0.095 & 0.086 & -0.035 & 0.025 & 0.042 & 1 & 0.088 & 0.568 & 0.088 \\
\hline VC0183 & -0.068 & -0.055 & 0.069 & -0.11 & 0.059 & -0.024 & -0.005 & 0.088 & 1 & 0.166 & 0.459 \\
\hline VC0184 & 0.02 & 0.028 & 0.151 & 0.027 & -0.002 & 0.001 & 0.007 & 0.568 & 0.166 & 1 & 0.141 \\
\hline VC0185 & -0.099 & -0.031 & 0.021 & -0.146 & 0.062 & -0.008 & -0.035 & 0.088 & 0.459 & 0.141 & 1 \\
\hline
\end{tabular}

$\mathrm{w}_{\mathrm{ij}}=-1$ genes $i$ and $j$ never occur in the same species

$\mathrm{w}_{\mathrm{ij}}=0$ expected co-occurrence between unrelated genes $i$ and $j$ drawn from a normal distribution

$\mathrm{W}_{\mathrm{ij}}>0.045$ suggests shared biological function (Kim and Peterson 2011)

$\mathrm{w}_{\mathrm{ij}}=1$ genes $i$ and $j$ always occur in the same species 
Partial Correlation Value $\mathrm{w}_{\mathrm{ij}}$ of VSP-2 Genes $i$ to $j$ (Supplemental File 2)

\begin{tabular}{|c|c|c|c|c|c|c|c|c|c|c|c|c|}
\hline & VC0490 & VC0491 & VC0492 & VC0493 & VC0494 & VC0495 & VC0496 & VC0497 & VC0498 & VC0502 & VC0503 & VC0504 \\
\hline VC0490 & 1 & 0.035 & 0.381 & 0.021 & -0.067 & 0.071 & 0.032 & -0.016 & -0.124 & -0.05 & -0.033 & 0.011 \\
\hline VC0491 & 0.035 & 1 & 0.426 & -0.021 & -0.001 & -0.008 & 0.014 & 0.008 & 0.014 & -0.019 & 0.004 & 0 \\
\hline VC0492 & 0.381 & 0.426 & 1 & 0.027 & 0.006 & 0.003 & 0.013 & 0.004 & 0.004 & 0.01 & -0.013 & -0.021 \\
\hline VC0493 & 0.021 & -0.021 & 0.027 & 1 & 0.008 & -0.007 & 0.062 & 0.006 & 0.02 & 0.003 & 0.018 & 0.195 \\
\hline VC0494 & -0.067 & -0.001 & 0.006 & 0.008 & 1 & 0.656 & 0.084 & 0.008 & -0.11 & -0.022 & 0.03 & -0.028 \\
\hline VC0495 & 0.071 & -0.008 & 0.003 & -0.007 & 0.656 & 1 & 0.104 & 0.118 & 0.085 & -0.007 & -0.009 & 0.02 \\
\hline VC0496 & 0.032 & 0.014 & 0.013 & 0.062 & 0.084 & 0.104 & 1 & 0.009 & 0.031 & -0.039 & -0.008 & 0.102 \\
\hline VC0497 & -0.016 & 0.008 & 0.004 & 0.006 & 0.008 & 0.118 & 0.009 & 1 & -0.058 & -0.043 & 0.028 & -0.004 \\
\hline VC0498 & -0.124 & 0.014 & 0.004 & 0.02 & -0.11 & 0.085 & 0.031 & -0.058 & 1 & -0.014 & -0.028 & 0.028 \\
\hline VC0502 & -0.05 & -0.019 & 0.01 & 0.003 & -0.022 & -0.007 & -0.039 & -0.043 & -0.014 & 1 & 0.088 & 0.013 \\
\hline VC0503 & -0.033 & 0.004 & -0.013 & 0.018 & 0.03 & -0.009 & -0.008 & 0.028 & -0.028 & 0.088 & 1 & -0.018 \\
\hline VC0504 & 0.011 & 0 & -0.021 & 0.195 & -0.028 & 0.02 & 0.102 & -0.004 & 0.028 & 0.013 & -0.018 & 1 \\
\hline VC0505 & -0.011 & 0.003 & 0.013 & 0.097 & -0.02 & 0.017 & 0.108 & 0.018 & -0.022 & -0.004 & -0.007 & 0.389 \\
\hline VC0506 & -0.006 & 0.001 & 0.002 & -0.004 & -0.026 & 0.024 & 0.045 & 0.018 & -0.005 & 0.01 & 0.064 & 0.09 \\
\hline VC0507 & -0.018 & 0.009 & 0.035 & 0.179 & -0.003 & 0.009 & 0.03 & -0.011 & 0.005 & -0.01 & -0.003 & 0.369 \\
\hline VC0508 & 0.053 & 0.007 & -0.002 & -0.029 & 0.028 & 0.111 & 0.073 & 0.06 & 0.017 & 0.123 & 0.098 & 0.003 \\
\hline VC0509 & 0.012 & -0.001 & -0.023 & 0.037 & 0.057 & -0.02 & 0.216 & 0.023 & 0.058 & 0.095 & -0.022 & 0.161 \\
\hline VC0510 & 0.015 & 0.011 & 0.001 & -0.012 & 0.049 & 0.067 & -0.005 & 0.085 & 0.064 & 0.128 & 0.174 & -0.004 \\
\hline VC0512 & -0.015 & -0.006 & 0 & 0.004 & -0.006 & 0.028 & 0.041 & 0.037 & 0.012 & 0.154 & 0.1 & -0.002 \\
\hline VC0513 & 0.001 & 0.01 & 0.004 & 0.03 & -0.013 & -0.007 & 0.049 & -0.008 & -0.01 & 0.09 & 0.045 & -0.01 \\
\hline VC0514 & 0.015 & -0.007 & -0.009 & 0.001 & -0.03 & 0.026 & -0.034 & 0.005 & -0.052 & 0.012 & 0.1 & 0.028 \\
\hline VC0515 & -0.106 & 0.006 & 0.008 & 0.007 & -0.079 & 0.029 & 0.035 & -0.065 & -0.145 & 0.14 & -0.011 & 0.03 \\
\hline VC0516 & -0.018 & 0 & 0.006 & 0.005 & 0.061 & 0.066 & 0.02 & 0.14 & -0.06 & -0.046 & 0.204 & 0.021 \\
\hline
\end{tabular}

$\mathrm{w}_{\mathrm{ij}}=-1$ genes $i$ and $j$ never occur in the same species

$\mathrm{w}_{\mathrm{ij}}=0$ expected co-occurrence between unrelated genes $i$ and $j$ drawn from a normal distribution

$\mathrm{W}_{\mathrm{ij}}>0.045$ suggests shared biological function (Kim and Peterson 2011)

$\mathrm{w}_{\mathrm{ij}}=1$ genes $i$ and $j$ always occur in the same species 
Partial Correlation Value $\mathrm{w}_{\mathrm{ij}}$ of VSP-2 Genes $i$ to $j$ (Supplemental File 2) (con't)

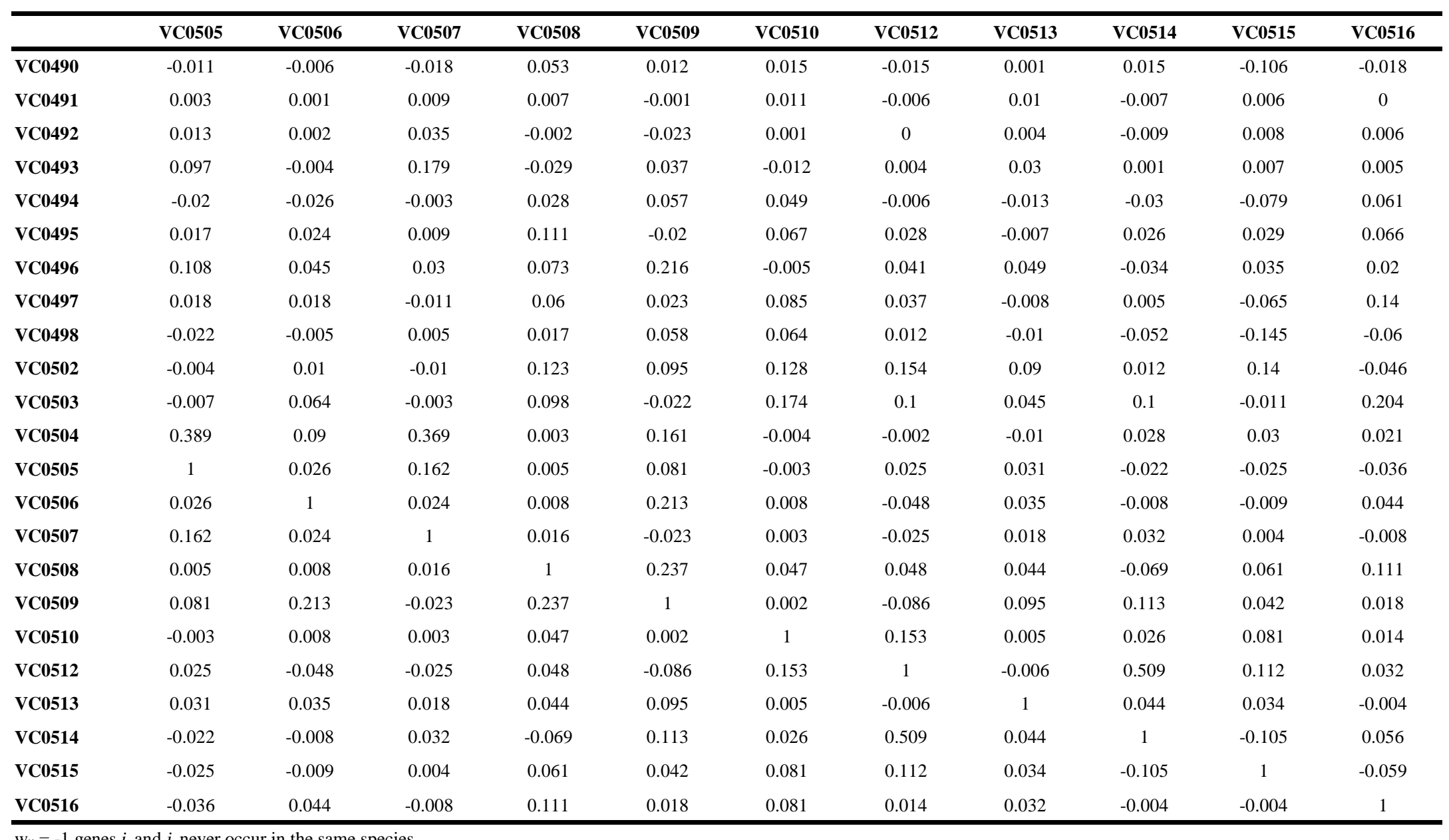

$\mathrm{w}_{\mathrm{ij}}=-1$ genes $i$ and $j$ never occur in the same species

$\mathrm{w}_{\mathrm{ij}}=0$ expected co-occurrence between unrelated genes $i$ and $j$ drawn from a normal distribution

$\mathrm{W}_{\mathrm{ij}}>0.045$ suggests shared biological function (Kim and Peterson 2011)

$\mathrm{w}_{\mathrm{ij}}=1$ genes $i$ and $j$ always occur in the same species 